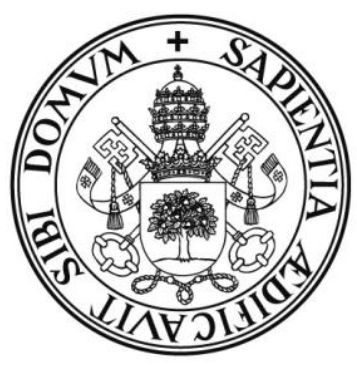

\title{
ESTUDIO DE LA CALCIFICACIÓN VASCULAR EN LOS PACIENTES CON ENFERMEDAD RENAL AVANZADA
}

\author{
Tesis Doctoral de: Álvaro Revilla Calavia
}

Universidad de Valladolid.

Facultad de Medicina.

Departamento de Cirugía, Oftalmología, Otorrinolaringología y

Fisioterapia

Dirigida por:

Prof. Dr. D. CARLOS VAQUERO PUERTA

Dr. D. ENRIQUE M. SAN NORBERTO GARCÍA

Dra. DÑA. ANA FERNÁNDEZ URBÓN 


\section{Dedicatoria}

A mi mujer Ana, mis hijas Ana y Laura porque son el pilar fundamental de todos mis logros.

Mis padres Virgilio y Vicenta por educarme e inculcarme que cada día hay que seguir trabajando.

Mis hermanos (Ana, Manuel, Miguel, Jorge) que son un apoyo incondicional

A mi familia política (Luis, Feli, Eva y Luis) por acogerme desde el primer día como uno más.

\section{Agradecimientos}

Al Profesor Dr. Carlos Vaquero Puerta, Catedrático de Cirugía y director de este trabajo, por la confianza depositada en mi.

Al Dr. Enrique María San Norberto García, co-director de este trabajo por confiar en mi desde el momento cero e impulsar la realización de este trabajo.

A la Dra. Ana Fernandez Urbón, co-directora de este trabajo porque todos los que me conocen saben que sin ella este proyecto hubiera sido imposible.

Servicio de Nefrología del Hospital Universitario Rio Hortega, en especial a la Dra. Belén Gómez Giralda por su apoyo logístico y sobretodo moral durante la realización del trabajo.

A los integrantes del servicio de Angiologia y Cirugía Vascular del Hospital Clínico Universitario de Valladolid por su colaboración colaboración.

A los pacientes que han formado parte del estudio por su paciencia y 

ABREVIATURAS 

ACV Accidente Cerebrovascular

AHA American Heart Association / Asociación Americana del Corazón

AIT Accidente Isquémico Transitorio

Angio TC Angiotomografía computarizada

AngioRM Angiorresonancia magnética

ARA Antagonistas Receptores Angiotensina

ASD Angiografía Sustracción digital

CFr Reserva Coronaria flujo

DP Diálisis Peritoneal

EAP Enfermedad Arterial Periférica

EC Enfermedad Coronaria

ECV Enfermedad Cardiovascular

eNOS Óxido nítrico sintasa endotelial

ERC Enfermedad Renal Crónica

ERCA Enfermedad Renal Crónica Avanzada

ESRD End Stage Renal Disease/ Insuficiencia renal estadio terminal

FA Fibrilación Auricular

FGe Filtrado Glomerular estimado

FMD Dilatación Mediada por Flujo

FR Factor Riesgo

FRCV Factor Riesgo Cardiovascular 
GGT Gamma Glutamil Transferasa

GIM Grosor íntima media

HD Hemodiálisis

HDL High Density Lipoprotein/ Lipoproteina alta densidad

HPTS Hiperparatiroidismo secundario

HTA Hipertensión Arterial

HVI Hipertrofia Ventrículo Izquierdo

IECA Inhibidores Enzima Convertidora de Angiotensina

IFG Índice Filtración Glomerular

IL1 Interleucina 1

IL10 Interleucina 10

IL6 Interleucina 6

IL8 Interleucina 8

ITB Índice Tobillo Brazo

LDL Low Density Lipoprotein / Lipoproteina baja densidad

MDCT Angiografía Computarizada Multidetector

MmHg Milímetros de mercurio

NO Óxido Nítrico

OMS Organización Mundial Salud

PCR Proteina C Reactiva

PWV Pulse Wave Velocity / Velocidad onda pulso aórtica

SRAA Sistema Renina Angiotensina Aldosterona 
TNF $\quad$ Factor de Necrosis Tumoral

TRS Tratamiento Renal Sustitutivo

VSG Velocidad Sedimentación Glomerular

vWF Factor Von Willebrand 

ÍNDICE 



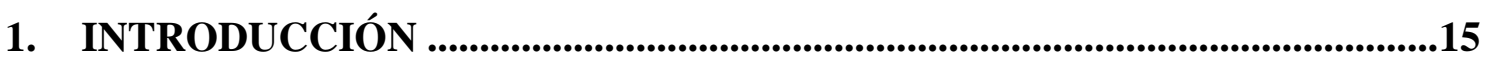

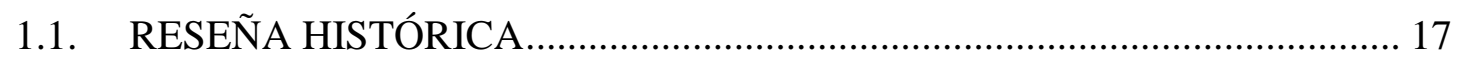

1.2. DEFINICIÓN E IMPORTANCIA DE LA PATOLOGÍA VASCULAR ........ 19

1.3. FORMACIÓN DE LA PLACA DE ATEROMA............................................. 20

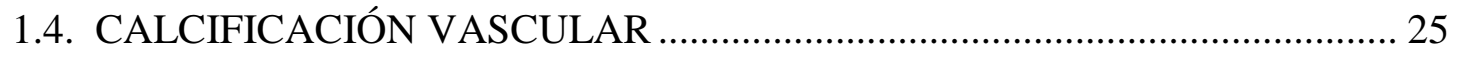

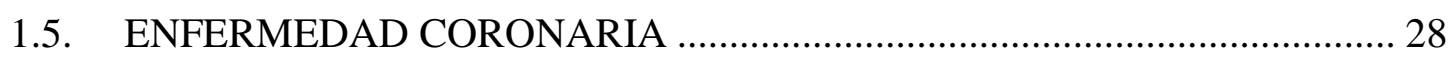

1.6. ENFERMEDAD VASCULAR PERIFÉRICA............................................... 29

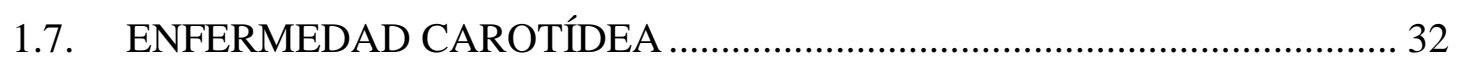

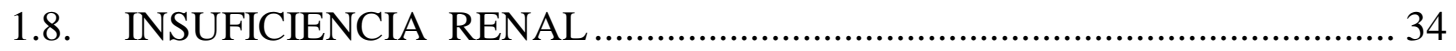

1.9. FACTORES DE RIESGO CARDIOVASCULAR ………………................. 43

1.9.1.Factores de riesgo en la población general.................................................... 43

1.9.2. Factores de riesgo en insuficiencia renal..................................................... 51

1.10. DIAGNÓSTICO DE ENFERMEDAD CARDIOVASCULAR ..........................56

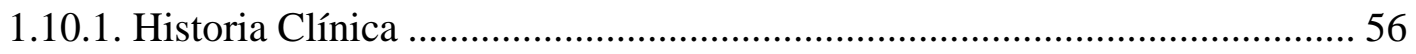

1.10.2. Exploración física................................................................................. 57

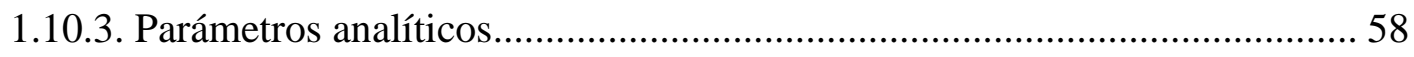

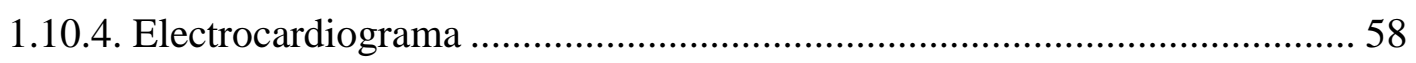

1.10.5. Exploraciones hemodinámicas: el índice tobillo-brazo. ............................... 58

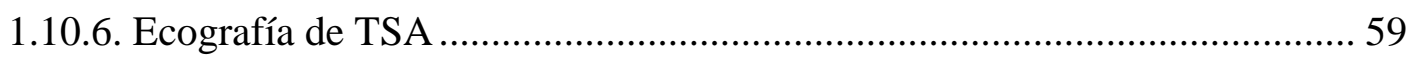

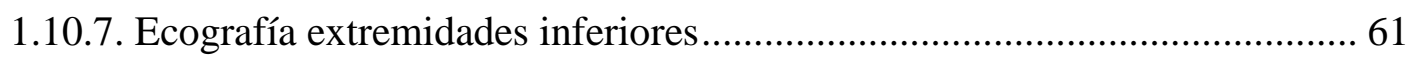

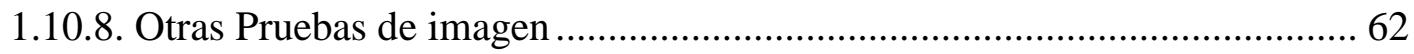

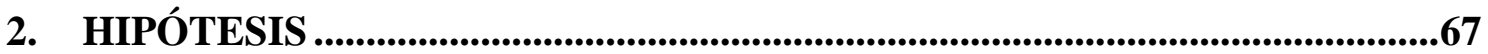

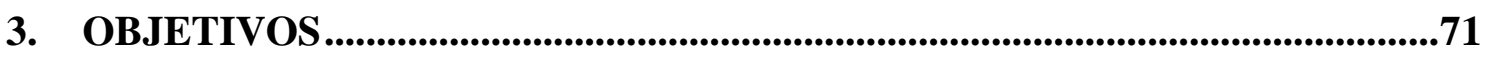

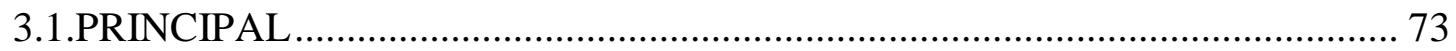

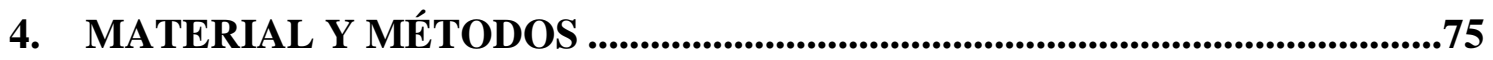

4.1. GENERALIDADES DEL ESTUDIO ............................................................ 77

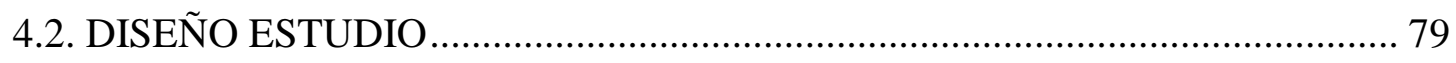




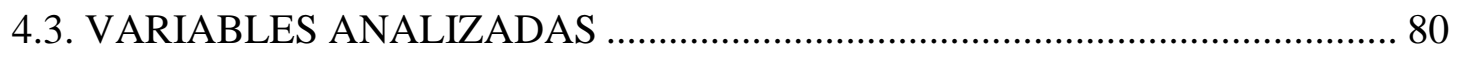

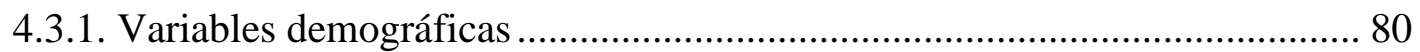

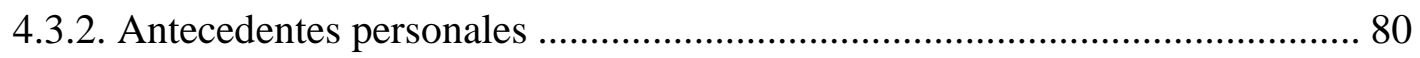

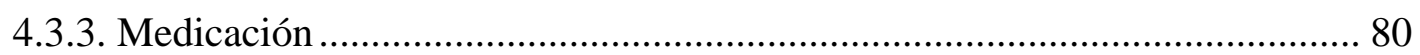

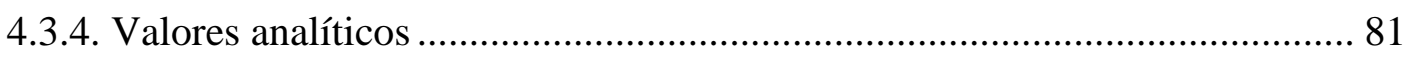

4.3.5. Pruebas valoración ateroesclerosis y función cardiaca ................................. 81

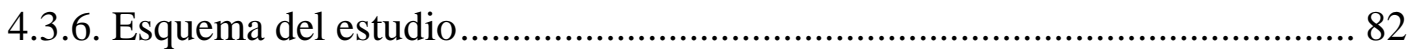

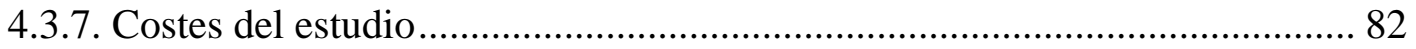

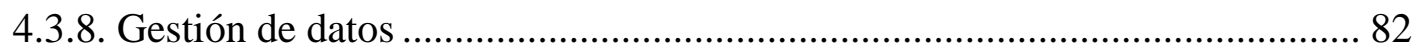

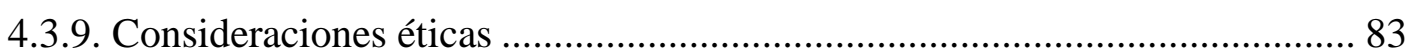

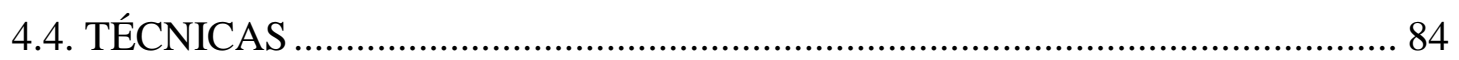

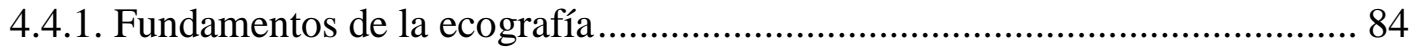

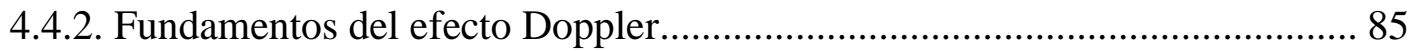

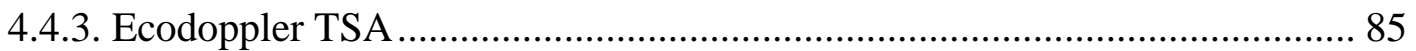

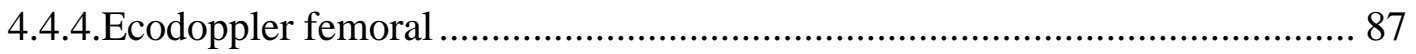

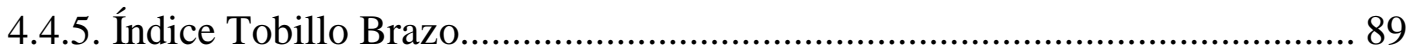

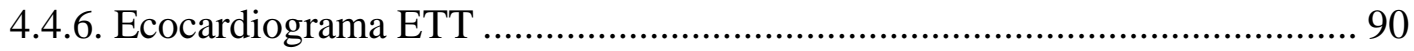

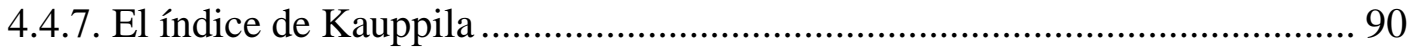

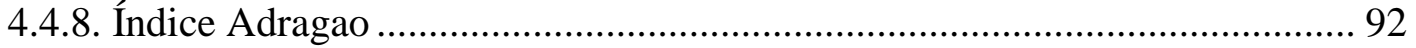

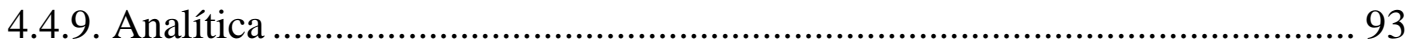

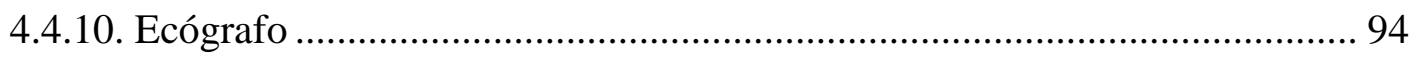

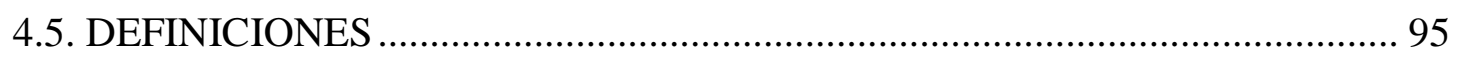

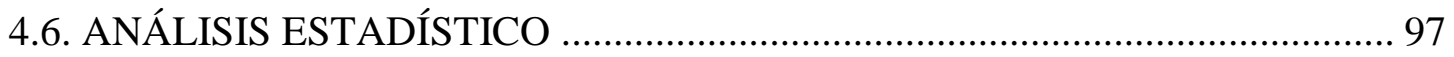

5. RESULTADOS.....................................................................................................................99

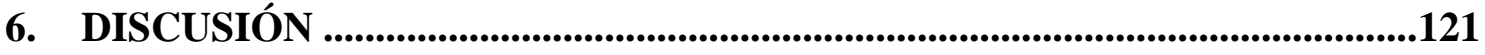

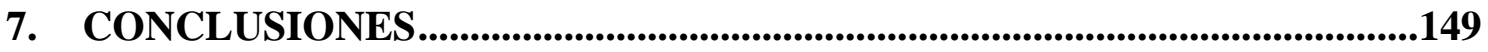

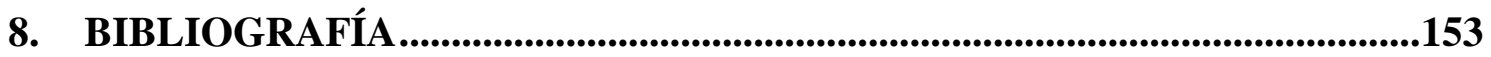

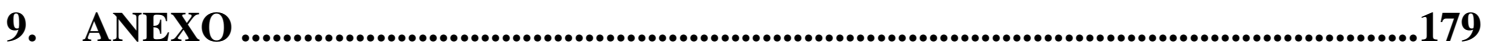




\section{INTRODUCCIÓN}





\subsection{RESEÑA HISTÓRICA}

\section{Antiguo Egipto}

Los egipcios describieron la petrificación de las arterias, lo que probablemente se corresponde con la ateroesclerosis ${ }^{(1)}$.

La princesa egipcia Ahmose-Meryet-Amon, que vivió en Tebas (Luxor) entre 1580 y 1550 a.C, es la primera persona en la historia de la humanidad diagnosticada de enfermedad arterial coronaria. El estudio «Horus» analizó la ateroesclerosis de 52 momias egipcias, en 44 de ellas se pudieron reconocer todavía las arterias. La calcificación arterial (un marcador de la ateroesclerosis) estaba presente en 20 de las momias escaneadas (que rondaban los 45 años de edad) ${ }^{(2)}$.

\section{Edad Media}

Hay poca o ninguna evidencia de que las personas de aquella época padecieran enfermedades cardiovasculares (ECV). La ausencia relativa de esta patología se puede atribuir a la ingesta de alimentos naturales y orgánicos con cantidades mínimas de carbohidratos y grasas. Además, la actividad física era constante.

\section{Era industrial}

La Revolución Industrial, sin embargo, cambió todo eso. Con la introducción de modos más rápidos de transporte como automóviles y máquinas, que podían hacerse cargo de muchas de las actividades cotidianas, la actividad física se redujo considerablemente. Por otra parte, la automatización representó el proceso de toma de alimentos ricos en grasas. La incidencia de las ECV aumentó desde el inicio de siglo hasta el punto en que llegó a ser la primera causa de muerte en los países industrializados. En Estados Unidos esto sucedió en 1920, en España no ocurrió hasta finales de la década de los 50 . 
La influencia de la alimentación sobre el desarrollo de la ateroesclerosis fue descrita por primera vez en 1913 por Anitschkow. En 1932, Wilhelm Raab describió la relación existente entre la dieta y la enfermedad coronaria (EC) en distintas zonas y en 1953 se describió una asociación entre las concentraciones de colesterol y la mortalidad por EC en diversas poblaciones. En 1948, el Estudio de Framingham identificó los factores que contribuyen a la enfermedad cardiovascular ${ }^{(3)}$. Años más tarde, en 1953, Kinsell observó una acción depresora de los aceites vegetales sobre los niveles de colesterol en sangre, cuando se introducen en la dieta sustituyendo a las grasas animales. Por su parte, Ahrens identificó a las grasas poliinsaturadas como los componentes fundamentales de esta reducción. Estas observaciones sirvieron para que otros autores iniciaran investigaciones para determinar de qué forma afectan los diferentes nutrientes sobre los niveles de colesterol en sangre ${ }^{(4)}$. Concretamente, los estudios de Jeys y Hegsted fueron reveladores en cuanto a dos hechos que marcaron las líneas de investigación de los años siguientes:

- El efecto del colesterol de las grasas saturadas es el doble del efecto reductor ejercido por las grasas poliinsaturadas.

- La forma más eficaz para reducir los niveles de colesterol consistirá en eliminar de la dieta las grasas saturadas.

Este aumento en la mortalidad continuó hasta finales de la década de los 60, en que las investigaciones epidemiológicas llevadas a cabo clarificaron las causas de las ECV. A partir de entonces, la calidad y disponibilidad de los cuidados médicos, unidos a una mayor toma de conciencia de la población promovida por campañas de divulgación, hizo que la mortalidad por este tipo de enfermedades disminuyese. La tendencia descendente comenzó a notarse en primer lugar en la costa oeste de los Estados Unidos y tardó algo más en llegar a países como España. A pesar de todo, hoy en día, sigue siendo la principal causa de muerte. 


\subsection{DEFINICIÓN E IMPORTANCIA DE LA PATOLOGÍA VASCULAR}

La denominación de enfermedades cardiovasculares hace referencia a un conjunto de enfermedades que afectan al corazón y a los vasos sanguíneos. La Asociación Americana del Corazón (AHA) incluye en este grupo, la patología coronaria (arteriopatía coronaria y cardiopatía isquémica), el ictus o accidente cerebral vascular (ACV), la hipertensión arterial (HTA), la cardiopatía reumática y enfermedad arterial periférica (EAP). Este grupo, también llamado, enfermedades ateroesclerosas se desarrollan de manera insidiosa a lo largo de la vida y suelen estar avanzadas cuando aparecen los síntomas ${ }^{(5)}$.

Las enfermedades cardiovasculares son la principal causa de muerte y discapacidad en Europa ${ }^{(6)}$ y suponen una importante carga social y económica. La enfermedad coronaria (EC) es la causa de muerte en un amplio porcentaje de personas, pero el accidente cerebrovascular (ACV), la insuficiencia renal y las complicaciones debidas a la isquemia de las extremidades inferiores también contribuyen a un mal pronóstico.

Dado que la aterosclerosis es una enfermedad sistémica, los médicos deben valorar la importancia de detectarla precozmente, para poder establecer el tratamiento correcto y así evitar el daño de los principales órganos. Si se diagnostica un tipo de ECV se debería realizar el estudio en otros lechos vasculares, ya que frecuentemente se asocian. Tal y como demostró recientemente el registro REACH, un importante porcentaje de pacientes con EC crónica presentan enfermedad cerebrovascular, enfermedad arterial de las extremidades asociadas ${ }^{(7)}$. 


\subsection{FORMACIÓN DE LA PLACA DE ATEROMA}

La función del endotelio es servir de superficie antiadherente con capacidad de adaptarse a las necesidades reológicas del árbol arterial.

Hay que entender la placa de ateroma como un proceso activo y focal, que afecta a la pared del vaso y particularmente a la íntima. La American Heart Association Committee on Vascular Lesions clasifica las placas de ateroma en distintos estadios. Fuster et al. ${ }^{(8)}$ han simplificado esta clasificación en distintas fases evolutivas, en relación con la progresión morfológica y clínica de la placa..La calcificación arterial es un proceso evolutivo de la enfermedad aterosesclerosa.

Fase 1: Hiperplasia intimal. Representa el inicio de la placa. Existen dos factores generales que producen un daño endotelial. El primero es debido al efecto reológico del flujo vascular. Aquellos sitios donde existen turbulencias serán los lugares donde el endotelio soporte un mayor estrés y donde se puede formar la placa de ateroma con mayor probabilidad, esto explica la alta prevalencia de placas en las bifurcaciones vasculares. Un segundo factor es el denominado biológico y donde se consideran los factores de riesgo cardiovascular, como la hipercolesterolemia, el tabaco, la diabetes, agentes infecciosos, etc. Ambos mecanismos provocarán un daño endotelial que produce un aumento de su permeabilidad y con ello la entrada del colesterol-LDL (lipoproteínas de baja densidad) hacia la pared del vaso ${ }^{(9)}$. El LDL tiene una razón para entrar en los lugares de mayor turbulencia y es que forma parte de la membrana de la célula muscular lisa. Cuando aumenta la permeabilidad por cualquiera de los factores de riesgo arriba mencionados, el incremento de llegada del LDL produce un engrosamiento del interior de la pared del vaso que sirve de mecanismo de defensa, reforzando estos lugares para que la arteria no se rompa y pueda soportar este flujo. Sin embargo, si entra más cantidad de la que se necesita, el LDL se oxida. Este LDL oxidado actúa como agente quimiotáctico del monocito que circula en la luz del vaso, el cual acude a la llamada adhiriéndose mediante unas proteínas generadas en el endotelio (factores de adhesividad). El monocito comienza a fagocitar los LDL oxidados y se convierte por ello en una célula especializada, es decir se transforma en macrófago (Fig.1). 


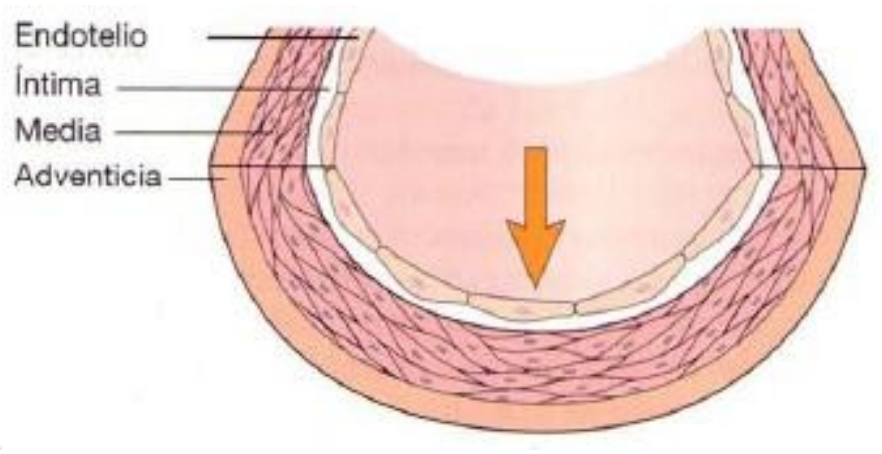

Fig.1: Lugar donde se desarrolla la hiperplasia intimal.

Es, por tanto, un primer mecanismo de defensa de la pared, recibiendo la ayuda de otros factores como el HDL (lipoproteína alta densidad) que colabora en la limpieza de este exceso de LDL oxidado. El exceso de grasa fagocitada (células espumosas) y retenida en la pared del vaso, producirá cambios macroscópicos visibles como estrías grasas, que pueden estar ya presentes en jóvenes e incluso en niños. El endotelio dañado también inducirá otros dos mecanismos de defensa: uno es la vasoconstricción, observado en ocasiones en el transcurso de estudios angiográficos o de reparación vascular (angioplastia, etc.) y un segundo mecanismo, más importante, es la adhesión de las plaquetas al endotelio (Fig.2), las cuales liberan un factor que atrae a las células musculares lisas del interior de la pared trasladándose a la íntima y formando tejido conectivo, produciendo una hiperplasia intimal. Stary et al. ${ }^{(10)}$, observaron cómo el engrosamiento intimal en muchos casos engrosaba la pared pero no reducía la luz del vaso. Esta respuesta arterial se denomina «remodelamiento positivo»y por tanto estos cambios no pueden ser demostrados en estudios angiográficos (Fig.3). 

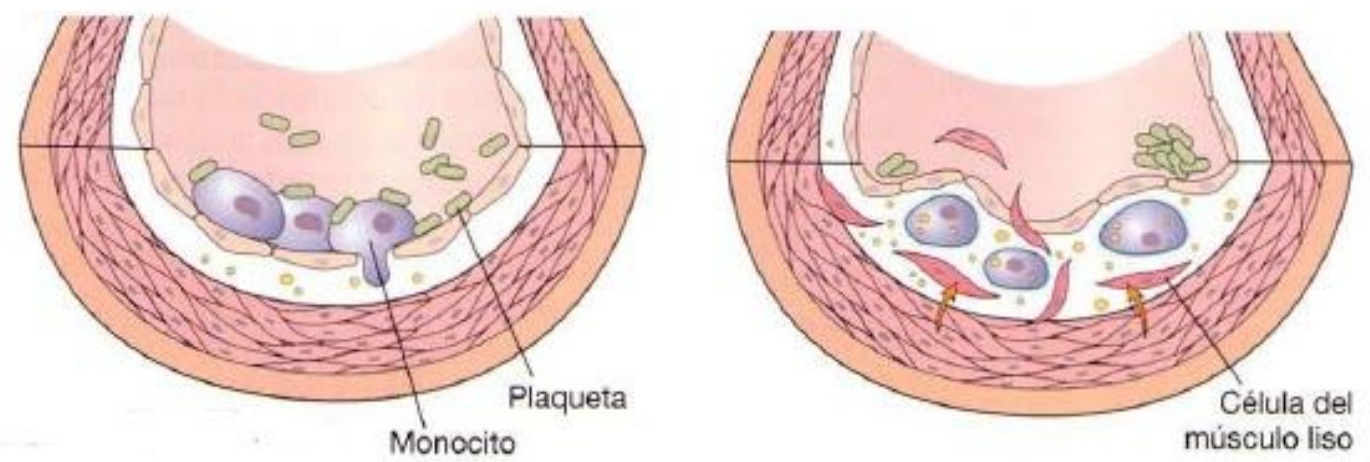

Fig. 2 y 3: Adhesión plaquetas al endotelio y migración de células musculares lisas.

Fase 2: Placa vulnerable. Por tanto, existe un mecanismo de limpieza del LDL en la pared del vaso, realizado fundamentalmente por los macrófagos y el HDL tratando de evitar la progresión de la enfermedad. Pero si se sigue produciendo la entrada de más LDL, favorecido por los factores de riesgo ya mencionados, se producirá un exceso de LDL oxidado que los macrófagos no podrán eliminar. Cuando esto ocurre el sistema de limpieza queda sobrepasado y se llega a un desorden celular. Los macrófagos llenos de colesterol se mueren, produciéndose la apoptosis. Microscópicamente se ven los macrófagos perdiendo textura y disminuyendo el tamaño de su núcleo para desaparecer en un magma de restos celulares y ésteres de colesterol. Comienzan a aparecer células multinucleadas que fagocitan a los macrófagos apoptóticos y cristales de colesterol en un último intento reparativo, produciéndose los hallazgos histológicos de una reacción a cuerpo extraño. Al conjunto de macrófagos muertos, cargados de lípidos y a las células multinucleadas con restos de macrófagos y lípidos se le denomina núcleo lipídico. Este centro lipídico está rodeado por una capa de tejido conectivo que se conoce como cápsula fibrosa. Hay que resaltar que en esta fase, el componente lipídico de la placa puede reducirse cuando se instaura tratamiento con estatinas.

Fases 3-4: Ruptura de la placa. Este tipo de placa vulnerable puede romperse hacia la luz del vaso vertiendo el contenido lipídico y desencadenando la activación simultánea de varios factores de la coagulación, produciéndose la trombosis vascular que es responsable del problema cardiovascular agudo ${ }^{(11)}$ (Fig.4). Este centro lipídico tiene por tanto una importante capacidad trombótica debida a un alto contenido de factor tisular, que es producido por el macrófago apoptótico. Pero recordemos que el 
núcleo lipídico está rodeado por un muro, la cápsula fibrosa. Esta cápsula puede ser gruesa (placa estable) o fina (placa inestable), esta última se puede romper fácilmente (Fig.5). Esta placa se denomina inestable, ya que presenta riesgo de ruptura ${ }^{(12)}$.

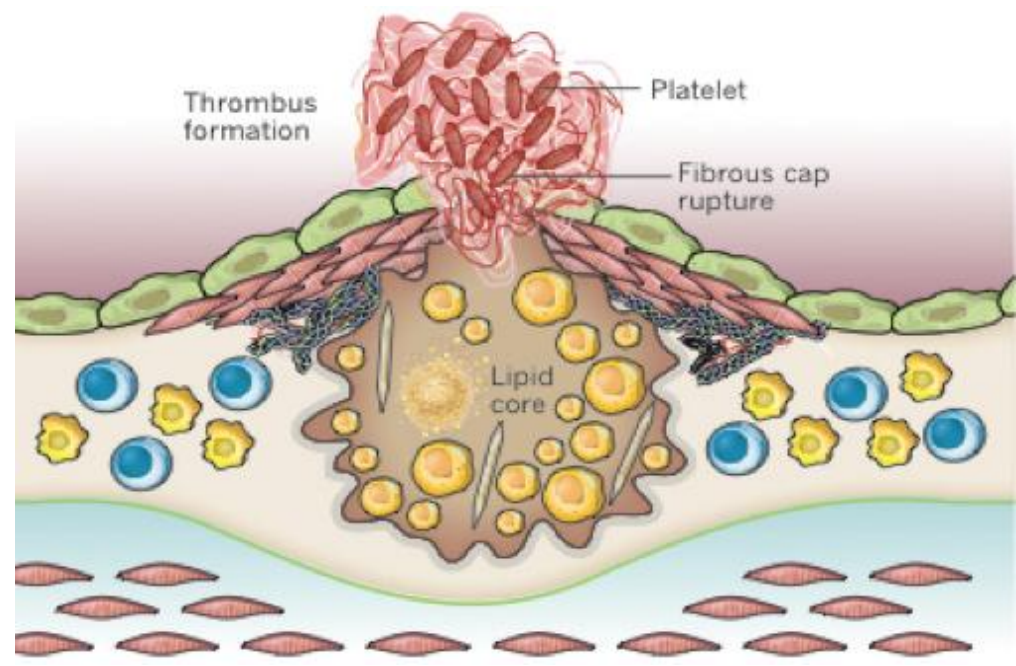

Fig.4: Ruptura placa ateroma. Comienzo formación trombo.

La razón por la que la placa tiende a su ruptura espontánea se debe a que los macrófagos apoptóticos liberan una enzima llamada metaloproteinasa, que favorece la lisis de los tejidos circundantes, en este caso la cápsula fibrosa ${ }^{(13)}$. Yuan et al, estudiaron las carótidas de 53 pacientes con accidentes cerebrales isquémicos, observando cómo el $75 \%$ presentaba placas con cápsula fibrosa rota o fina, mientras que sólo un $9 \%$ tenía placas de ateroma con cápsula fibrosa gruesa. Valorar estos hallazgos es de extraordinaria importancia, ya que la presencia de una cápsula fibrosa rota o fina conlleva un riesgo de ACV isquémico 23 veces superior a aquellos pacientes con placas que tienen una cápsula fibrosa gruesa ${ }^{(14)}$. 

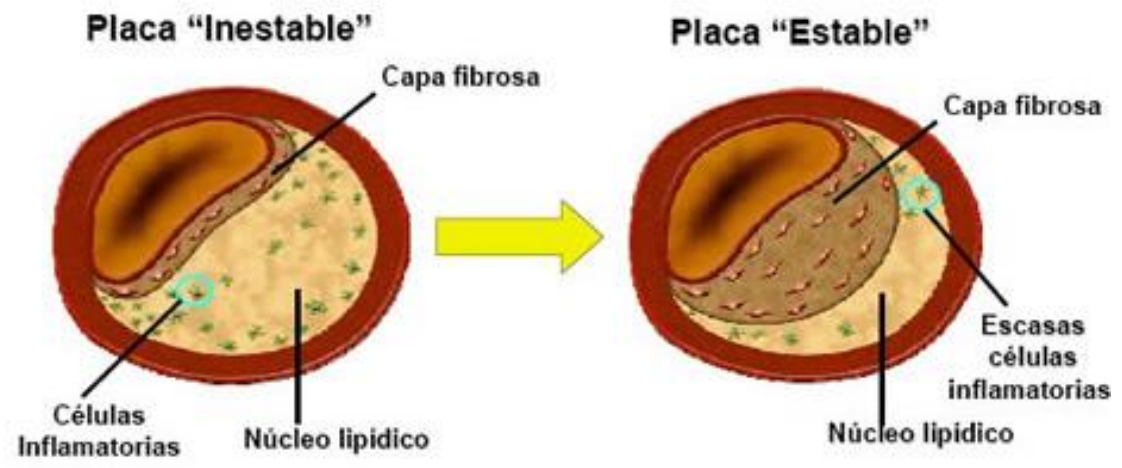

Fig.5. Diferencias estructurales entre placa estable e inestable

Fase 5: Placas fibrosas. Las placas de ateroma en las distintas fases descritas hasta ahora, representan aproximadamente el 70\% del total de las lesiones ateromatosas que podemos encontrar. Sin embargo un $30 \%$ son placas totalmente fibróticas y aunque también se han encontrado en procesos cardiovasculares agudos, dependen más del porcentaje de la estenosis que producen y son responsables de gran parte de la enfermedad ateromatosa crónica, que ha sido tradicionalmente estudiada con imagen (angina estable, claudicación intermitente, etc.). Este tipo de placa es la evolución de las anteriores, en la cual la fibrosis ha continuado produciéndose crónicamente. No suelen ser responsables de problemas trombóticos, si bien pueden ocurrir, aunque en una proporción menor que las placas con alto contenido lipídico. Fuster et al ${ }^{(8)}$ han encontrado una menor proporción de macrófagos en este tipo de placas y por tanto un menor contenido en metaloproteinasas, por eso son más estables, tendiendo menos a la ruptura y llegando en la mayoría de los casos a la calcificación. 


\subsection{CALCIFICACIÓN VASCULAR}

Tradicionalmente la calcificación vascular se ha considerado como un proceso degenerativo que frecuentemente ocurría al avanzar la edad, y bajo alguna enfermedades como puede ser la diabetes, la HTA o en los estadios finales de la ERC. Actualmente la calcificación vascular es considerada un proceso activo parecido a la mineralización y metabolismo óseo, en el que están implicadas diversas proteínas.

Los resultados recientes parecen indicar que en grandes arterias, el fenómeno de calcificación vascular va siempre asociado a la presencia de placa de ateroma, más que a anomalías del metabolismo mineral. Esto no excluye que alteraciones del metabolismo mineral puedan estar agravando el fenómeno de calcificación vascular.

Mecanismos procalcificantes y anticalcificantes desempeñan un papel importante en la fisiopatología de la calcificación vascular. Las terapias orientadas a disminuir la calcificación vascular en pacientes en diálisis deberían ir orientadas tanto a hacer descender la carga aterosclerótica de dichos sujetos como a restaurar los mecanismos anticalcificantes o inhibir los procalcificantes

En la calcificación vascular el depósito de fosfato cálcico, en forma de cristales de hidroxiapatita (similar al hueso), puede ocurrir en los vasos sanguíneos y en las válvulas cardíacas ${ }^{(15)}$. Se ha clasificado la calcificación arterial dependiendo del lugar donde se deposite el calcio, bien sea en la íntima (asociada a la placa de ateroma) ${ }^{(16)}$, o en la capa media arterial (conocida como esclerosis de Mönckeberg).Este segundo tipo está asociado a la rigidez vascular por mineralización de las fibras elásticas y la arteriosclerosis observada con la edad, diabetes y enfermedad renal crónica (ERC) ${ }^{(17)}$.

La primera está relacionada con un aumento del depósito de lípidos y el infiltrado de células inflamatorias mientras que en la segunda tendría más influencia el cambio de fenotipo de las células de músculo liso vascular hacia células parecidas a osteoblastos. En pacientes con ERC se observa una mezcla de ambas calcificaciones ${ }^{(18-}$ 19). 
Actualmente existen datos que sugieren que esta clasificación no sería tan clara y que ambas serían manifestaciones del proceso aterosclerótico ${ }^{(20)}$ al menos en grandes arterias.

La descripción original de Mönckeberg es del año $1903^{(21)}$. En su artículo se describía la presencia de calcificaciones en la capa media de las arterias de 18 pacientes sin placa evidente. Sin embargo, la descripción se hizo sin la ayuda de técnicas actuales para medir depósito de lípidos, matriz extracelular, etc. Actualmente varios autores refieren que lo que realmente estaba describiendo eran distintos grados de evolución de la placa aterosclerótica ${ }^{(22-23)}$.En la revisión que realizaron Valdivieso et al analizaron las características de las lesiones ateroscleróticas, desde el aumento del grosor íntimamedia, disrupción de la lámina elástica interna o incluso depósito de lípidos. Las grandes arterias presentaban una capa media con un número muy bajo de células de músculo liso vascular, siendo más sensibles al proceso aterosclerótico que al cambio fenotípico hacia células parecidas a osteoblastos.

Este mismo grupo, indica que en grandes arterias de pacientes en diálisis, la calcificación vascular predominante está asociada a la presencia de aterosclerosis ${ }^{(24)}$.

\section{Mecanismos de la calcificación vascular}

La calcificación vascular es un proceso activo y regulado en el que intervienen diferentes mecanismos no excluyentes entre sí $^{(25)}$.

Calcio y fósforo. Algunos autores se refieren a ellos como los «mecanismos pasivos de la calcificación». Los niveles elevados de $\mathrm{Ca}, \mathrm{P}$ y $\mathrm{Ca}$ x $\mathrm{P}$ (prevalentes en pacientes con ERC y significativamente ligados a muerte por enfermedad cardiovascular $^{(26)}$.

Muerte celular y apoptosis. La pared del paciente urémico está lesionada por procesos de inflamación y estrés oxidativo, por lo tanto es razonable pensar que exista apoptosis celular. Proudfoot et al. ${ }^{(27)}$ muestran que la apoptosis regula la calcificación vascular in vitro. 
Inhibidores de la calcificación. Las células de los vasos expresan en condiciones normales moléculas inhibidoras de la mineralización. La pérdida de su expresión, como sucede en la ERC, provoca lo que se denomina «pérdida de la inhibición natural», dando lugar a una calcificación espontánea y a un aumento de la mortalidad.

Ejemplos de sustancias Inhibidoras de calcificación: Matrix Gla Protein, Fetuína A, Osteopontina, Osteoprotegerina

Activadores de la calcificación. Además de la hiperfosfatemia y de la hipercalcemia existen estudios que sugieren la presencia de sustancias en el suero de los pacientes con ERC capaces de estimular la calcificación ${ }^{(28)}$.

Por ejemplo: Fosfatasa alcalina, Core binding factor alpha 1, Las bone morphogenic proteins (BMPs), RANKL (también denominada OPGL) 


\subsection{ENFERMEDAD CORONARIA}

La aterosclerosis coronaria es la forma más común de $\mathrm{ECV}^{(29-30)}$. Supone la primera causa de muerte en la población española, al igual que en el resto de países europeos $^{(5)}$. A pesar de la tendencia a la disminución de la mortalidad por las enfermedades cardiovasculares, el impacto sanitario de éstas se espera que aumente. La enfermedad se inicia por la agresión mantenida de los factores de riesgo cardiovascular (FRCV) sobre determinadas áreas del árbol arterial. Esta agresión altera el normal funcionamiento del endotelio vascular, lo que provoca el acúmulo de grasa y células inflamatorias en la pared arterial. Los FRCV son los mismos para todos los territorios vasculares, entre ellos están incluidos la HTA, el tabaquismo, la dislipemia, la obesidad y la diabetes ${ }^{(31)}$.

Esta enfermedad suele mantenerse silente durante años sin provocar ninguna limitación ni sintomatología en la persona que la padece. Cuando las lesiones avanzan pueden llegar a estrechar de forma significativa la luz de la arteria coronaria provocando cuadros de angina de pecho estable, o pueden erosionarse o romperse de forma brusca provocando la formación de un trombo que obstruya completamente la luz coronaria y desencadene un infarto agudo de miocardio o incluso una muerte súbita ${ }^{(32)}$. En muchas ocasiones observamos la calcificación arterial en las arterias coronarias. Desafortunadamente, una vez que las lesiones están establecidas, no existen medicaciones específicas que hagan desaparecer la aterosclerosis.

En 2011, el estudio DARIOS analizó la prevalencia de estos factores de riesgo en nuestro medio incluyendo 28.887 participantes de entre 34 y 75 años de diez comunidades autónomas españolas. Los resultados de este estudio mostraron unas prevalencias del 43\% para la HTA, 27\% para el hábito tabáquico, 29\% para la obesidad y $13 \%$ para la diabetes. Por último, el $41 \%$ de la población presentaba dislipemia (colesterol total $\geq 250 \mathrm{mg} / \mathrm{dl}$ ) y más del $75 \%$ presentaba valores de colesterol total $>190$ $\mathrm{mg} / \mathrm{dl}$ o de $\mathrm{LDL}>115 \mathrm{mg} / \mathrm{dl}^{(33)}$.

El mejor tratamiento es la prevención de la enfermedad actuando tempranamente sobre los FRCV, con el fin de evitar o retrasar en lo posible el desarrollo de las lesiones. 


\subsection{ENFERMEDAD VASCULAR PERIFÉRICA}

La manifestación de la enfermedad ateroesclerosa de las arterias se denomina enfermedad arterial periférica (EAP) ${ }^{(34)}$, se define como una afectación oclusiva de las arterias de las extremidades inferiores. Es una patología habitualmente infradiagnosticada, ya que sólo el $25 \%$ de los pacientes presenta síntomas y cuando aparece la clínica la obstrucción es mayor del 70\%. Por tanto, muchos pacientes están asintomáticos. En este caso, la enfermedad arterial de las extremidades inferiores se diagnostica mediante examen clínico (ausencia de pulsos) o el índice tobillo-brazo (ITB). Es importante resaltar que los pacientes aunque estén asintomáticos tienen un alto riesgo de episodios cardiovasculares. Los cuadros clínicos de menor a mayor gravedad son los siguientes ${ }^{(35)}$ :

- Claudicación intermitente: Es la presentación más típica de la enfermedad. Los pacientes refieren dolor localizado en la pantorrilla (más raramente en cara posterior de muslo y glúteos) cuando caminan una distancia fija determinada, que les obliga a detenerse y descansar para posteriormente poder proseguir la marcha. La distancia de claudicación se acorta en subidas o si incrementan la velocidad. Se debe al déficit de perfusión que experimenta el tejido muscular cuando la actividad física precisa un aporte sanguíneo superior. En caso de un nivel más proximal de obstrucción arterial (es decir, el segmento aortoilíaco), los pacientes pueden quejarse de extensión del dolor a los muslos y glúteos. La claudicación glútea aislada es rara y se debe a enfermedad hipogástrica bilateral grave.

El dolor debe distinguirse del relacionado con la enfermedad venosa (normalmente en reposo, mayor durante la tarde, que suele desaparecer con algo de actividad muscular), la artritis de las rodillas o las caderas (dolor mientras se deambula pero que no desaparece en reposo) y la neuropatía periférica (caracterizada más por la inestabilidad mientras se deambula, sin que el dolor desaparezca en reposo). La claudicación intermitente típica también puede originarse por estenosis dorsolumbar.

- Dolor de reposo: Se localiza en las zonas más distales de la extremidad, generalmente en los dedos del pie o el empeine. Es de características intensas y empeora 
con el decúbito, aliviándose al poner el pie en declive. No responde a analgésicos convencionales y es muy incapacitante, impidiendo dormir adecuadamente. Debería distinguirse del calambre muscular o la artritis. Los pacientes suelen quejarse de frío permanente en los pies

- Lesiones tróficas: consisten en áreas de necrosis o gangrena y úlceras isquémicas. La gangrena suele localizarse en uno o varios dedos, consistiendo en necrosis del tejido sin infección activa (gangrena seca) o con infección asociada (gangrena húmeda); en casos avanzados, progresa hacia el resto del pie, talón y pierna. Las úlceras isquémicas pueden localizarse en las zonas más distales de los dedos, los espacios interdigitales, dorso del pie o talón, apareciendo de forma espontánea o tras traumatismos banales que no tendrían consecuencias en pacientes no isquémicos.

Otras veces se trata de lesiones mixtas, asociándose a lesiones etiológicamente no isquémicas (úlceras de decúbito, venosas o hipertensivas) que no cicatrizan adecuadamente por déficit de perfusión.

Las clasificaciones clínicas de Fontaine en Europa y Rutherford en los estudios americanos, se recoge todo el espectro de la sintomatología (Tabla I).

Los pacientes con dolor de reposo isquémico y/o lesiones tróficas establecidas se engloban en el concepto de isquemia crítica, y su pronóstico (vital y para la extremidad) es mucho peor que el de los pacientes con claudicación intermitente.

\begin{tabular}{|clcl|}
\hline Clasificación Fontaine & \multicolumn{2}{l|}{ Clasificación de Rutherford } \\
\hline Estadio & Clínica & Estadio & Clínica \\
I & Asintomático & 0 & Asintomático \\
IIA & Claudicación ligera $(>200 \mathrm{~m})$ & 1 & Claudicación ligera \\
IIB & Claudicación moderada-severa & 2 & Claudicación moderada \\
& $(<200 \mathrm{~m})$ & & \\
III & Dolor isquémico en reposo & 3 & Claudicación severa \\
IV & Ulceración o gangrena & 4 & Dolor isquémico en reposo \\
& & 5 & Pérdida de tejido menor \\
& & 6 & Importante pérdida tisular \\
\hline
\end{tabular}

Tabla I. Clasificaciones de Fontaine y Rutherford. 
Un porcentaje alto de pacientes con arteriopatía periférica crónica permanecen asintomáticos, generalmente con isquemias no avanzadas y cuyo grado de sedentarismo o inmovilidad física por otras causas hace que no lleguen a padecer claudicación intermitente. En muchas ocasiones observamos que la calcificación arterial aparece en la arteriopatía oclusiva crónica, sobretodo cuando esta es de etiología diabética o en insuficiencia renal. 


\subsection{ENFERMEDAD CAROTÍDEA}

En los países occidentales, el ACV isquémico tiene un importante impacto en la salud pública, pues es la primera causa de incapacidad a largo plazo y la tercera causa principal de muerte. La mortalidad por ACV varía del 10 al 30\% y los supervivientes siguen en riesgo de padecer episodios cardiacos isquémicos y neurológicos recurrentes. El riesgo de sufrir un ACV y accidentes isquémicos transitorios (AIT), definidos en la mayoría de los estudios como déficits neurológicos transitorios que suelen durar 1-2 h y no más de 24 h, aumenta con la edad ${ }^{(36)}$.

Los factores de riesgo de ACV más graves son HTA, hipercolesterolemia, tabaquismo, diabetes, enfermedad cerebrovascular, fibrilación auricular (FA) y otras enfermedades cardiacas que aumentan el riesgo de complicaciones embólicas. La arteriosclerosis extensiva y en particular la estenosis de la arteria carótida interna suceden en alrededor del $20 \%$ de todos los ACV isquémicos ${ }^{(36)}$. La estenosis de la arteria carótida se considera sintomática en caso de que los AIT o ACV hayan afectado al área correspondiente en los últimos 6 meses $^{(37)}$. En la gran mayoría de los casos, la estenosis de la arteria carótida está ocasionada por la arteriosclerosis evidenciándose en muchos casos la calcificación de la pared arterial. Otras etiologías menos comunes son radioterapia, vasculitis, disección o displasia fibromuscular. El término estenosis de la arteria carótida alude a la estenosis de la porción extracraneal de la arteria carótida interna y al grado de estenosis según los criterios del North America Symptomatic Carotid Endarterectomy Trial (NASCET) ${ }^{(38)}$. En el ensayo NASCET, el riesgo de ACV homolateral recurrente en pacientes con estenosis sintomática de la arteria carótida tratados de manera conservadora fue del 4,4\% por año para estenosis del 50$69 \%$ y del $13 \%$ por año para las $>70 \%$. En pacientes con estenosis asintomática de la arteria carótida $>60 \%$, el riesgo de ACV es de alrededor del $1-2 \%$ por año ${ }^{(39)}$. No obstante, el riesgo puede aumentar a un 3-4\% por año en personas mayores o en presencia de estenosis u oclusión de la arteria carótida contralateral, pruebas de embolización silente en las imágenes cerebrales, heterogeneidad de la placa carotídea, estado inflamatorio generalizado y EAP o EC asociada. 
Las manifestaciones de la enfermedad de las arterias carótidas pueden dividirse en hemisféricas y oculares. La isquemia hemisférica (cortical) suele consistir en debilidad, parálisis, entumecimiento u hormigueo, todos los síntomas afectan a la misma parte del cuerpo y contralateral a la arteria carótida causante. También pueden presentarse síntomas neuropsicológicos, como por ejemplo afasia si el hemisferio dominante se ve afectado, u omisión si el afectado es el hemisferio no dominante. Una embolia en la arteria de la retina puede causar ceguera total o parcial, temporal o permanente, en el ojo homolateral. El déficit ocular temporal también se llama amaurosis fugax. Aunque los síntomas neurológicos de la enfermedad carotidea normalmente los ocasiona una embolización distal, existen causas menos frecuentes, como por ejemplo, una hipoperfusión cerebral transitoria (AIT de flujo débil) o permanente (ACV hemodinámico). 


\subsection{INSUFICIENCIA RENAL}

La enfermedad renal crónica (ERC) es un término genérico que define un conjunto de enfermedades heterogéneas que afectan la estructura y función renal. La variabilidad de su expresión clínica es debida, al menos en parte, a su etiopatogenia, la estructura del riñón afectada (glomérulo, vasos, túbulos o intersticio renal), su severidad y el grado de progresión.

Las guías KDIGO 2012 (Kidney Disease Improving Global Outcomes) ${ }^{(40-41)}$ han confirmado la definición de ERC (independientemente del diagnóstico clínico) como la presencia durante al menos tres meses de:

- FG inferior a $60 \mathrm{ml} / \mathrm{min} / 1.73 \mathrm{~m}^{2}$.

- o lesión renal (definida por la presencia de anormalidades estructurales o funcionales del riñón, que puedan provocar potencialmente un descenso del FG).

La lesión renal se pone de manifiesto directamente a partir de alteraciones histológicas en la biopsia renal (enfermedades glomerulares, vasculares, túbulointersticiales) o indirectamente por la presencia de albuminuria, alteraciones en el sedimento urinario, alteraciones hidroelectrolíticas o a través de técnicas de imagen.

Las Guías K/DOQI publicada en 2013, confirma la definición previa de ERC, pero añade a los estadios de filtrado glomerular (G1 a G5) tres grados de albuminuria (A1 a A3) y la causa de ERC. La causa de la ERC se establecerá por la presencia o ausencia de una enfermedad sistémica con potencial afectación renal o mediante las alteraciones anatomopatológicas observadas o presuntas ${ }^{(42)}$. Según esto, la función renal queda clasificada en 5 niveles (Tabla II).

Clásicamente el término de enfermedad renal crónica terminal (ERCT), se ha utilizado fundamentalmente para referirse a la situación subsidiaria de iniciar tratamiento sustitutivo de la función renal (TRS) ${ }^{(43)}$, actualmente el estadio que precisa de TRS se denomina estadio 5D.

La ERC es un problema emergente en todo el mundo. En España, según los resultados del estudio EPIRCE (Epidemiología de la Insuficiencia Renal Crónica en 
España), se estimó que aproximadamente el $10 \%$ de la población adulta sufría de algún grado de ERC, siendo del 6,8\% para los estadios 3-5 aunque existían diferencias importantes con la edad. En pacientes seguidos en atención primaria con enfermedades tan frecuentes como la HTA o DM, la prevalencia de ERC puede alcanzar cifras del 3540\%. Actualmente existen unos 20.000 pacientes en diálisis (estadio 5D) en España ${ }^{(44)}$

La ERC es un problema de Salud Pública, ya que en su fase terminal, el tratamiento que requiere, tiene un elevado coste, además existe un aumento del riesgo de eventos cardiovasculares en estos pacientes.

Se estima que el $40 \%$ de la población española con enfermedad renal no diagnosticada, fallecerá (principalmente de problemas cardiovasculares) antes de entrar en un programa de diálisis.

Se considera ERC avanzada a los pacientes incluidos en las categorías 3b, 4 y 5 .

\begin{tabular}{|lcl|}
\hline Categoría por FG & FGe & Descripción \\
\hline G1 & $>90$ & Normal o elevado \\
G3a & $60-89$ & Ligeramente disminuido \\
& $45-59$ & $\begin{array}{l}\text { Ligero-moderadamente } \\
\text { disminuido }\end{array}$ \\
G3b & $30-44$ & Moderado-gravemente \\
& & disminuido \\
G4 & $15-29$ & Gravemente disminuido \\
G5 & $<15$ & Fallo renal \\
\hline Categoría por albuminuria & Intervalo & Descripción \\
\hline A1 & $<30 \mathrm{mg} / \mathrm{g}$ & Normal o aumento leve \\
& $<3 \mathrm{mg} / \mathrm{mmol}$ & \\
A2 & $30-299 \mathrm{mg} / \mathrm{g}$ & Aumento moderado \\
& $3-29 \mathrm{mg} / \mathrm{mmol}$ & \\
A3 & $>300 \mathrm{mg} / \mathrm{g}$ & Aumento grave \\
& $>30 \mathrm{mg} / \mathrm{mmol}$ & \\
\hline
\end{tabular}

Tabla II. Estadios enfermedad renal crónica. 
La supervivencia global de los pacientes en diálisis es de un 12,9\% a los diez años, a pesar de los avances técnicos del tratamiento. Ello es debido presumiblemente al hecho de que el $50 \%$ tiene una media de tres factores de riesgo cardiovascular y una gran comorbilidad asociada. Por todos estos motivos se acepta hoy que la ERC constituye una de las principales causas de muerte en el mundo occidental ${ }^{(45)}$.

La prevalencia de la ERC aumenta por el envejecimiento de la población, el incremento de la prevalencia de sus factores de riesgo como la enfermedad cardiovascular, la DM, la HTA o la obesidad y, obviamente, por el diagnóstico precoz de la misma. En Europa, se ha detectado un incremento anual cercano al 5\% de la $\mathrm{ERC}^{(46)}$.

El coste medio por paciente en TRS (estadio 5D) es seis veces mayor que el tratamiento de pacientes con infección por el VIH y 24 veces mayor que el tratamiento de pacientes con EPOC y asma. El coste medio anual por paciente tratado con

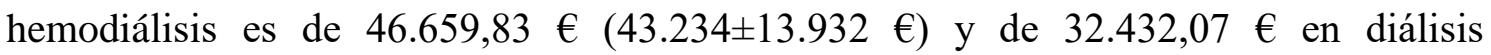
peritoneal. Se estima que el TRS consume el 2,5\% del presupuesto del Sistema Nacional de Salud y más del 4\% de atención especializada, esperando un incremento anual de estos costes ${ }^{(47)}$.

Al igual que en la población general, la enfermedad cardiovascular es la principal causa de muerte en pacientes con ERC, representando algo más del $40 \%$ de la mortalidad total. La esperanza de vida se reduce drásticamente en la ERC en estadios avanzados en comparación con la población general, lo que sugiere que la incidencia y letalidad de las enfermedades cardiovasculares es mayor en este tipo de pacientes. De hecho se sabe que la mortalidad por causa cardiovascular se incrementa de 20 a 30 veces más con respecto a la población general $^{(43,48)}$.

El riesgo de accidentes cardiovasculares no fatales, también es de 10-30 veces mayor en pacientes con ERC en estadios avanzados que en el resto de la población ${ }^{(43)}$. Son por lo tanto más propensos a la progresión o al desarrollo de patología cardiovascular con respecto a la población general ${ }^{(49)}$ ya que presentan un aumento del estado proinflamatorio , disfunción endotelial, HTA y dislipemia , estos factores hacen que se acelere la progresión de la ateroesclerosis y por tanto la patología coronaria ${ }^{(50)}$. 
Ya en estadios precoces de la ERC existe una mayor asociación con la patología cardiovascular, incrementándose de forma continua con la disminución de la función renal $^{(51)}$. Distintos estudios han demostrado que los pacientes con ERC moderada tienen ya en su mayoría patología coronaria sobreañadida ${ }^{(52)}$.

Las complicaciones cardiovasculares que sufren los pacientes con ERC podrían ser divididas en dos grandes bloques para un mejor entendimiento:

1. Hipertrofia de ventrículo Izquierdo, que junto con las alteraciones en el remodelado cardiaco y la fibrosis miocárdica constituye la lesión más prevalente en la $\mathrm{ERC}^{(53)}$.

2. Enfermedad arterial, que a su vez se divide en dos mecanismos de lesión.

a. Lesión de la capa intima arterial

b. Calcificación de la capa media arterial

Las diferentes técnicas de TRS son diálisis peritoneal (DP), hemodiálisis (HD), hemofiltración, así como la posibilidad de un trasplante renal. Hay que plantearse el TRS cuando el FG es $<15 \mathrm{ml} / \mathrm{min} / 1.73 \mathrm{~m}^{2}$ o antes si aparecen signos o síntomas de uremia o dificultad en el control de la hidratación (hecho frecuente en el caso del paciente con DM), la HTA o empeoramiento del estado nutricional. En general, se iniciará diálisis cuando el FG está situado entre 8 y $10 \mathrm{ml} / \mathrm{min} / 1.73 \mathrm{~m}^{2}$ y es mandatorio con FG $<6 \mathrm{ml} / \mathrm{min} / 1.73 \mathrm{~m}^{2}$, incluso en ausencia de sintomatología urémica ${ }^{(41)}$.

La diálisis es un proceso que consiste en la movilización de líquidos y partículas de un compartimento líquido a otro a través de una membrana semipermeable. Clínicamente, la diálisis es el proceso mecánico de eliminar productos residuales del metabolismo proteico sin alterar el equilibrio hidroelectrolítico y restableciendo el equilibrio acido-básico en pacientes con compromiso de la función renal ${ }^{(54)}$.

Los tres principios químicos que rigen la diálisis son:

La difusión: es el proceso por el cual dos soluciones de diferente concentración cuando se ponen en contacto, llegan a formar una mezcla uniforme, a causa del movimiento constante de las partículas de las dos soluciones, que tienden a distribuirse uniformemente por todo el volumen de la solución. 
La ósmosis, consiste en el desplazamiento de líquido a través de una membrana semi-impermeable desde el lado de menor concentración al de mayor concentración. Este fenómeno se utiliza en la diálisis peritoneal (tanto la difusión como la ósmosis sirven para equiparar las densidades a ambos lados de la membrana).

La ultrafiltración es el paso de agua y solutos producidos por una diferencia de presiones a los dos lados de la membrana. De esta forma se favorece el paso de agua y las móleculas que la acompañan en una u otra dirección ${ }^{(55)}$.

A la hora de elegir el método de diálisis que se va a emplear, hay que tener en cuenta entre otras cosas la situación clínica del paciente y la urgencia del tratamiento. En la actualidad, el paciente puede elegir entre diversos métodos de diálisis, ya sea en un hospital, en un centro asistencial o en su domicilio.

\section{HEMODIÁLISIS}

Mediante transporte difusivo y convectivo, se extraen los solutos retenidos y mediante ultrafiltración, se ajustará el volumen de los líquidos corporales consiguiendo sustituir de este modo la función excretora del riñón. El resto de las funciones, deberán intentarse suplir de otro modo, pues sólo el trasplante puede realizarlas por completo.

La hemodiálisis es intermitente y se realiza normalmente en el ámbito hospitalario. Una rápida corrección de un desequilibrio electrolítico puede predisponer a algún tipo de arritmia, mientras que una rápida eliminación de líquido suele ser mal tolerada por los pacientes

Durante un tratamiento de hemodiálisis, la sangre del paciente circula fuera del cuerpo a través de un riñón artificial, el dializador. En principio, un dializador contiene dos cámaras separadas por una membrana, una de ellas inundada por la sangre y la otra por el líquido de diálisis. La membrana es artificial y semipermeable, permitiendo así el paso del agua y de los solutos hasta cierto tamaño. Está elaborada habitualmente con derivados de la celulosa (celofán, cuprofán, etc...) o con otras sustancias más complejas (poliacrilonitrilo, poliamidas, polisulfona, etc...). Los poros de dicha membrana provocan el paso de sustancias (solutos y agua) que aparecen aumentadas en el circuito 
sanguíneo frente a una solución fisiológicamente estándar La circulación extracorpórea es controlada por una máquina de diálisis, la cual prepara también el líquido de diálisis. Cuando comienza el tratamiento, la sangre del paciente contiene exceso de líquido y productos de desecho. Para eliminar el líquido se aplica un gradiente de presión a través de la membrana en el dializador. Esto fuerza al agua a abandonar la sangre, a penetrar la membrana y entrar en el líquido de diálisis mediante el proceso de ultrafiltración. La cantidad de líquido ultrafiltrado durante la sesión entera de tratamiento deberá corresponder al exceso de volumen ${ }^{(56)}$.

A medida que el líquido de diálisis se ve libre de productos de desecho, se crea un gradiente de concentración a través de la membrana. Esto hace que los productos de desecho pasen mediante difusión desde la sangre al líquido de diálisis. El resultado del tratamiento es que el volumen de la sangre queda ajustado, y que los productos de desecho son eliminados de ella. Los dos procesos de eliminación de líquido (ultrafiltración) y de eliminación de solutos (difusión) tienen lugar normalmente en forma simultánea. La tasa de eliminación de líquidos durante un tratamiento de hemodiálisis se halla determinada por el gradiente total de presión y las características del dializador.

Gradiente total de presión: La tasa de ultrafiltración es directamente proporcional al gradiente total de presión a través de la membrana, es decir, la presión transmembrana verdadera. El gradiente total de presión consta de las presiones hidrostáticas en los compartimentos de la sangre y del líquido de diálisis del dializador, así como de la presión osmótica ejercida por las proteínas del plasma en la sangre (presión oncótica).

Características del dializador: Las distintas membranas poseen diferente capacidad de ultrafiltración por lo que requieren gradientes de presión muy diferentes para ofrecer la misma eliminación de líquido. El tipo de membrana y el área de superficie son los determinantes más importantes.

La tasa de eliminación de solutos mediante difusión está determinada por los cuatro parámetros siguientes: flujo de sangre, en la hemodiálisis estándar, se sitúa normalmente a 200-300 ml/min, tasa de flujo de líquido de diálisis, gradiente de 
concentración entre la sangre y el líquido de diálisis y por último, las características del dializador.

Incrementando el flujo de sangre se logra un mayor aclaramiento sobre todo de moléculas pequeñas, como la urea y la creatinina. Para moléculas más grandes un flujo de sangre incrementado tiene poco efecto sobre el aclaramiento.

Para la eliminación óptima de solutos, el flujo del líquido de diálisis deberá ser aproximadamente dos veces mayor que la tasa del flujo de sangre. Casi todas las máquinas de diálisis se gradúan para ofrecer un flujo de $500 \mathrm{ml} / \mathrm{min}$, lo que en la práctica es suficiente para flujos de sangre de hasta 300-350 ml/min.

Gradiente de concentración: para las moléculas pequeñas el transporte difusivo es directamente proporcional al gradiente de concentración a través de la membrana. El gradiente es mantenido por el flujo de sangre y el líquido de diálisis.

Características del dializador: los diferentes dializadores tienen distintas características de rendimiento. El tipo de membrana, el espesor y el área son los más importantes determinantes de la eliminación difusiva de solutos. La geometría del flujo del dializador y la distribución del flujo afecta también al transporte de solutos.

Finalmente, la eliminación de solutos por convección está determinada por la tasa de ultrafiltración y las propiedades de tamizado de la membrana. Esto es normalmente de menor importancia en la hemodiálisis estándar ${ }^{(55)}$.

\section{DIÁLISIS PERITONEAL}

La diálisis peritoneal es otra técnica de depuración extrarrenal que puede utilizarse para tratar la insuficiencia renal aguda y crónica. En este tipo de diálisis, el líquido de diálisis se introduce en la cavidad abdominal por medio de un catéter y el peritoneo se comporta como una membrana semipermeable y selectiva a determinadas sustancias, ya que igual que las membranas utilizadas en hemodiálisis no permite el paso de los elementos formes aunque sí de las toxinas. Todo ello lo realiza mediante difusión y osmosis. Gracias al desarrollo de catéteres de silástic implantables de forma 
quirúrgica para acceso permanente a la cavidad peritoneal, equipos de diálisis peritoneal automáticos de ciclo cerrado y bolsas de plástico para el dializado, este procedimiento se realiza en el hogar para el tratamiento a largo plazo de pacientes con insuficiencia renal crónica ${ }^{(57)}$.

Los dos tipos de diálisis peritoneal más utilizados son la DPCA y la DPA ${ }^{(58)}$.

\section{1.- DPCA (diálisis peritoneal continua ambulatoria)}

La DPCA, es una técnica manual en la que la sangre se depura dentro del organismo, utilizando para ello la propia membrana peritoneal a través de un catéter en el espacio peritoneal. En los pacientes con una enfermedad aguda y en aquellos que requieren diálisis esporádicas, se introduce un catéter estéril para cada procedimiento. En el paciente con una enfermedad crónica tratado de forma rutinaria, se coloca un catéter permanente.

Se infunden uno o dos litros de solución estéril de diálisis (dializado) en la cavidad abdominal mediante el catéter donde fluye por gravedad y después se pinza el tubo. Se despinza el tubo y se permite salir el líquido del abdomen por acción de la gravedad. Una vez el líquido ha drenado del abdomen. La mayoría de los pacientes cambian la solución 4 veces/día.

\section{2.-DPA (diálisis peritoneal automatizada)}

La DPA funciona igual que la DPCA con la única diferencia de que es un proceso automatizado. La máquina cicladora es programada por el enfermero/a según prescripción médica. Se programa: $\mathrm{n}^{\circ}$ de ciclos (tiempo de infusión, tiempo de permanencia, tiempo de drenaje), líquido a infundir, drenaje de cada ciclo, drenaje total. Normalmente funciona durante la noche y el paciente una vez terminada la sesión sólo debe preocuparse de desconectarse de la cicladora. Normalmente el paciente debe llevar durante el día el último intercambio en el abdomen. Es una técnica adecuada para los individuos activos sin interrupciones de la rutina diaria y muy adecuada en niños. El mayor inconveniente es la necesidad de la máquina cicladora. 


\section{HEMOFILTRACIÓN CONTINUA}

Este tipo de TRS se utiliza cuando existe fracaso renal agudo (FRA), debe iniciarse de forma precoz. La principal indicación es control de la volemia, homeostasis electrolítica, control del equilibrio ácido-base y eliminación de sustancias tóxicas producto del metabolismo, especialmente urea y creatinina. Debido a la mejoría alcanzada en las áreas de cuidados intensivos, numerosos pacientes que antiguamente hubieran fallecido, actualmente presentan FRA en el contexto del Síndrome de Disfunción Multiorgánica (SDMO). En esta situación la hemodiálisis convencional no es el método de sustitución renal ideal ya que se han descrito, como efectos secundarios asociados a ella: hipotensión, hipoxemia, aumento del consumo de oxígeno, arritmias cardíacas y desarrollo de edema cerebral. Por otra parte, la diálisis peritoneal (DP) tiene múltiples limitaciones: Riesgo de peritonitis, aclaramientos de urea pobres y disminución de la movilidad diafragmática ${ }^{(59-61)}$. 


\subsection{FACTORES DE RIESGO CARDIOVASCULAR}

La ECV está fuertemente relacionada con el estilo de vida, especialmente con el consumo de tabaco, los hábitos alimentarios poco saludables, la inactividad física y el estrés psicosocial. Según la Organización Mundial de la Salud (OMS), con cambios adecuados del estilo de vida se podría prevenir más de tres cuartas partes de la mortalidad cardiovascular.

La prevención de la ECV sigue siendo un reto importante para la población general, los responsables políticos y los profesionales de la salud. Dicha prevención comprende una serie de acciones coordinadas, poblacionales e individuales, dirigidas a erradicar, eliminar o minimizar el impacto de estas enfermedades y la discapacidad asociada a ellas $^{(3,34)}$.

Los factores de riesgo, están constituidos por cualquier hábito o característica biológica que sirva para predecir la probabilidad de un individuo de desarrollar una enfermedad cardiovascular. La existencia de un factor de riesgo (FR) no implica obligatoriamente una relación causa-efecto con la enfermedad. El conocimiento y detección de los factores de riesgo desempeña un importante papel para la valoración del riesgo cardiovascular. La presencia de varios FR en un mismo individuo multiplica su riesgo de forma importante. Si bien todos los FR favorecen el desarrollo de la enfermedad ateroesclerótica en los diferentes lechos vasculares.

\subsubsection{Factores de riesgo en la población general}

\section{A-.Factores no modificables}

1. Raza: Hace ya algunos años que se han demostrado diferencias en la incidencia de la enfermedad cardiovascular según la raza. En un principio se creía que estas diferencias se debían a hábitos de vida y a cuestiones ambientales, factores que aunque sí que influyen, también se ven afectados por la genética de las personas. Así, los individuos de raza asiática tienen un $38,7 \%$ de probabilidades de fallecer frente al $31 \%$ de las probabilidades de los de raza blanca durante el mismo periodo de tiempo ${ }^{(62)}$. 
La British Heart Foundation realizó un pormenorizado trabajo que revela que los ciudadanos británicos de origen surasiático tienen un 50\% más de probabilidades de fallecer por enfermedad cardiovascular que los de origen europeo. Este hecho se debe a que estas personas tienen los vasos coronarios más pequeños que los europeos, triplicando el desarrollo de trombos y favoreciendo, así, la aparición de arterioesclerosis.

Aunque, en general, los individuos de raza negra sufren menos enfermedad cardiovascular que los caucásicos o los asiáticos, la incidencia en cardiopatía isquémica es muy superior. Esto se debe a que tienen una mayor predisposición a sufrir hipertensión lo que favorece la arterioesclerosis. Se calcula, que de media, los hombres tienen $6 \mathrm{mmHg}$ más de presión sistólica en reposo que sus homólogos blancos, y que las mujeres tienen hasta $17 \mathrm{mmHg}$, lo que las sitúa como el grupo poblacional de mayor riesgo ${ }^{(63)}$.

2. Sexo: La prevalencia de la arteriopatía periférica, sintomática o asintomática, es ligeramente mayor en hombres que en mujeres, en particular en los grupos de edad más jóvenes, ya que en edades más avanzadas se va reduciendo esta diferencia hasta casi igualarse ${ }^{(34)}$. En el caso particular de la EC, el riesgo es aproximadamente 4 veces superior en el varón que en la mujer, para una misma concentración de colesterol sérico. La edad de aparición de la EC se retrasa entre 10 y 15 años en las mujeres respecto a los varones. Con la menopausia aumenta de forma importante la incidencia de EC en mujeres, pero sin llegar a alcanzar la de los varones en ningún momento ${ }^{(32)}$.

3. Edad: Es el factor de riesgo con mayor valor predictivo. Existe un notable incremento tanto de la incidencia como de la prevalencia de la enfermedad a medida que aumenta la edad, independientemente del sexo y de la raza. Este aumento oscila entre el $3 \%$ y el $10 \%$ en menores de 60 años, porcentaje que aumenta hasta el $15 \%$ y el $20 \%$ en las personas mayores de 70 años. Las tasas correspondientes para las mujeres fueron del 2,7 y el 10,8. En el estudio de Framingham, la incidencia de claudicación intermitente entre los varones creció de 0,4/1.000 entre 35 y 45 años a 6/1.000 entre los de 65 o más años ${ }^{(3)}$.

Se incluye como riesgo la edad superior a 55 años en varones y la superior a 65 años en la mujer. Por lo que respecta a los antecedentes familiares de enfermedad 
cardiovascular prematura, se considera como factor de riesgo el antecedente de la misma, en un familiar de primer grado en varones antes de los 55 años y en mujeres antes de los 65 años $^{(64)}$.

\section{B-.Factores modificables}

1. Tabaquismo: Existe una asociación contrastada entre la ECV y el tabaquismo. Esta asociación es de igual intensidad, aunque consideremos el tabaco bajo en nicotina ${ }^{(34)}$, los puros o la pipa implican un riesgo algo inferior ${ }^{(32)}$. Las manifestaciones de la ECV también aumentan con el número de cigarrillos fumados/día ${ }^{(31)}$. Los fumadores importantes tienen un riesgo cuatro veces mayor de desarrollar claudicación intermitente comparados con los no fumadores. Los fumadores pasivos tienen aumentado el riesgo de EC entre un 10 y un $30 \%$.

Cuando se abandona el hábito tabáquico, el riesgo decrece en un 50\% durante el primer año y se aproxima al de los no fumadores al cabo de 2 años ${ }^{(65)}$. Dejar de fumar es imperativo en el paciente que presenta ECV, ya que es de crucial importancia para controlar su progresión y sus complicaciones ${ }^{(66-68)}$.

Los mecanismos a través de los cuales el tabaco favorece la ateroesclerosis son múltiples y entre ellos destacan la lesión del endotelio por el monóxido de carbono circulante, el aumento del fibrinógeno y del factor VII, el aumento de la adherencia y la agregabilidad de las plaquetas, el aumento de la oxidación de las LDL y el descenso de la concentración de $\mathrm{HDL}^{(69)}$.

2. Diabetes Mellitus: La diabetes se asocia a un aumento de 2-3 veces en la probabilidad de aparición de una ECV, independientemente de que sea insulinodependiente o no y este aumento es mayor en las mujeres que en los varones; la intolerancia a la glucosa se asocia también a un aumento de 1.5 veces en el riesgo de aparición de $\mathrm{ECV}^{(3)}$, de hecho las ECV encabezan las causas de muerte en diabéticos. Hay una relación directa entre los años de duración de la diabetes y el riesgo de $\mathrm{EC}^{(32)}$. Los diabéticos de tipo II tienen un riesgo cardiovascular elevado que en ocasiones es similar al de los sujetos no diabéticos que ya han presentado un evento coronario. Por ello, las principales guías consideran a los diabéticos como sujetos de alto riesgo 
cardiovascular en los que se debe aplicar un tratamiento igual al de los pacientes que han presentado un episodio cardiovascular previo $^{(70)}$.

La diabetes mellitus favorece la aterotrombosis por distintos mecanismos: un perfil lipídico desfavorable (elevación de los triglicéridos, descenso del cHDL, partículas de LDL pequeñas y densas), presencia de LDL modificadas, hiperinsulinismo, hipercoagulabilidad y aumento de marcadores inflamatorios ${ }^{(71)}$. Se ha señalado que la resistencia a la insulina es un mecanismo frecuente de estos factores de riesgo, a cuya combinación se denomina síndrome metabólico ${ }^{(71-72)}$.

La EAP en pacientes con diabetes es más agresiva comparada con la que se presenta en sujetos no diabéticos, con afectación precoz de vasos grandes junto a una neuropatía $^{(71,73-75)}$ cabe destacar que en estos pacientes pueden obtenerse valores anormalmente altos y por tanto falsos negativos en el ITB.

El paciente diabético deberá realizar un control estricto al menos una vez al año de TA, Colesterol (ya que la DM aumenta los niveles de LDL) y hemoglobina glicosilada que debe ser inferior al 7\%. Además intentar mantener la glucemia capilar en torno a $100 \mathrm{mg} / \mathrm{dl}^{(5,76)}$.

3. Hipertensión arterial: La hipertensión se asocia a todas las formas de enfermedad cardiovascular ${ }^{(31)}$. Es uno de los grandes factores de riesgo, con independencia de la edad, el sexo o la raza. Las cifras de presión arterial, tanto sistólicas como diastólicas, se correlacionan con la incidencia de EC y ACV. El riesgo aumenta de forma continua en el rango de presiones, de forma que los individuos con hipertensión arterial límite tienen un riesgo algo superior que los normotensos.

El papel de la HTA en el proceso de la ateroesclerosis se conoce poco. Se ha postulado que el exceso de presión dañaría el endotelio y aumentaría su permeabilidad. Además, la HTA podría estimular la proliferación de las células musculares lisas o inducir la rotura de la placa.

La presencia de lesión en los órganos diana (hipertrofia del ventrículo izquierdo y/o microalbuminuria) se acompaña de un incremento del riesgo cardiovascular. Se aconseja mantener cifras tensionales en torno a $120 \mathrm{mmHg}$ de tensión sistólica y 80 $\mathrm{mmHg}$ de tensión diastólica ${ }^{(76)}$. 
El tratamiento con IECAs ha demostrado un efecto beneficioso que va más allá de la disminución de la presión arterial en el grupo de alto riesgo. En el ensayo HOPE, el tratamiento con el IECA ramipril redujo significativamente los episodios CV en un $25 \%$ en pacientes con EAP sintomática sin fracción de eyección baja conocida o insuficiencia cardiaca ${ }^{(77)}$. El ensayo ONTARGET reveló que el telmisartán era equivalente al ramipril en estos pacientes ${ }^{(78)}$.

Es importante saber, que los fármacos Beta bloqueantes no están contraindicados en pacientes con $\operatorname{EAP}^{(79)}$. En un metaanálisis de 11 estudios controlados y aleatorizados, se descubrió que los Beta bloqueantes no afectaban negativamente a la capacidad de deambulación o los síntomas de claudicación intermitente en pacientes con enfermedad arterial leve o moderada ${ }^{(80)}$. Tras 32 meses de seguimiento de 490 pacientes con EAP y EC, se vio que los Beta bloqueantes causaron un importante descenso relativo de casi el $53 \%$ en la aparición de nuevos episodios coronarios ${ }^{(81)}$.

4. Dislipemia: En el estudio de Framingham, una concentración de colesterol en ayunas mayor de $7 \mathrm{mmol} / \mathrm{l}(270 \mathrm{mg} / \mathrm{dl})$ se asoció a una duplicación de la incidencia de $\mathrm{ECV}$, aunque el denominado índice aterogénico o cociente entre colesterol total y colesterol HDL resultó ser un mejor factor pronóstico de la aparición de ECV, lo deseable es que sea menor de $4^{(35)}$.

No existe un valor numérico exacto que marque los niveles de colesterol normales, por lo que se habla de rangos de normalidad o, mejor incluso, de valores deseables en cada persona según su nivel de riesgo. Los niveles de colesterol total se pueden clasificar de la siguiente manera: Deseables: < $200 \mathrm{mg} / \mathrm{dl}$, Límite alto: 200-239 $\mathrm{mg} / \mathrm{dl}$. Alto: $\geq 240 \mathrm{mg} / \mathrm{dl}^{(76)}$.

Las LDL, que son las principales lipoproteínas de transporte de colesterol en la sangre, presentaban también una asociación directa con la ECV. La concentración de LDL en los adultos jóvenes predice la aparición de ECV en una fase posterior de la vida, lo cual respalda la idea, de que la relación entre el LDL y la aparición de enfermedad es un proceso continuo que se inicia en una etapa temprana de la vida ${ }^{(3)}$. Las directrices actuales identifican el LDL como el objetivo principal del tratamiento de la hipercolesterolemia. 
Los niveles deseables de LDL son unas cifras inferiores a $100 \mathrm{mg} / \mathrm{dL}$, o menores a $70 \mathrm{mg} / \mathrm{dL}$ si además asocian enfermedad vascular en varios territorios ${ }^{(82)}$.

El National Cholesterol Education Program (NCEP) considera un HDL $<40$ $\mathrm{mg} / \mathrm{dl}$ como FR, mientras que las concentraciones por encima de $60 \mathrm{mg} / \mathrm{dl}$ se valoran como un factor de riesgo negativo ${ }^{(70)}$.

En relación con los niveles de HDL, los valores recomendables son $45 \mathrm{mg} / \mathrm{dl}$ para los hombres y $50 \mathrm{mg} / \mathrm{dl}$ para las mujeres, aunque sería deseable para ambos sexos alcanzar niveles de $60 \mathrm{mg} / \mathrm{dl}^{(83)}$.

La hipertrigliceridemia se asocia a una mayor progresión y número de complicaciones de la ECV. Los niveles de triglicéridos se pueden clasificar de la siguiente manera: Deseables: <150 mg/dl. Límite alto: 150-199 mg/dl. Altos: 200-499 $\mathrm{mg} / \mathrm{dl}$. Muy altos: $>500 \mathrm{mg} / \mathrm{dl}$.

Con objeto de obtener unos valores fiables, no se debe comer ni beber nada a excepción de agua durante las 10-12 horas anteriores a la medida de los niveles de lípidos en la sangre.

Las estatinas reducen el riesgo de mortalidad, episodios Cardiovasculares en pacientes con EAP. En el Estudio Health Protection, en el seguimiento a 5 años, la simvastatina consiguió una reducción relativa significativa del 19\% y una reducción absoluta del $6.3 \%$ en los episodios Cardiovasculares más graves independientemente de la edad, el sexo o las concentraciones séricas de lípidos ${ }^{(84-85)}$.

5. Índice masa corporal (IMC): La obesidad es un trastorno metabólico crónico asociado a numerosas comorbilidades, como $\mathrm{ECV}^{(31)}$, diabetes mellitus tipo 2, HTA y apnea del sueño ${ }^{(71)}$. Además, la obesidad es un factor independiente del riesgo de mortalidad por todas las causas $^{(86)}$, relación que fue identificada por los investigadores de Framingham hace 40 años.

Aparte de las alteraciones del perfil metabólico, cuando se acumula un exceso de tejido adiposo, se producen diversas adaptaciones de la estructura y la función cardiacas. De manera similar a lo observado con el LDL, un estudio reciente ha indicado que tener un IMC más alto durante la infancia se asocia a un aumento del riesgo de EC en la edad adulta. Esta asociación parece ser más intensa en los niños que 
en las niñas y aumenta con la edad en ambos $\operatorname{sexos}^{(3)}$. La prevención del sobrepeso y la obesidad ha pasado a ser un elemento clave para la prevención de las enfermedades

cardiovasculares. Se recomienda la dieta mediterránea y hacer ejercicio diario.

Lo deseable es en una cifra de IMC inferior a $25 \mathrm{Kg} / \mathrm{m}^{2(76)}$.

6. Hiperhomocisteinemia: Se ha observado que existe una mayor prevalencia de hiperhomocisteinemia en la población con ECV que en la población general.

El mecanismo de acción de la hiperhomocisteinemia es doble: por una parte promueve la oxidación de LDL y por otra, inhibe la síntesis de óxido nítrico. Aunque se ha descrito como factor de riesgo independiente, en la actualidad existe controversia ya que los últimos estudios publicados concluyen que aunque se disminuyan los niveles de homocisteinemia en sangre no se consigue la disminución de los efectos adversos cardiovasculares $^{(87)}$.

7. Insuficiencia renal crónica: Existe una asociación entre insuficiencia renal y ECV, y viceversa. Se describe la insuficiencia renal como un factor de riesgo en sí mismo para el desarrollo de patología cardiovascular ${ }^{(88)}$.

Llama la atención el hecho demostrado de que, en grados moderados de insuficiencia renal, el riesgo de muerte por eventos cardiovasculares es mayor que en la enfermedad renal en estadios terminales que precisen tratamiento sustitutivo, es decir, diálisis o trasplante renal. Esto resulta de especial importancia en personas mayores de 60 años, cuando se ha producido por razones puramente fisiológicas un descenso de la función renal. Debido a ello, el nefrólogo durante el seguimiento de la enfermedad renal de sus pacientes debe controlar la progresión de la enfermedad renal e intentar contener y evitar la patología cardiovascular asociada ${ }^{(89)}$.

En los últimos años se ha ido describiendo que la ERC está asociada, desde sus estadios iniciales, con la enfermedad vascular sistémica y que ambos trastornos comparten factores de riesgo y mecanismos de progresión. Por un lado, la prevalencia de ERC es elevada entre los pacientes con ECV y, por otro lado, el riesgo de progresión de la ERC es superior en los pacientes con este tipo de trastornos, lo que ha llevado a proponer que el riñón juega un papel fundamental en la patología vascular 
Las evidencias se han ido acumulando de tal forma que en la actualidad se entiende que la ERC, desde los estadios incipientes, constituye un importante factor de riesgo de morbimortalidad total y cardiovascular. Múltiples estudios de base poblacional o con grupos de pacientes de mayor o menor riesgo cardiovascular han mostrado una relación entre la función renal disminuida, evaluada tanto por cifras elevadas de creatinina como por descensos estimados del aclaramiento de creatinina o del FG, y la morbimortalidad cardiovascular y la mortalidad por cualquier causa.

Actualmente se afirma que:

1) La proteinuria es un factor de riesgo para enfermedad cardiovascular tanto en pacientes con diabetes como sin diabetes.

2) Un aclaramiento de creatinina o un FG bajo es un factor de riesgo para enfermedad cardiovascular en pacientes diabéticos y no diabéticos.

3) Los pacientes con enfermedad renal crónica, presentan un riesgo aumentado de presentar ECV.

4) Los pacientes con enfermedad renal crónica deben ser considerados como pacientes de alto riesgo cardiovascular ${ }^{(90)}$.

\section{RECOMENDACIONES DE LA AHA PARA EVITAR ECV}

Abandono del tabaquismo

Actividad física regular

IMC $<25$

Circunferencia de cintura: $<94 \mathrm{~cm}$ (varones), $<80 \mathrm{~cm}$ (mujeres)

Presión arterial < 120/80 mmHg

Colesterol total $<200 \mathrm{mg} / \mathrm{dl}$

Cifras cLDL $<2,5 \mathrm{mmol} / \mathrm{I}(100 \mathrm{mg} / \mathrm{dl}) ; \mathrm{cHDL}>45 \mathrm{mg} / \mathrm{dl}$

En pacientes con diabetes mellitus tipo 2: Glucemia en ayunas $<7,0 \mathrm{mmol} / \mathrm{l}(125 \mathrm{mg} / \mathrm{dl})$

En pacientes sanos Glucemias < 100mg/dl

Tabla III. Recomendaciones de la AHA para prevenir eventos cardiovasculares ${ }^{(76)}$. IMC: índice de masa corporal; LDL: lipoproteínas de baja densidad; HDL: lipoproteínas alta densidad 


\subsubsection{Factores de riesgo en insuficiencia renal}

Además de los factores de riesgo que presenta la población general, en la insuficiencia renal aparecen varios mecanismos que agravan o empeoran la enfermedad arteroesclerosa. Existe un estado inflamatorio generalizado (reflejado en una elevación de la PCR) y otras comorbilidades, que producen patología cardiovascular. Algunas de ellas son : anemia, síndrome metabólico, hipertensión arterial, hiperuricemia, disfunción endotelial, oxidación, hiperlipidemia, alteración en el metabolismo del calcio-fósforo, calcifilaxis, diabetes, resistencia a la insulina, proteinuria, hiperhomocisteínemia y obesidad $^{(91)}$.

Actualmente se habla de nuevos factores de riesgo y entre ellos se encuentran la anemia, estrés oxidativo y catabolismo proteico.

Estado de inflamación: Hoy se acepta de manera generalizada que la inflamación desempeña un papel fundamental en el desarrollo y progresión de las lesiones ateroscleróticas (Fig.6), condicionando la aparición de manifestaciones clínicas en la evolución. La inflamación es una frecuente manifestación de la enfermedad renal y cardiovascular $^{(32)}$. Existen marcadores de inflamación como la proteína $\mathrm{C}$ reactiva (PCR), que se halla en relación directa con la intensidad de la inflamación subyacente y constituye un marcador de mal pronóstico, ya que se asocia con malnutrición y arteriosclerosis en el llamado síndrome MIA (malnutrición, inflamación y arteriosclerosis). Son muy numerosas las publicaciones que enfatizan la relación de los niveles de PCR, el síndrome MIA y la mortalidad ${ }^{(92-94)}$. 


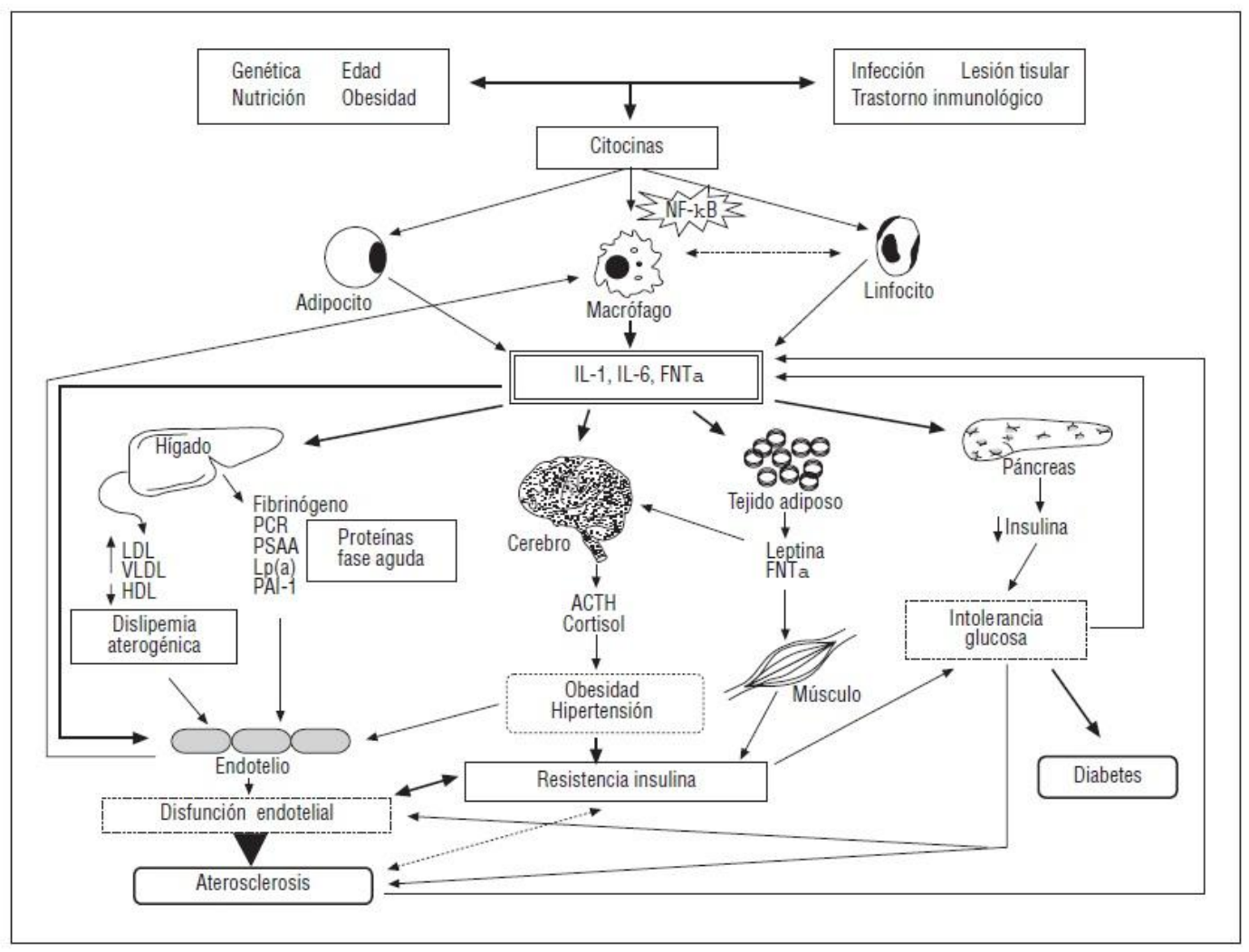

Fig.6: Mecanismo inflamatorio de la ateromatosis.

Metabolismo mineralo-óseo: las guías $\mathrm{KDIGO}^{(41)}$ han relacionado las alteraciones del metabolismo mineralo óseo de la ERC, no sólo con la génesis del hiperparatiroidismo secundario (HPTS) y de la osteodistrofia renal, sino que también lo han asociado a la progresión de la ERC, así como a sus complicaciones, incluyendo las cardiovasculares, aumentando de un modo significativo la morbimortalidad de los pacientes con $\mathrm{ERC}^{(95)}$.

Estas alteraciones son un trastorno sistémico que se caracteriza por anomalías del metabolismo del calcio, fósforo, hormona paratiroidea (PTH) y vitamina D, que, más allá de producir alteraciones esqueléticas, se relacionan también con la aparición de calcificaciones cardiovasculares o en otros tejidos blandos ${ }^{(96)}$.

La calcificación vascular es un proceso celular activo. La sobreexpresión de inductores de transformadores de células osteogénicas y la formación de hidroxiapatita (el fósforo posee probablemente un papel principal), causa la diferenciación de las células de músculo liso vasculares en osteoblastos-like. Se han descubierto los factores reguladores de calcio y fosfatos que poseen propiedades como inhibidores de la 
calcificación sistémica o local. Estos factores tienen un papel clave en el tratamiento de las calcificaciones no deseadas.

Murshed et al., sin embargo demostró que incluso los desórdenes más complejos del metabolismo mineralo-óseo se pueden prevenir controlando la concentración extracelular de fósforo. Por lo tanto, se puede pensar que el proceso de calcificación se desarrolla por un único estimulo en la aceleración y progreso en la ERC ${ }^{(41)}$.

Anemia: es de tipo multifactorial. Se ha demostrado la asociación entre anemia y mortalidad. Así mismo, ha quedado patente la clara relación entre la anemia y la hipertrofia ventricular izquierda (HVI) en pacientes en diálisis. Esto es muy relevante ya que la HVI es un factor predictor de mortalidad en estos enfermos. La prevalencia es más elevada a medida que aumentan los años que han estado en diálisis ${ }^{(97)}$. Es lo que se ha llamado hipertrofia ventricular excéntrica o concéntrica con cambios en los miocitos, que son distintos en la remodelación ventricular. Las causas que explican el efecto de la anemia sobre el miocardio o músculo cardíaco son la caída de aporte de oxígeno, así como el aumento del gasto cardíaco, el descenso de las resistencias periféricas, la activación simpática y el estrés oxidativo. La normalización de la anemia en estos pacientes no va asociada con una vuelta a las tasas de mortalidad propias de los estadios incipientes de la ERC. El nivel de hemoglobina deseado se sitúa entre 11 y $12 \mathrm{~g} / \mathrm{dL}$ y valores por encima de los anteriores han demostrado un aumento de morbimortalidad $^{(98-99)}$.

Estrés oxidativo: Los radicales de oxidación son producidos de forma normal en el metabolismo diario e incluso cumplen una función defensiva frente a agentes patógenos y células tumorales. Teniendo en cuenta que el riñón es el principal órgano con capacidad antioxidante del organismo, en la ERC se produce un desequilibrio entre la producción y la eliminación. Como consecuencia, existe un aumento de diferentes radicales libres como el peróxido de hidrógeno $\left(\mathrm{H}_{2} \mathrm{O}_{2}\right)$, el superóxido $\left(\mathrm{O}_{2}{ }^{-}\right)$o los radicales hidroxilo $\left(\mathrm{OH}^{-}\right)$. Los principales antioxidantes (la superoxidodismutasa o la glutation peroxidasa) están disminuidos en la ERC. El estrés oxidativo, induce la disfunción endotelial y la progresión de la ateroesclerosis por la reducción de la disponibilidad del óxido nítrico ${ }^{(100)}$. 
Catabolismo proteico: al consumo energético-proteico de los pacientes en diálisis, que conlleva una alteración de indicadores nutricionales como son niveles bajos de albúmina, prealbúmina, colesterol total, creatinina y pérdida de masa muscular se denomina actualmente PEW (Protein-Energy-Wasting) ${ }^{(101)}$. Estas anomalías están fuertemente ligadas a un aumento de las tasas de morbimortalidad global y cardiovascular $^{(102-103)}$.

Proteinuria: existe una relación directa entre la proteinuria franca, propia de la ERC y el riesgo de patología cardiovascular. Es un factor de progresión de la ERC y se asocia muy frecuentemente a HTA y a trastornos lipídicos, que en sí mismos son FRCV. En el estudio LIFE (Losartan Intervention For End point reduction in hipertension study), se encontró una relación directa entre el grado de microalbuminuria y el riesgo de mortalidad por eventos cardiovasculares, que se invertía cuando la primera disminuía tras un tratamiento hipotensor, sobre todo con los ARA II ${ }^{(104)}$.

\section{Marcadores Bioquímicos}

Concentración de albúmina sérica <4g/DI.

Concentración de prealbúmina sérica <30mg/DI.

Concentración de colesterol total $<100 \mathrm{mg} / \mathrm{dL}$.

Masa Corporal

$\mathrm{IMC}<23 \mathrm{~kg} / \mathrm{m}^{2}$.

Pérdida involuntaria de peso seco ( $>5 \%$ en tres meses o $>10 \%$ en seis meses).

Porcentaje de grasa corporal total $<10 \%$.

\section{Masa muscular}

Sarcopenia: reducción de masa magra corporal $>5 \%$ en tres meses o $>10 \%$ en seis meses.

Reducción de CMB (<percentil 10).

Baja concentración de creatinina sérica o descenso ajustado por función renal.

\section{Ingesta alimentaria(involuntariamente disminuida)}

Ingesta diaria proteica en ERC $<0,5 \mathrm{~g} / \mathrm{kg} /$ día y $>1,0 \mathrm{~g} / \mathrm{kg} /$ día en HD.

Ingesta diaria energética $<25 \mathrm{Kcal} / \mathrm{kg} /$ día mantenida durante 2 meses.

Anorexia: Pérdida subjetiva del apetito.

Tabla IV: Parámetros de definición de PEW. CMB: circunferencia muscular del brazo 
Hiperuricemia: Es una alteración muy frecuente en la ERC. Las células progenitoras endoteliales tras fenómenos isquémicos aumentan su producción de ácido úrico, la hiperuricemia crónica está estadísticamente relacionada como un factor independiente en la mortalidad cardiovascular, se asocia a mayor riesgo de infartos coronarios y accidentes cerebrovasculares de origen isquémico.

Inicialmente se creía que el ácido úrico sólo era patógeno como molécula extracelular al precipitar en forma de cristales en los distintos tejidos. Actualmente, se ha visto que la lesión es intracelular, más concretamente a nivel endotelial ${ }^{(105)}$.

La hiperuricemia se ha asociado, en grandes estudios poblacionales, a la aparición de hipertensión, el estudio NAS (Normative Aging Study) manifiesta que según se eleva el nivel de ácido úrico basal aumenta el riesgo de desarrollo futuro de HTA, otros estudios relacionan hiperuricemia con HVI y diabetes ${ }^{(106-107)}$. 


\subsection{DIAGNÓSTICO DE ENFERMEDAD CARDIOVASCULAR}

\subsubsection{Historia Clínica}

Es obligatorio registrar los factores de riesgo y las comorbilidades conocidas. Debe anotarse la HTA, la dislipemia, la diabetes mellitus, el consumo de tabaco y los antecedentes de ECV. La historia clínica debería incluir una revisión de los distintos lechos vasculares y sus síntomas específicos:

- Historial familiar de la ECV.

- Síntomas que indiquen angina.

- Cualquier dificultad para la deambulación (p. ej., fatiga, dolor o calambre localizado en las nalgas, los muslos, las pantorrillas o los pies), especialmente cuando los síntomas desaparecen rápidamente al descansar.

- Cualquier dolor en reposo, localizado en el tercio medio de las piernas o los pies y su asociación con estar en bipedestación o en decúbito.

- Cualquier herida de las extremidades con mala evolución.

- Dolor de las extremidades superiores por esfuerzo, especialmente si está asociado a mareo o vértigo.

- Cualquier síntoma neurológico transitorio o permanente.

- Antecedentes de hipertensión o insuficiencia renal.

- Dolor abdominal o diarrea postprandial y si se asocian a pérdida de peso llamativa.

- Disfunción eréctil.

Es importante hacer hincapié en que la historia clínica es clave a la hora de hacer una valoración cardiovascular. Hay que recordar que muchos pacientes, incluso con la enfermedad en estado avanzado, permanecen asintomáticos o describen síntomas atípicos. 


\subsubsection{Exploración física}

A pesar de que el examen físico por si solo tiene sensibilidad, especificidad y reproducibilidad relativamente escasas, es obligatorio un enfoque sistemático que debe incluir al menos:

-La medición de la presión arterial en ambos brazos y una anotación de la diferencia entre ellos.

-Auscultación y palpación de las áreas de la fosa supraclavicular y cervical.

-Palpación del pulso de las extremidades superiores. Las manos deben inspeccionarse detenidamente.

-Auscultación cardiaca en tórax y base del cuello

-Palpación abdominal y auscultación en distintos niveles, entre ellos flancos, región periumbilical y regiones iliacas.

-Auscultación de las arterias femorales a nivel inguinal.

-Palpación de las zonas femoral, poplítea, dorsal del pie y tibial posterior. La ausencia de pulso nos informa de una estenosis $\mathrm{u}$ oclusión hemodinámicamente significativa por encima del nivel de pulso palpado, mientras que la presencia de todos ellos nos permite descartar la enfermedad con un elevado valor predictivo negativo. La presencia de pulso femoral pero no poplíteo ni distales nos indica oclusión femoropoplítea; la ausencia de pulso femoral implica oclusión iliaca y la presencia de pulso femoral y poplíteo con ausencia de tibial anterior y posterior oclusión infrapoplítea.

-Se debe inspeccionar los pies y el color, temperatura e integridad de la piel y se debe anotar la presencia de ulceraciones.

-Se observará la presencia de signos adicionales que indiquen enfermedad arterial de las extremidades inferiores, como pérdida de pelo en las pantorrillas y cambios en la piel. 


\subsubsection{Parámetros analíticos}

En primer lugar, es fundamental la determinación del perfil lipídico, con los niveles de colesterol total, LDL y HDL.

Parámetros de inflamación: PCR, VSG, IL-1.

Parámetros de metabolismo mineralo-óseo y hiperpratiroidismo : Ca, P, VitD, PTH.

Parámetros de control de diabetes: glucosa y hemoglobina glicosilada.

Parámetros de nutrición o síndrome de PEW: albúmina, prealbúmina, prot totales.

Parámetros de anemia e infección serie roja y serie blanca.

Parámetros de destrucción celular muscular cardiaca (.cardiopatía isquémica) e insuficiencia cardiaca: troponina, CK-MB, proBNP.

Parámetros función renal e iones: creatinina, urea, cloro, sodio y potasio.

\subsubsection{Electrocardiograma}

El electrocardiograma es, junto con la clínica, una de las principales herramientas para el diagnóstico de la Cardiopatía Isquémica. Tanto en los eventos agudos como en los crónicos, el Electrocardiograma nos facilita el diagnóstico, mostrándonos cambios, sobre todo en el segmento ST y la onda T.

También es una herramienta muy útil para el diagnóstico de otros procesos. De su interpretación dependen enfermedades como las Arritmias Cardiacas o las alteraciones de la conducción. Además, el Electrocardiograma, puede ser de utilidad en otras enfermedades extracardiacas como el Tromboembolismo Pulmonar o alteraciones electrolíticas $^{(108)}$.

\subsubsection{Exploraciones hemodinámicas: el índice tobillo-brazo.}

El doppler continuo nos permite detectar flujo arterial y las características del sonido o su representación gráfica (onda) nos dan una idea cualitativa del grado de 
isquemia. Es uno de los métodos más baratos y más accesibles para la estratificación del riesgo cardiovascular ${ }^{(109)}$.

También permite realizar una evaluación cuantitativa del grado de isquemia mediante el cálculo del índice tobillo-brazo. Un ITB anormal es predictor de evento cardiovascular incluso en paciente asintomático ${ }^{(110)}$.

Cuando las arterias presentan severa calcificación (como en diabéticos o insuficientes renales), no se colapsan con el manguito de presión, dándonos cifras falsamente elevadas (superior a 1.3) que no son valorables; en estos casos se puede realizar un cálculo del índice dedo-brazo mediante fotopletismografía.
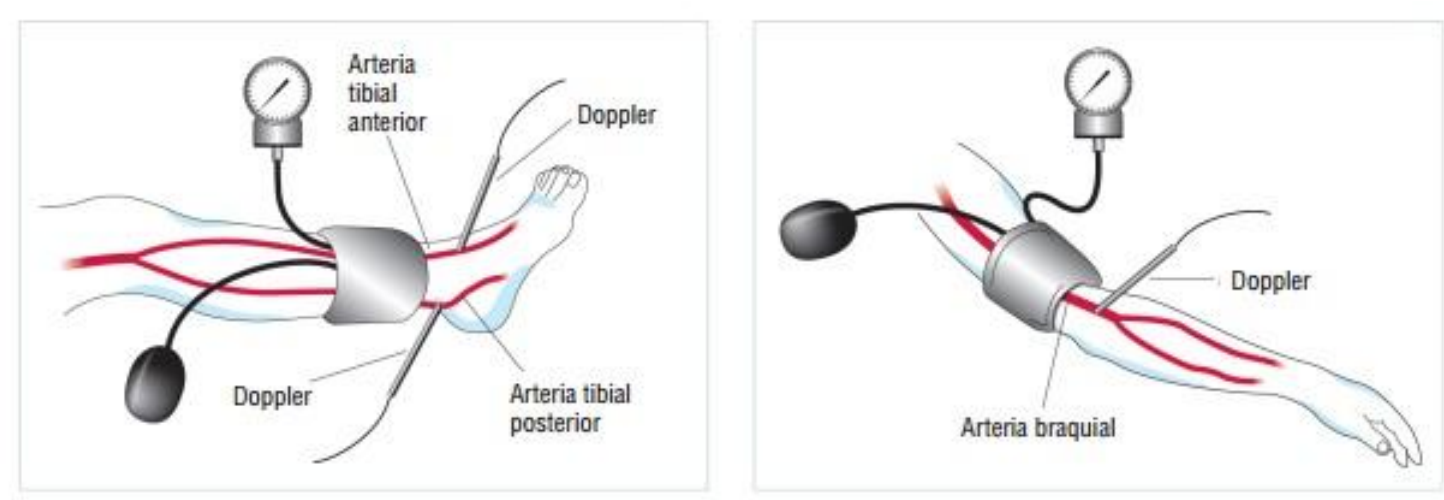

Fig.7: Medición Índice Tobillo Brazo (ITB).

\subsubsection{Ecografía de TSA}

\section{$\underline{\text { A-.Ecodoppler carotídeo. Estenosis carotídea }}$}

Dadas sus características ser incruenta, accesible, fiable, reproducible y de bajo coste, la utilización de la ecografía como técnica inicial de despistaje de estenosis carotídea extracraneal está ampliamente aceptada y es la exploración inicial obligada. Si bien se requieren observadores experimentados y un protocolo de imagen estricto. Más controvertido sería su uso como única técnica diagnóstica para la planificación prequirúrgica. 
Los enfermos sintomáticos de enfermedad cerebrovascular con infartos cerebrales isquémicos, AIT o amaurosis fugax constituyen el principal grupo a estudiar y en ellos las pruebas diagnósticas tienen un doble objetivo:

1. Confirmar la presencia de estenosis carotídea ipsilateral a la lesión neurológica con la finalidad de atribuir etiológicamente el evento isquémico.

2. Si existe estenosis cuantificar el grado de ésta para determinar el tipo de tratamiento a realizar.

Además de en enfermos sintomáticos, actualmente hay un gran interés por valorar la presencia de estenosis carotídea en enfermos asintomáticos, sobre todo en pacientes que presenten múltiples factores de riesgo cardiovascular y/o con patología coronaria o vascular periférica de origen ateromatoso ${ }^{(111)}$.

Existen otros factores que condicionan la aparición de síntomas en enfermos con estenosis carotídea como son la morfología y la constitución de la placa ateromatosa ${ }^{(14)}$.

\section{$\underline{\text { B-.Grosor íntima-media carotídeo (GIM) }}$}

Una de las pruebas que más consistencia tiene para detectar la ateroesclerosis en fases precoces, es el espesor de la capa íntima de la arteria carótida. Además de predecir posibles eventos cerebrovasculares, tiene buena correlación con eventos cardiovasculares $^{(6)}$. Los estudios han demostrado que la ecografía carotídea es más sensible que la clasificación de calcificación coronaria para la detección de ateroesclerosis subclínica $^{(112)}$.

Por ello, la medición del grosor de la íntima-media carotídea se ha convertido en una herramienta muy utilizada en distintos ensayos clínicos, particularmente como una forma de monitorizar el efecto de las distintas terapias medicamentosas, como las estatinas, en la modificación de la placa de ateroma ${ }^{(113)}$.

En el estudio de Niu et al. ${ }^{(114)}$ Se evaluó el grosor intima media y la elasticidad arterial, encontrando que la asociación de múltiples factores de riesgo tiene un mayor impacto en el índice íntima-media carotídeo. 
Otros autores no sólo se limitan a medir el GIM en carótida común sino que también utilizan otros parámetros ecográficos como son GIM carótida interna, grosor máximo de la placa en carótida ${ }^{(115)}$.

\subsubsection{Ecografía extremidades inferiores}

\section{$\underline{\text { A-.Ecodoppler arterial de extremidades inferiores }}$}

El GIM femoral se ha investigado menos, pero también se ha asociado con los factores de riesgo tradicionales y con la existencia de EC, con un valor predictivo superior al del GIM carotídeo. Recientemente un estudio prospectivo ha demostrado que la presencia de placas femorales y un GIM femoral aumentado, es un factor de riesgo independiente de la incidencia de EC más allá del valor predictivo de los factores convencionales $^{(116)}$.

\section{$\underline{\text { B-.Dilatación mediada por flujo (FMD) }}$}

Es un método validado para predecir futuros eventos cardiovasculares. Su valor pronóstico se ha demostrado en pacientes con ateroesclerosis en estadio avanzado. Es una herramienta valiosa para los estudios de riesgo de patología ateroesclerótica. Es fácil de usar, fiable y reproductible pero está limitada principalmente porque requiere una larga curva de aprendizaje y los resultados pueden estar influenciados por factores externos como la comida, la cafeína, el estrés o la temperatura ${ }^{(109)}$.

Actualmente, las guías ESC (European Society of Cardiology) no respaldan la medición de FMD para uso clínico ni para monitorizar el efecto del tratamiento ${ }^{(117)}$. La FMD según las guías de la AHA tiene un grado de recomendación III/B para la estratificación de riesgo cardiovascular ${ }^{(118)}$.

\section{C-.Velocidad de la onda de pulso aórtica (PWV)}

La rigidez arterial se considera hoy día un biomarcador cada vez más importante en la evaluación del riesgo cardiovascular y en la detección de una enfermedad vascular incipiente. Muchos estudios han mostrado que este parámetro es un predictor independiente de mortalidad cardiovascular en ancianos, hipertensos, diabéticos y pacientes con enfermedad renal así como en la población sana ${ }^{(109)}$. 
Las guías de la Sociedad Europea de Hipertensión y Cardiología han postulado que la determinación de la rigidez arterial, la medición de la placa carotídea y el índice tobillo/brazo como marcadores del status vascular. Cualquier alteración de estas mediciones puede definir un estado de vasculopatía que aumenta significativamente el riesgo cardiovascular ${ }^{(117)}$.

Dentro de los distintos métodos de evaluación de la rigidez arterial, el más ampliamente utilizado en la literatura es la velocidad de la onda de pulso aórtica o pulse wave velocity (PWV), específicamente en el área que va desde el arco aórtico o la carótida común a la arteria femoral común.

\subsubsection{Otras Pruebas de imagen}

\section{$\underline{\text { A-.Angiografía }}$}

Tradicionalmente, la angiografía por sustracción digital (ASD) era la técnica de referencia de las imágenes vasculares, el gold standard ${ }^{(119)}$. Se obtiene una imagen bidimensional muy precisa de la luz permeable de los vasos. Dadas sus características invasivas (requiere punción arterial) y que el uso de contraste limita su utilización en insuficientes renales, se ha visto reemplazada por otros métodos de diagnóstico igual de efectivos y no invasivos, quedando relegada a los procedimientos endovasculares (tanto a nivel cardiaco, cerebrovascular o en arterias periféricas) y para aquellos casos en los que con las imágenes no invasivas existen dudas diagnósticas.

\section{$\underline{\text { B-.Angiografía por tomografía computarizada multidetector }}$}

Las ventajas que presenta la angiotomografía computarizada multidetector (MDCT) son la no invasividad (por ello está especialmente indicada en casos de malos accesos vasculares o en ausencia de pulsos), que ha disminuido el tiempo de examen y reducido los artefactos por movimientos y respiración (los estudios se realizan en una apnea) y muestra a la vez imágenes de los vasos sanguíneos y de los órganos. El espesor de corte es submilimétrico.

Sólo a nivel cardiaco todavía se utiliza más la coronariografia en el diagnóstico. 
Por el contrario, su precisión disminuye en zonas calcificadas, aunque se ha visto que la cantidad de calcio coronario detectado en las MDCT sin contraste está relacionado de forma proporcional con eventos $\operatorname{cardiacos}^{(31)}$. A nivel cerebral puede aportar información sobre las zonas isquémicas.

Otros inconvenientes de esta prueba son las elevadas dosis de radiación utilizadas, un estudio equivale a 500 radiografías de tórax o cinco años de radiación natural.

Al ser más rápida la adquisición de imágenes, se usa potencialmente menos contraste, aunque se han descrito casos de nefropatía inducida por contraste

. Cuando la MDCT se utiliza con fines diagnósticos, la nefrotoxicidad se puede limitar minimizando el volumen de los agentes de contraste y asegurando la hidratación adecuada antes y después de la prueba. El beneficio potencial de la acetilcisteína a la hora de limitar la nefrotoxicidad es incierto.

Las ventajas de la MDCT sobre la angiorresonancia magnética (AngioRM) (desarrollada en el siguiente apartado) son su posible uso en casos de marcapasos, desfibriladores, stents arteriales, prótesis en articulaciones, calcificaciones murales y que la dimensión del voxel es de 5-14 veces más pequeño que la AngioRM, teniendo una mejor resolución espacial.

\section{C-.Angiografía por resonancia magnética (Angio RM)}

La angiorresonancia es otra alternativa no invasiva que además no presentan artefactos por calcio.

Entre las contraindicaciones absolutas se incluyen marcapasos cardiacos, desfibriladores automáticos implantables, neuroestimuladores, implantes cocleares, primer trimestre del embarazo e insuficiencia renal grave. Se han desarrollado marcapasos adecuados para las imágenes por resonancia magnética. La claustrofobia, los objetos metálicos extraños y el segundo y el tercer trimestre de embarazo se consideran contraindicaciones relativas. 
La angiografía por RM sin contraste intravenoso, puede utilizarse para visualizar el lecho vascular. El desarrollo de las técnicas "Angiosurf” y "Bodysurf " ha supuesto un avance significativo en el campo de las imágenes ${ }^{(120)}$. El "Angiosurf”, se puede utilizar un protocolo que consigue una imagen de las arterias de la cabeza, torácicas y periféricas desde las carótidas hasta los tobillos ${ }^{(121)}$.

Las ventajas de la AngioRM sobre el MDCT son la falta de radiación del paciente, importante sobre todo en niños, es repetible y permite realizar series dinámicas, por lo que hay mejor caracterización tisular y de flujo. La tecnología ha mejorado por lo que ahora se pueden obtener estudios en menor tiempo y se usa gadolinio en lugar de contraste iodado ${ }^{(119,122)}$.

\section{$\underline{\text { D-.Ecocardiograma }}$}

Existen dos tipos de exploración ecocardiográfica, la ecocardiografía transesofágica (ETE), que ofrece una calidad mejor de imágenes debido a la proximidad del corazón y se realiza insertando un endoscopio en el esófago.

Ecocardiografía transtorácica (ETT): es la que más se utiliza. Ayuda a visualizar el corazón mediante el desplazamiento de la sonda sobre el tórax y la pared abdominal superior. Permite obtener imágenes del corazón desde distintos ángulos, que varían según la posición de la sonda.

La ecocardiografía es hoy el elemento fundamental del diagnóstico no invasivo, de las enfermedades cardiovasculares, ya que permite realizar un dictamen muy preciso de forma incruenta, rápida y sin radiación. Permite ver de forma precisa las cavidades cardíacas y las válvulas o el pericardio, pero aunque aporta datos muy precisos de la morfología y la funcionalidad del corazón, no permite ver bien las arterias coronarias.

Debido a todas sus ventajas potenciales, se están realizando estudios para validar esta prueba dentro del screening de ateroesclerosis, casi todos ellos en pacientes renales $^{(123-124)}$, que además de tener un gran riesgo cardiovascular tienen muchas limitaciones diagnósticas por el uso de contrastes. Ya se ha comentado con anterioridad que presentan hipertrofia de ventrículo izquierdo, alteraciones en el remodelado cardiaco y fibrosis miocárdica ${ }^{(53)}$. 
Gluba-Brzózka et al. ${ }^{(50)}$ han publicado un estudio sobre 80 pacientes renales en los que se observa un aumento de prevalencia de hipertrofia ventricular izquierda, disfunción ventricular (definida como fracción de eyección menor del 44\%) y una mayor calcificación de las válvulas mitral y aórtica. En los pacientes en estadio V de insuficiencia renal fue llamativo el aumento de casos de insuficiencia tricuspídea.

Unagami et al. ${ }^{(125)}$ publican una mayor disfunción diastólica sin alteración de la función sistólica en 101 pacientes sometidos a hemodiálisis. 



\section{HIPÓTESIS}



La enfermedad cardiovascular es la principal causa de muerte en pacientes con enfermedad renal crónica (ERC), representando algo más del $40 \%$ de la mortalidad total. La esperanza de vida se reduce drásticamente en la ERC en estadios avanzados en comparación con la población general, lo que sugiere que la incidencia y letalidad de las enfermedades cardiovasculares es mayor en este tipo de pacientes. De hecho se sabe que la mortalidad por causa cardiovascular se incrementa de 20 a 30 veces más con respecto a la población general.

El riesgo de accidentes cardiovasculares no fatales, también es de 10-30 veces mayor en pacientes con ERC en estadios avanzados que en el resto de la población. Son, por lo tanto, más propensos a la progresión o al desarrollo de patología cardiovascular con respecto a la población general ya que presentan un aumento del estado proinflamatorio, disfunción endotelial, hipertensión arterial (HTA) y dislipemia , estos factores hacen que se acelere la progresión de la ateroesclerosis y por tanto la patología coronaria.

Tradicionalmente, la calcificación vascular se ha considerado como un proceso degenerativo que frecuentemente ocurría al avanzar la edad, y bajo alguna enfermedades como puede ser la diabetes, la HTA o en los estadios finales de la ERC. Actualmente la calcificación vascular es considerada un proceso activo.

Los resultados recientes parecen indicar que en grandes arterias, el fenómeno de calcificación vascular va siempre asociado a la presencia de placa de ateroma, más que a anomalías del metabolismo mineral. Esto no excluye que alteraciones del metabolismo mineral puedan estar agravando el fenómeno de calcificación vascular. LA calcificación está asociada a la rigidez vascular por mineralización de las fibras elásticas y la arteriosclerosis observada con la edad, diabetes y enfermedad renal crónica. Los estudios indican que en grandes arterias de pacientes en diálisis, la calcificación vascular predominante está asociada a la presencia de aterosclerosis.

Dentro de los diversos tipos de terapia renal sustitutiva (TRS), los más frecuentemente empleados son la diálisis peritoneal (DP) y la hemodiálisis (HD). Ambos métodos poseen diferentes mecanismos de difusión, ósmosis y ultrafiltración. A la hora de elegir el método de diálisis que se va a emplear, hay que tener en cuenta entre otras cosas la situación clínica del paciente y la urgencia del tratamiento. En la actualidad, el paciente puede 
elegir entre diversos métodos de diálisis, ya sea en un hospital, en un centro asistencial o en su domicilio. No obstante, las posibles repercusiones fisiopatológicas y complicaciones derivadas de ambas técnicas son completamente diferentes.

Por lo tanto, investigando las manifestaciones subclínicas de la enfermedad aterosclerosa avanzada, como son las calcificaciones vasculares, en pacientes con enfermedad renal renal sin enfermedad cardiovascular sintomática podemos conocer el impacto de la aterosclerosis relacionada con la insuficiencia renal. Además, el estudio de la implicación de los dos tipos de TRS más ampliamente implantados (DP y HD) sobre el desarrollo y avance de la enfermedad aterosclerosa nos puede permitir avanzar en el conocimiento de la elevada prevalencia de enfermedad cardiovascular en enfermos con insuficiencia renal avanzada. 
3. OBJETIVOS 



\subsection{PRINCIPAL}

Conocer la presencia de las calcificaciones vasculares como marcador avanzado de aterosclerosis, en pacientes con enfermedad renal avanzada sin enfermedad cardiovascular sintomática y estudiar la influencia de la terapia renal sustitutiva (hemodiálisis y diálisis peritoneal) sobre la evolución de las mismas.

\subsection{SECUNDARIOS}

- Conocer los factores de riesgo cardiovascular, así como la presencia de fibrilación auricular e hipertrofia de ventrículo izquierdo, que presentan los pacientes con enfermedad renal avanzada sin enfermedad cardiovascular sintomática en nuestro entorno.

- Estudiar las calcificaciones vasculares (carotídeas, femorales y aorto-ilíacas) y los parámetros analíticos del metabolismo mineralo-óseo, de los pacientes con enfermedad renal avanzada en terapia sustitutiva renal mediante hemodiálisis mediante la utilización de pruebas no invasivas.

- Investigar las calcificaciones vasculares (carotídeas, femorales y aorto-ilíacas) y los parámetros analíticos del metabolismo mineralo-óseo, de los pacientes con enfermedad renal avanzada en terapia sustitutiva renal mediante diálisis peritoneal mediante la utilización de pruebas no invasivas.

- Comparar la evolución de las las calcificaciones vasculares (carotídeas, femorales y aorto-ilíacas) y los parámetros analíticos del metabolismo mineraloóseo, en los pacientes con enfermedad renal avanzada en terapia sustitutiva renal mediante hemodiálisis o diálisis peritoneal. 



\section{MATERIAL Y MÉTODOS}





\subsection{GENERALIDADES DEL ESTUDIO}

El presente estudio, es prospectivo observacional, realizado en pacientes en Enfermedad Renal Crónica Avanzada (ERCA).

Pacientes pertenecientes al Hospital Universitario Rio Hortega de Valladolid, España, centro médico de tercer nivel, que cuenta con un total de 600 camas. La recogida de datos se ha llevado a cabo durante de 1 año y dos meses, en el periodo comprendido entre Enero de 2015 y Marzo de 2016.

Cada sujeto se ha valorado en dos ocasiones con un periodo de 1 año entre ambas.

\section{Criterios de inclusión:}

Pacientes mayores de 18 años.

Pacientes sometidos a TRS, tanto en la modalidad de HD como en la modalidad de DP que llevaran entre 1 y 3 años en tratamiento o pacientes en estadios de enfermedad renal avanzada todavía sin TRS.

Sin antecedentes de enfermedad cardiovascular, entendiendo por ésta la enfermedad coronaria (cardiopatía isquémica), la enfermedad cerebrovascular y la enfermedad arterial periférica.

Que voluntariamente hayan firmado el consentimiento para participar en el estudio. (anexo 3)

Finalmente se reclutaron 50 sometidos a HD y 26 en DP. El grupo control lo han formado 66 pacientes con ERC estadios 4-5, valorados en la denominada consulta de ERCA que aún no estaban en el programa de TRS. 


\section{Criterios de exclusión:}

\section{Menores de 18 años}

Pacientes con historia de evento cardiovascular o diagnosticados previamente de ECV.

Pacientes que no han sido valorados en las dos ocasiones o no firmaran el consentimiento informado de participación del estudio.

El protocolo del estudio fue aprobado por la comisión de investigación del hospital. Se cumplieron los principios de la declaración de Helsinki. 


\subsection{DISEÑO ESTUDIO}

Se trata de un estudio de cohorte prospectivo. Se compararon los tres grupos ya mencionados, HD, DP y grupo control. Al ser un estudio estrictamente observacional, los investigadores no interaccionaban en los tratamientos médicos. Los pacientes fueron evaluados con diferentes técnicas cuando acudían a la consulta rutinaria del nefrólogo.

El investigador experto en realizar las pruebas ecográficas del sector carotídeo y femoral además de la exploración de ITB desconocía las comorbilidades del paciente así como las puntuaciones en los tests de Adragao y Kauppila. El investigador encargado de realizar los tests de Adragao y Kauppila desconocía las mediciones ecográficas.

Las características clínicas y demográficas y los datos concernientes dichas técnicas, fueron recogidos de forma prospectiva en todos los pacientes. 


\subsection{VARIABLES ANALIZADAS}

\subsubsection{Variables demográficas}

Edad

Sexo

\subsubsection{Antecedentes personales}

Diabetes Mellitus

Hipertensión Arterial

Dislipemia

Hábito Tabáquico

Fibrilación Auricular

Enfermedad Renal de Base

Trasplante Renal

Modalidad de TRS

\subsubsection{Medicación}

Antihipertensivos

Estatinas

Quelantes cálcicos del fósforo

Quelantes no cálcicos del fósforo

Vitamina D

Cinacalcet

Antiagregantes

Anticoagulantes

Insulina 
Antidiabéticos orales

Hipouricemiantes

\subsubsection{Valores analíticos}

Calcio

Fósforo

Vitamina D

PTH

Fosfatasa Alcalina

Hemoglobina glicosilada

Perfil lipídico: Colesterol total, triglicéridos, LDL,HDL

\subsubsection{Pruebas valoración ateroesclerosis y función cardiaca}

Ecocardiograma

Índice de Adragao

Índice de Kauppila

Ecodoppler TSA: Medición GIM Carotideo, GIM carotideo medio y presencia de placas

Ecodoppler femoral: Medición GIM femoral y GIM femoral medio y presencia de placas

Índice Tobillo/Brazo

Perfil lipídico: Colesterol total, triglicéridos, LDL,HDL 


\subsubsection{Esquema del estudio}

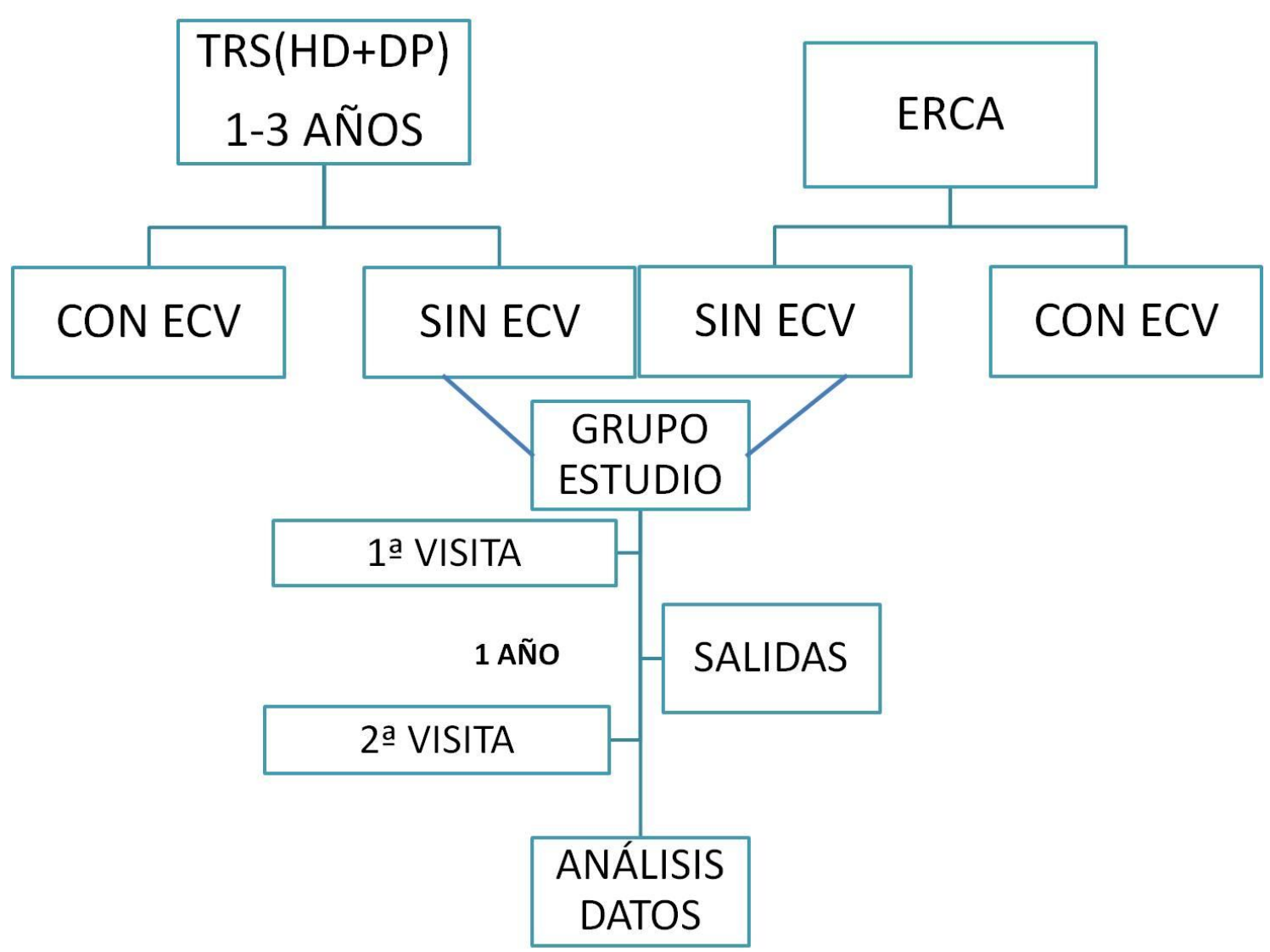

\subsubsection{Costes del estudio}

El estudio no ha llevado costes económicos adicionales, ya que se ha utilizado las analíticas de rutina y pruebas de imagen recomendadas por los protocolos del servicio de Nefrología.

La ecografía carotídea y femoral, como el ITB que no se realiza de rutina en este tipo de pacientes conllevan un mínimo coste económico.

\subsubsection{Gestión de datos}

Los datos análiticos, demográficos, antecedentes personales, medicación, ecocardiograma y radiografías, han sido recogidos desde el programa SiClinica3 del Hospital Universitario Rio Hortega. 
Los datos de las variables recogidos han sido introducidos en el programa de Microsoft Excel para su posterior análisis estadístico con el software SPSS.

\subsubsection{Consideraciones éticas}

El estudio fue aprobado por el comité ético del hospital .

La confidencialidad del programa SiClinica3 que gestiona los datos e informes de los pacientes esta en todo momento garantizada, ya que para poder entrar en el programa se tiene que disponer de un nombre de usuario y una clave de entrada.

Además el sistema informático realiza el seguimiento de los accesos a los informes: usuario, fecha, hora y operación realizada con dicho informe.

Durante el proceso de creación de base de datos, se identifica al paciente mediante sus iniciales, manteniendo así su privacidad. 


\subsection{TÉCNICAS}

\subsubsection{Fundamentos de la ecografía}

El diagnóstico mediante ultrasonidos se basa en la detección y la representación de la energía acústica reflejada a partir de las distintas interfases corporales. Las interacciones que se originan proporcionan la información que permite generar imágenes de las diferentes estructuras del cuerpo con carácter bidimensionales de alta resolución, en escala de grises, de la misma manera que proporcionan información para representar los parámetros de flujo. La dispersión de energía acústica que se origina en las interfases es el origen de la imagen convencional con ultrasonidos y del modo Doppler $^{(126)}$.

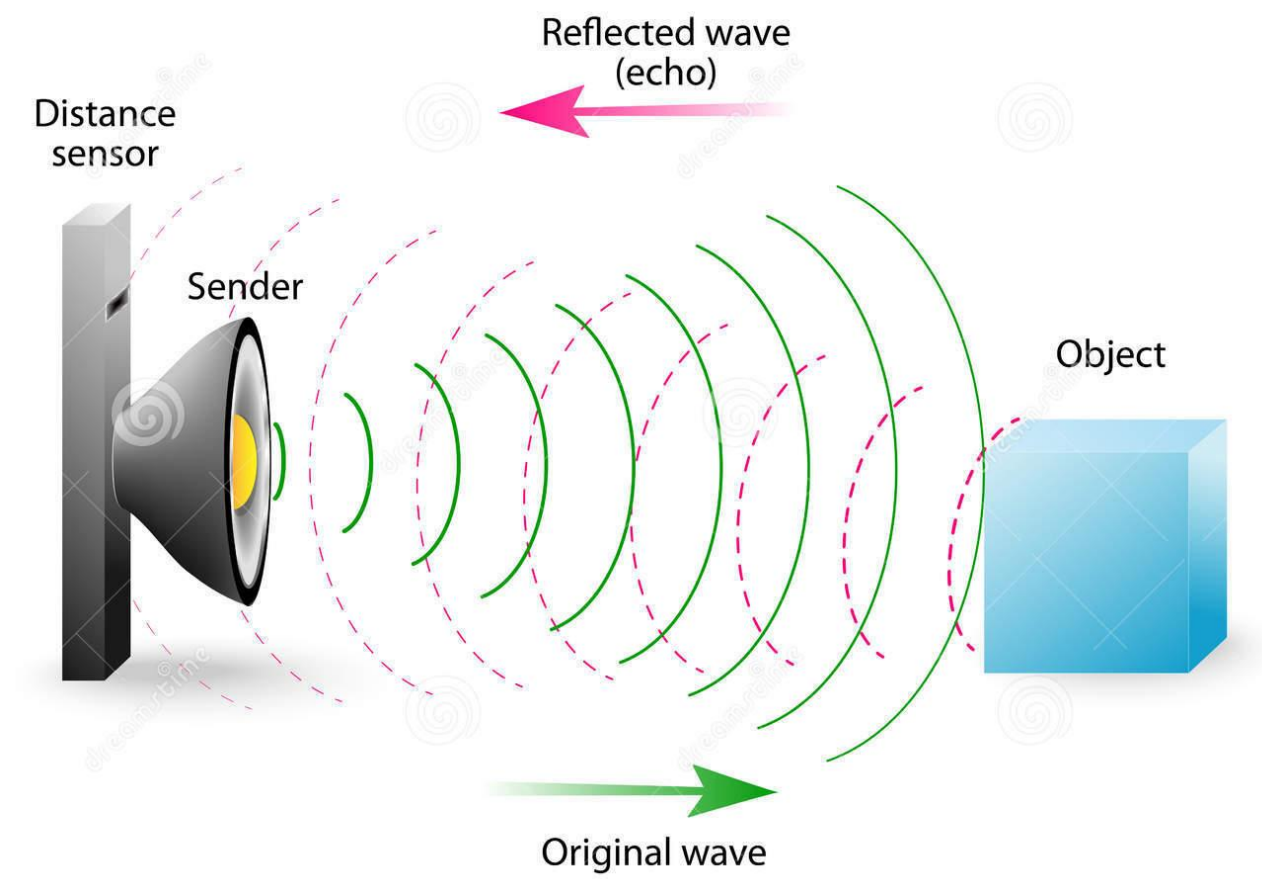

Fig. 8: Obtención ecografía a partir de la emisión de ultrasonidos. 


\subsubsection{Fundamentos del efecto Doppler}

Los objetos que se mueven hacia el transductor reflejan el sonido a una frecuencia mayor que la del pulso incipiente, y los que se alejan lo hacen a una frecuencia menor. El cambio de frecuencia Doppler consiste en la diferencia entre la frecuencia transmitida y la recibida.

El Doppler Color proporciona información en tiempo real de la morfología de los tejidos en escala de grises y del flujo sanguíneo en color, basándose en el análisis de la información de fase, de la frecuencia y la amplitud de los ecos de retorno. El color se asigna según las señales procedentes de los eritrocitos en movimiento, en base a la dirección del cambio de fase. La tonalidad del color lo determina la variación de frecuencia originada en ese punto (siendo más claro los cambios de alta frecuencia y más oscuro los de baja) ${ }^{(127)}$.

\subsubsection{Ecodoppler TSA}

La exploración es realizada por un investigador experto siguiendo las recomendaciones de exploración de ecografía carotidea del capítulo de Diagnóstico Vascular de la Sociedad de Angiología y Cirugía Vascular.

Con el paciente en decúbito supino sobre una camilla, cuello en extensión y ligeramente rotado y ambos brazos en supinación, pegados al cuerpo, para conseguir que los hombros desciendan el máximo posible; y con el explorador preferentemente colocado detrás del mismo. Utilizando un transductor de 5-7.5 MHz.

Se realiza un barrido en blanco y negro, con el transductor en sección transversal desde el origen de la CC (Carótida Común) hasta la sección más distal posible de las CE (Carótida Externa) y CI (Carótida Interna). Posteriormente se realiza un barrido en blanco y negro, con el transductor en sección longitudinal de los mismos sectores. Para la identificación correcta de CC, CE y CI puede realizarse la exploración colocando el transductor por delante o bien por detrás del músculo esternocleidomastoideo.

Observación cuidadosa de la morfología de las placas (en caso de haberlas). 
Observación de la Arteria Subclavia, colocando el transductor a nivel del espacio supraclavicular, por fuera de la inserción clavicular de músculo esternocleidomastoideo, y registro de la curva de velocidad de flujo prestando especial atención al perfil de la curva en aras a detectar una posible aceleración o amortiguación del mismo.

Identificación de la arteria Vertebral, que se realiza con más facilidad a nivel del segmento V2. Para ello, tras obtener una visión longitudinal de la Carótida Común, generalmente entre $\mathrm{C} 3$ y C6, se angula el transductor lateral y posterior, para lograr la visualización de la Arteria Vertebral. Las referencias anatómicas vienen proporcionadas por las apófisis transversas que aparecen en la imagen como líneas ecogénicas brillantes de forma rectangular, con sombra acústica posterior. Entre estas líneas de sombra acústica, aparece una banda anecoica que corresponde a la arteria vertebral. Observación de la Arteria Vertebral en origen y distalmente para descartar inversiones de flujo o aceleraciones de flujo en origen.

\section{Grosor Intima Media Carotideo}

Una vez localizada la carótida común, se realiza la visualización de la misma en un plano horizontal para realizar medidas más precisas y reproducibles. Como hay diferencias entre sístole y diástole, las imágenes se congelan al final de la diástole, cuando los cambios en el GIM son mínimos ${ }^{(128)}$.

Su cálculo se realiza localizando y midiendo el grosor de dos estructuras ecogénicas diferenciadas. Mediante ecografía en modo B y en escala de grises se aprecia una doble línea correspondiente a dos interfases ecogénicas: la más interna corresponde a la interfaz luz-íntima y la más externa a la media-adventicia. El índice se obtiene de la media entre el resultado de tres medidas en tres puntos próximos en un segmento. En nuestro caso se ha realizado las mediciones de GIM en tres sectores: un segmento de aproximadamente $10 \mathrm{~mm}$ en carótida común a $15 \mathrm{~mm}$ de la bifurcación carotidea, un segundo segmento que corresponde al bulbo carotideo y un tercer segmento en carótida interna, $15 \mathrm{~mm}$ distal al origen de la misma. En cada segmento se obtienen tres medidas y la media de ellas se toma como el valor de GIM de ese segmento. 
Se usa la pared arterial distal porque la proximal depende de la ganancia. El espesor de la capa íntima y la media no pueden medirse de forma individual porque no existe una línea clara definitoria y la íntima es demasiado estrecha. El endotelio es la parte más ancha de la íntima y mide 0.03-0.04mms. Los valores aceptados son GIM>1$1.5 \mathrm{~mm}$ patológico y GIM $<1 \mathrm{~mm}$ normal.

En la literatura se utiliza el GIM de carótida común. La arteria carótida común es ideal porque está cerca de la piel, es homogénea y generalmente no tiene placa de ateroma. El aumento del grosor se hace más evidente en la bifurcación carotídea y origen de la arteria carótida interna.

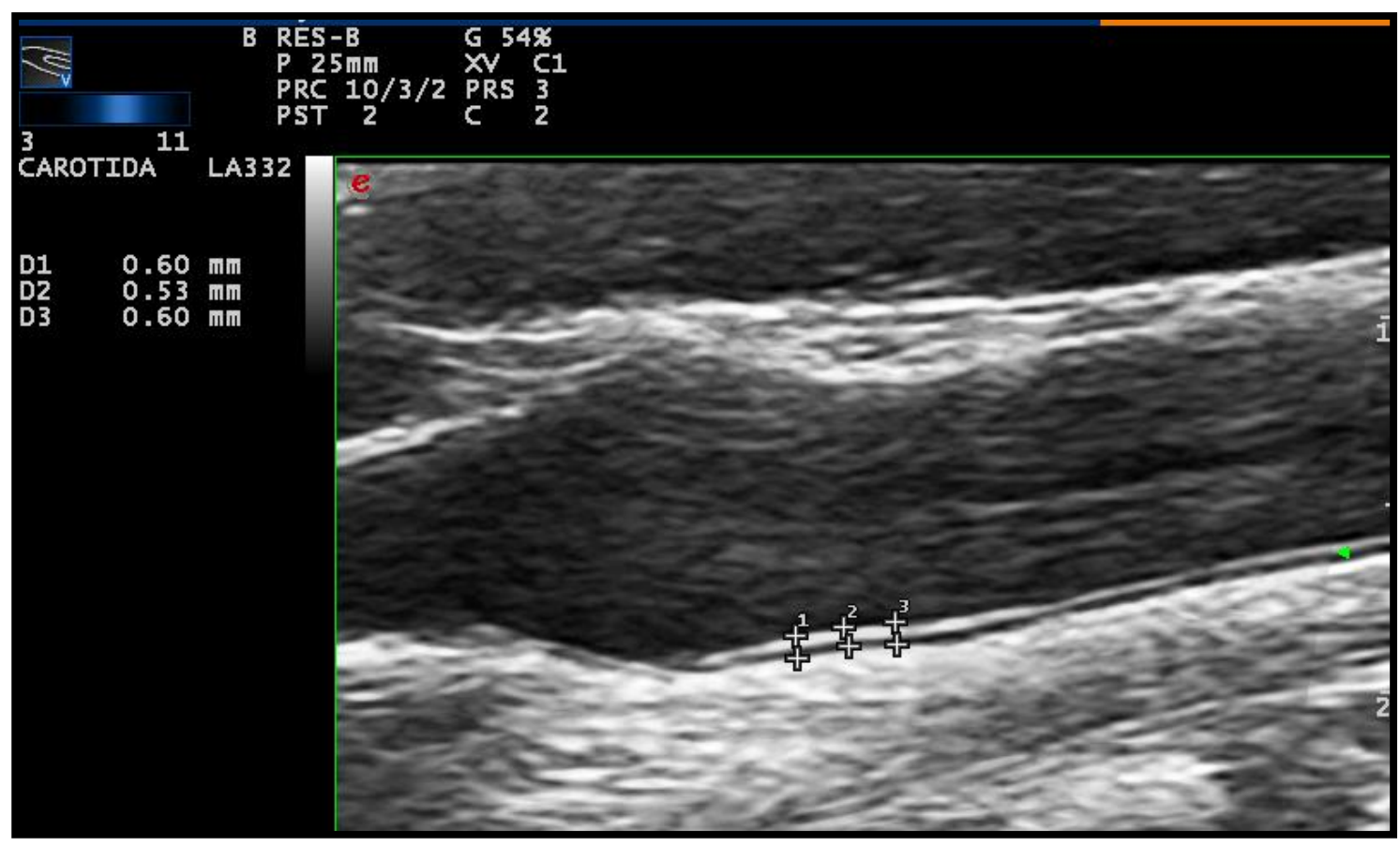

Fig.9. GIM Carótida Común

\subsubsection{Ecodoppler femoral}

Al igual que para la exploración anterior, el paciente debe colocarse en decúbito supino y suele ser suficiente con una sonda lineal de $7.5 \mathrm{MHz}$, se precisa una ligera flexión de la rodilla y rotación externa de la cadera para una mejor exposición del trípode femoral. 
Se realiza un primer barrido en blanco y negro (modo B), con el transductor en sección transversal desde el origen de la FC (Femoral Común) hasta la sección en tercio medio de FS (Femoral Superficial). Observando la bifurcación femoral y el origen de femoral profunda. Seguidamente en modo B (barrido en blanco y negro), se localiza el vaso y obtiene una visión en longitudinal del mismo.

La media de GIM femoral se ha calculado en estudios usando pacientes sanos de 20 a 60 años las cifras eran de $0.562 \pm 0.074$ para los hombres y de $0.543 \pm 0.063$ para las mujeres ${ }^{(129)}$.

En cada paciente se evaluaron el GIM y las placas de ateroma. Al igual que en la carótida, su cálculo se realiza localizando y midiendo el grosor de dos estructuras ecogénicas diferenciadas. Mediante ecografía en modo B y en escala de grises se aprecia una doble línea correspondiente a dos interfases ecogénicas: la más interna corresponde a la interfaz luz-íntima y la más externa a la media-adventicia. El índice se obtiene de la media entre el resultado de tres medidas en tres puntos próximos en un segmento. Se realizaron las mediciones en dos sectores, el segmento de $10 \mathrm{~mm}$ de femoral común, $1 \mathrm{~cm}$ proximal a la bifurcación y un $1 \mathrm{~cm}$ distal de la bifurcación en el caso de la arteria femoral superficial.

El cálculo del GIM femoral se obtiene del promedio del GIM de Femoral común de ambas extremidades inferiores y el cálculo de GIM Femoral medio, es el promedio del GIM femoral común y GIM de femoral superficial de ambas extremidades inferiores.

Las placas se definen como engrosamientos focales del GIM con una altura mayor o igual que $1.5 \mathrm{~mm}$ o superior al $50 \%$ del GIM adyacente. Para identificarlas en todo el territorio femoral accesible, se realizan secciones longitudinales y transversales en el estudio en modo B, y a continuación se efectúa la exploración con Doppler color, ajustando los parámetros técnicos (ganancia, frecuencia de repetición de pulsos e intervalo de velocidades) a las velocidades existentes en el vaso. El objetivo del estudio Doppler color es identificar con seguridad las placas anecoicas e hipoecoicas que pueden pasar inadvertidas en el estudio convencional. El análisis de las placas incluye su número y altura máxima ${ }^{(116)}$. 


\subsection{5. Índice Tobillo Brazo}

Para la determinación del ITB, el paciente se coloca en decúbito supino durante un periodo de unos 5-10 minutos. Se registra la presión sistólica en ambos brazos (se consideran patológicas diferencias de $\mathrm{P}$ entre ambos MMSS de más de $20 \mathrm{mmHg}$ ), utilizándose la más elevada de ambas. Igualmente se registra la P en ambos MMII, tanto en arteria pedia como tibial posterior, seleccionado la más alta de ambas en cada extremidad. En caso de no registrarse flujo en ninguna de las arterias del pie, puede localizarse la rama lateral de la arteria peronea, en la cara antero-externa del tobillo, por delante del maleolo lateral. Se utiliza un manguito de presión del tamaño adecuado, que se coloca justo por encima de los maleolos y una sonda de 5-10 mHz.

El ITB es más efectivo para el diagnóstico y valoración de la isquemia de MMII que la determinación de $\mathrm{P}$ absolutas. La presión del manguito se eleva unos $20 \mathrm{mmHg}$ por encima de la presión de interrupción del flujo arterial, descendiéndose después lentamente hasta la reaparición del flujo (Psist). El ITB es el cociente entre la Psist máxima en el tobillo y la Psist en brazo y en condiciones normales es ligeramente superior a 1 .

En nuestro estudio se ha estratificado el resultado del ITB en dos categorias, la primera, valor de la prueba patológico si se obtienen valores $<0.9$ o $>1.3$; si los valores se encuentran en el intervalo de 0.9-1.3 el resultado se califica como normal. No obstante también se ha realizado una división en los resultados patológicos, ya que los valores $<0.9$ indican existencia de estenosis y valores $>1.3$ son el resultado del fenómeno de calcificación de Monckeberg (calcificación de la capa media).

\begin{tabular}{|cc|}
\hline ITB & Resultados \\
\hline$<0,9$ & Disminuido \\
$0,9-1,3$ & Normalidad \\
$>1,3$ & Calcinosis \\
\hline
\end{tabular}

Tabla V: Significado valores ITB. 


\subsubsection{Ecocardiograma ETT}

En este trabajo se ha realizado un estudio ecocardiográfico estándar, llevado a cabo por un mismo cardiólogo. Se han usado 4 ventanas ecocardiográficas: paraesternal, apical, subcostal y supraesternal. En el plano paraesternal se han usado dos ejes: el eje largo y el eje corto. En estos planos se ha estudiado: válvula aórtica, aurícula izquierda, válvula mitral, ventrículo izquierdo, ventrículo derecho y aorta ascendente. Se han medido los diámetros ventriculares y los espesores del ventrículo con el modo M. De esas medidas se han inferido los volúmenes de las cuatro cámaras cardiacas y, de ellos, la fracción de eyección. En los diferentes planos apicales se han estudiado las cavidades derechas e izquierdas, el tabique interventricular e interauricular y las válvulas mitral, aórtica y tricúspide. En el plano subcostal se han estudiado tanto las cavidades derechas, como las izquierdas y se ha valorado la vena cava inferior, así como el tabique interauricular y la posibilidad de la existencia de derrame pericárdico ${ }^{(130)}$. Se ha valorado también la presencia o no de hipertrofia del ventrículo izquierdo.

En la práctica clínica rutinaria la estimación de la hipertrofia se realiza mediante la cuantificación de los espesores ventriculares del septo y de la pared posterior. Se admite que existe hipertrofia si el grosor de las paredes es igual o superior a los $12 \mathrm{~mm}$.

Cuando se ha valorado la fracción de eyección se ha clasificado como patológica cuando FEVI $<45 \%$ y cuando FEVI $>45 \%$ se calificaba como normal.

\subsubsection{El índice de Kauppila}

El método descrito por Kauppila ${ }^{(131)}$ es un método que ha demostrado tener una alta predición en la morbimortalidad cardiovascular en la población general y en la población en diálisis ${ }^{(132-133)}$.

Se mide sobre una radiografía lateral de abdomen que debe incluir las dos últimas vértebras torácicas y las dos primeras sacras, separar cada vértebra midiendo calcificación en pared anterior y posterior de aorta lumbar en cada segmento. La arteria aorta debe ser identificada como una estructura tubular por delante de la cara anterior de 
la columna. Sólo se considera el segmento de la aorta desde la primera a la cuarta vértebra lumbar.

La puntuación va de 1 a 3 por calcificación (de leve a severa) según la gravedad de la calcificación en la cara anterior y posterior de cada vértebra (4 segmentos anteriores: máximo 12 puntos; 4 segmentos posteriores: máximo 12 puntos). La puntuación va de 0 a 24 . Se ha demostrado una buena correlación entre las calcificaciones vasculares diagnosticadas por Kauppila y las calcificaciones coronarias diagnosticadas por $\mathrm{EBCT}^{(134)}$.

En el estudio se ha considerado que una puntuación de 5 o mayor es el corte para tener un buen valor predictivo siguiendo el ejemplo del estudio de Vannini et al ${ }^{(135)}$.

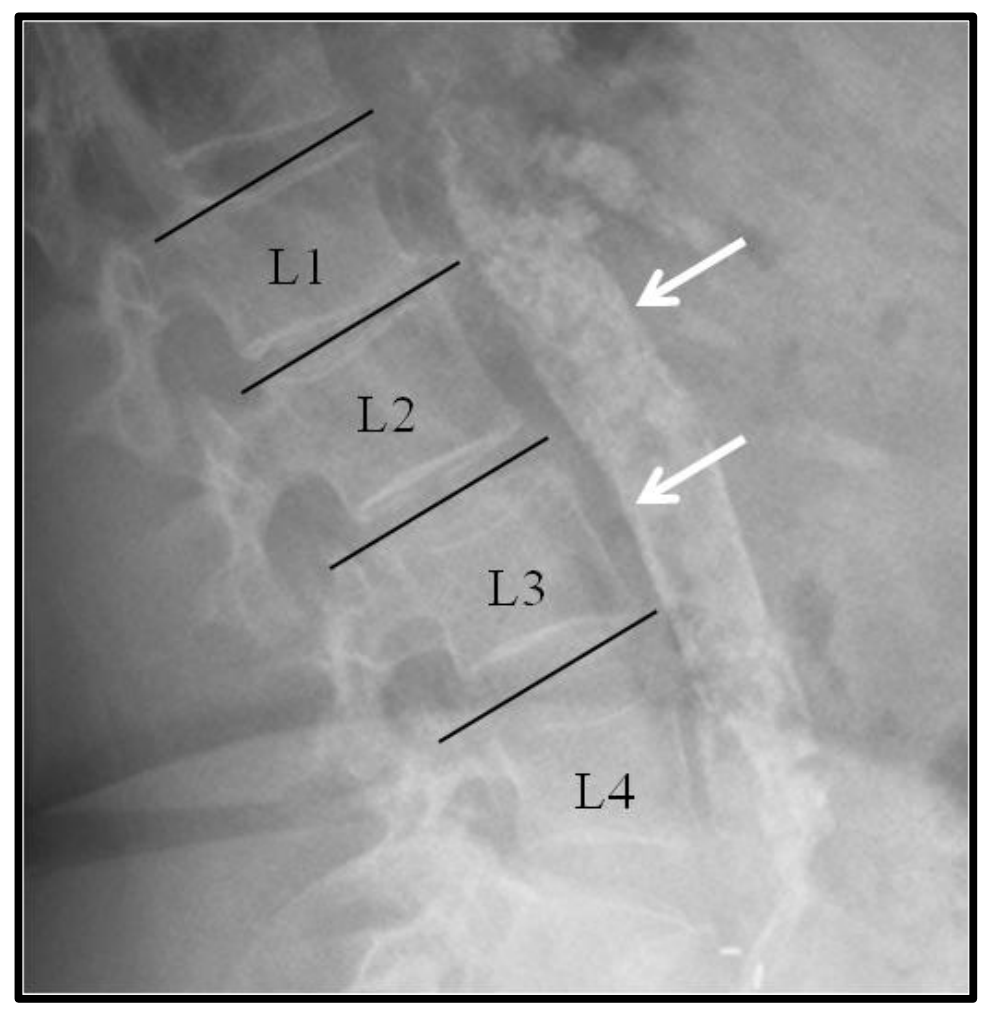

Fig.10: Test de Kauppila. 
Índice de Kauppila (0-24 Puntos)

$\begin{array}{ll}\text { Calcificaciones lineales en cada } & \text { Leve }=1 \\ \text { sección } & \text { Moderada }=2 \\ & \text { Severa }=3 \\ \text { Segmentos de Aorta valorados } & \text { Vértebras Lumbares de L1 a L4 } \\ & \text { Cara anterior y posterior } \\ \text { Ejemplo Figura } & \text { Kauppilla=3(L1ant)+3(L1post)+3(L2ant)+3(L2post) } \\ & +3(\text { L3ant)+3(L3post)+3(L4ant)+3(L4post) } \\ & \text { Total }=24\end{array}$

Tabla VI: Explicación cálculo Kauppila.

\subsection{8. Índice Adragao}

El índice de Adragao es una escala de valoración de calcificación muy sencilla que se basa en la radiografía simple de manos y pelvis. Es un buen test predictor de mortalidad cardiovascular asociada a alto riesgo de EC, enfermedad arterial periférica y hospitalizaciones por problemas cardiovasculares ${ }^{(136)}$.

La radiografía simple de pelvis se divide en 4 cuadrantes y se observa recorrido arteria femoral e ilíaca para ver si hay (1) o no hay (0) calcificación vascular. El mismo proceso se realiza en la radiografía simple de manos para observar calcificaciones en el recorrido de las arterias periféricas en mano y muñeca (Fig.11).

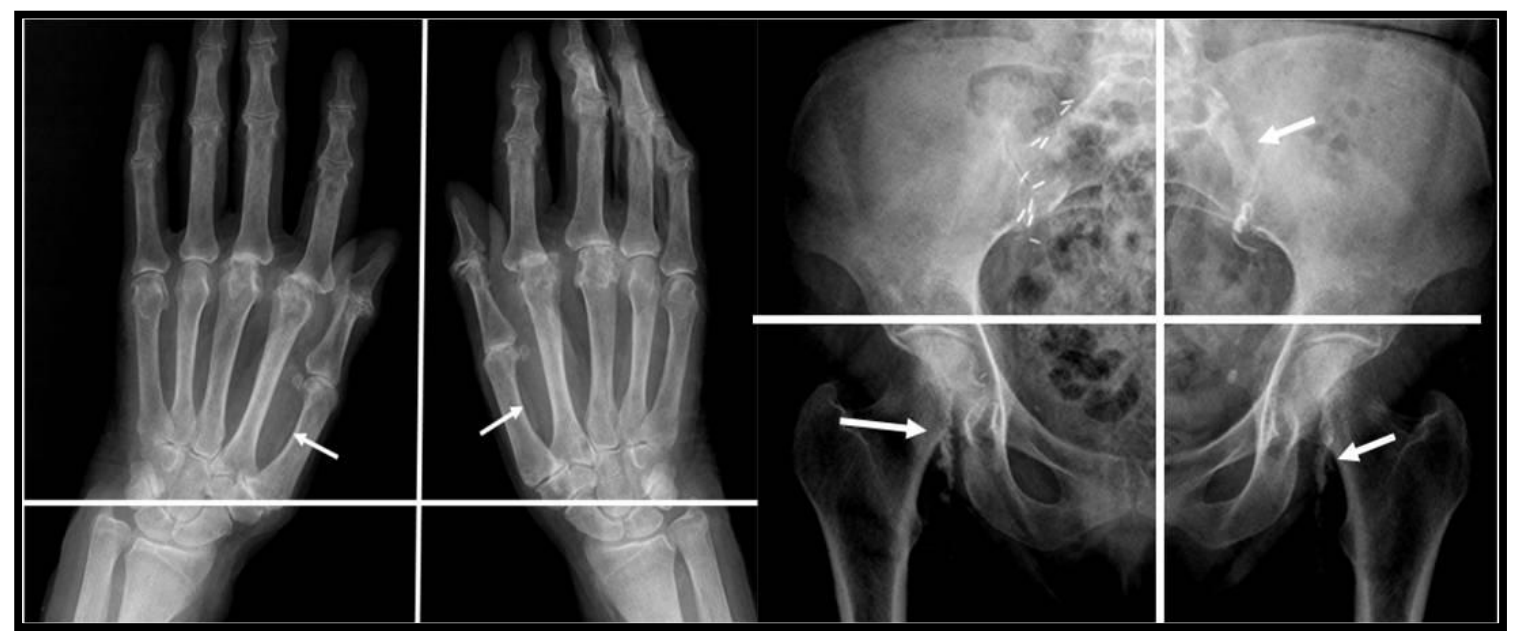

Fig.11: Test de Adragao. 


\section{Índice de Adragao (0-8 Puntos)}

$\begin{array}{ll}\text { Calcificaciones lineales en cada sección } & \text { Presencia }=1 \\ & \text { Ausencia }=0 \\ \text { 0Ejemplo } & \text { Puntuación de manos }=1+1+0+0 \\ & \text { Puntuación pelvis }=0+1+1+1 \\ & \text { Puntuación total }=5\end{array}$

Tabla VII. Ejemplo de cálculo de índice de Adragao.

\subsubsection{Analítica}

En el grupo de HD las muestras analíticas se obtuvieron antes de iniciar la segunda sesión semanal (todos los pacientes tienen un régimen de diálisis de tres días, bien lunes-miércoles-viernes o martes-jueves-sábado), en los pacientes de DP y grupo control se obtuvieron las muestras el día que acudían a la consulta.

En todos los casos los pacientes estaban en ayunas.

Se han realizado determinaciones analíticas correspondientes a los parámetros que a continuación se detallan:

Recuento hematológico completo de sangre periférica.

Parámetros del metabolismo fosfo-cálcico (Ca, P, VitD, PTH),

Perfil lipídico (colesterol total, HDL, LDL, Triglicéridos).

El filtrado glomerular fue estimado por los niveles de creatinina usando la ecuación CKD-EPI ajustada por sexo.

Los valores del rango de normalidad correspondientes a los parámetros analizados del Hospital Universitario Rio Hortega de Valladolid son los que se detallan, en el anexo. 


\subsubsection{Ecógrafo}

Para las exploraciones se ha usado el ecógrafo doppler color Esaote modelo Mylab25Gold, es un equipo de gama alta dedicado al estudio por ultrasonidos. Posee multiprocesador y multitarea por lo que permite la obtención de imágenes de gran resolución, así como métodos de optimización de imágenes Xview (elimina motas y ruidos no deseados) y Mview (para la sonda lineal). Posee pulso independiente para imagen B y Doppler. Matriz de alta densidad y rendimiento, mayor ancho de banda que permiten imágenes estándares y armónicas. Elevada sensibilidad para una detección doppler precisa, reflejada en señales CFM, Power y PW(imagen volumétrica)/CW (imagen lineal).

Dispone a su vez de Optimizador digital de flujo, sistema de almacenamiento digital en CD-ROM , DVD y USB, unidad integrada de gestión de datos y pacientes, capacidad para oblicuar la imagen, en sondas vasculares, de $40^{\circ}$, monitor LCD de alto rendimiento de 15", módulo de formación de imágenes por composición espacial y en frecuencias, permitiendo una mejor definición, modo trapezoidal para sondas lineales y sectoriales, existe la posibilidad de imagen volumétrica 3D y 4D. Es un equipo multifrecuencia, es decir, dispone de varias frecuencias para cada transductor.

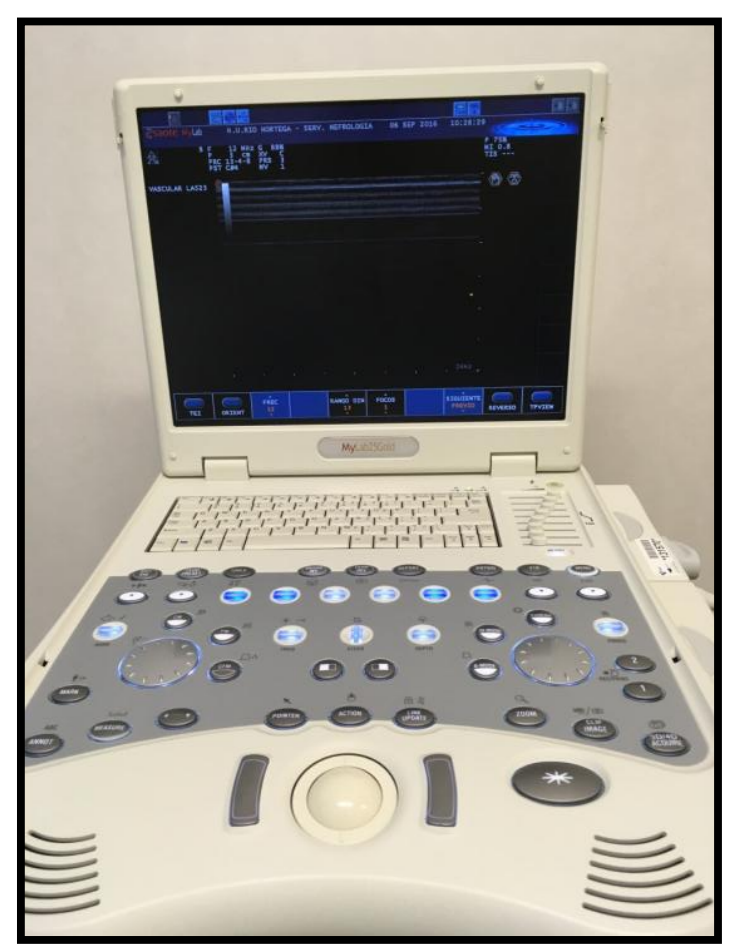

Fig.12: Ecógrafo Esaote Mylab 25 Gold. 


\subsection{DEFINICIONES}

Placa: Cuando el GIM $\geq 15 \mathrm{~mm}$.

GIM Carotideo: es el promedio de GIM medido en carótida común derecha y GIM obtenido en Carótida común izquierda.

$$
\text { GIM Carotideo }=\frac{\text { GIM CCD }+ \text { GIM CCI }}{2}
$$

GIM Carotideo Medio: es el promedio del GIM de todos los segmentos (CC, Bulbo, CI) de carótida derecha e izquierda.

$$
G I M \text { Carotideo }=\frac{G I M C C D+G I M B D+G I M C I D+G I M C C I+G I M B I+G I M C I I}{6}
$$

GIM Femoral: es el promedio de GIM medido en femoral común derecha y GIM obtenido en femoral común izquierda.

$$
G I M \text { Femoral }=\frac{G I M F C D+G I M F C I}{2}
$$

GIM Femoral Medio: es el promedio del GIM medido en femoral común y superficial derecha y GIM obtenido en femoral común y superficial izquierda.

$$
G I M \text { Femoral Total }=\frac{G I M F C D+G I M F S D+G I M F C I+G I M F S I}{4}
$$

GIM Total: es el promedio del GIM Carotideo (GIM de CC) y GIM Femoral (GIM de FC).

$$
\text { GIM total }=\frac{G I M C+G I M F}{2}
$$

Clasificación de ITB: ITB patológico aquel que sus valores que son $<0.9$ o $>1.3$;

ITB normal a valores situados entre 0.9 y 1.3 . 
Ecocardiograma: FEVI< 45\% Patológico.

FEVI $>45 \%$ Normal.

$\underline{\text { HVI }}$ : grosor Septo Inter Ventricular (SIV) $\geq 12 \mathrm{~mm}$.

Adragao: $\quad$ Normal $<4$

Patológico $\geq 4$.

Kauppila ; Normal $<5$.

Patológico $\geq 5$.

Clasificación niveles de VitD:

Deficiencia de VitD a valores $<15 \mathrm{mcg} / \mathrm{L}$.

Insuficiencia de VitD a valores entre $15-30 \mathrm{mcg} / \mathrm{L}$.

Valores normales de VitD a valores entre 30-80 mcg/L.

HipervitD a valores $>80 \mathrm{mcg} / \mathrm{L}$. 


\subsection{ANÁLISIS ESTADÍSTICO}

Los datos fueron expresados como medias +/- desviación estándar. Una probabilidad del menos del $5 \% \quad(\mathrm{p}<0.005)$ fue considerada estadísticamente significativa. Se empleó en el estudio estadístico el paquete estadístico SPSS 20.0 (SPSS, Chicago, IL, USA).

\section{Las diferentes variables se analizaron siguiendo las correspondientes distribuciones estadísticas:}

Las variables categóricas se analizaron mediante una distribución de ChiCuadrado $\left(X^{2}\right)$ o Test exacto de Fisher.

Las variables cuantitativas se analizaron mediante un Test ANOVA unilateral o Kruskal-Wallis.

\section{Análisis de la varianza de un factor:}

Para estudiar si las diferencias encontradas en las medias de los distintos grupos eran estadísticamente significativas. El procedimiento ANOVA de un factor genera un análisis de varianza para una variable dependiente cuantitativa (variables estudiadas) por una variable de un solo factor (grupos control, hemodiálisis y diálisis peritoneal). El estadístico F del ANOVA de un factor se basa en el cumplimiento de dos supuestos fundamentales: normalidad y homocedasticidad.

La normalidad significa que la variable dependiente se distribuye normalmente en las poblaciones muestrales (tantas como grupo definidos por la variable independiente o factor). No obstante, si los tamaños de los grupos son grandes (como en este estudio), se comporta razonablemente bien incluso con distribuciones poblacionales sensiblemente alejadas de la normalidad. Por otro lado, la prueba de Levene estudia la igualdad de la varianza.

Evalúa diferencias entre las medias de los grupos, además, para realizar múltiples comparaciones entre los grupos específicos de tratamiento (hemodiálisis y diálisis peritoneal) se realizará un test post-hoc de Tukey. En este método todas las 
comparaciones son referidas a una misma diferencia mínima. En el caso de estudiar las diferencias de los grupo de tratamiento frente al grupo control (hemodiálisis vs controles, diálisis peritoneal vs controles), se realiza el ajuste de Dunnet.

En casos en que no exista homogeneidad de la varianza, se realizará una prueba no paramétrica de Kruskal-Wallis y las múltiples comparaciones entre cada uno de los grupos se estudiarán mediante un test de U de Mann-Whitney.

\section{Cálculo del tamaño muestral}

Según el estudio de Arroyo et $\mathrm{al}^{(137)}$, sabemos que el valor medio del GIMC en España en pacientes en estadio $5 \mathrm{D}$ es $0.689 \pm 0.154 .{ }^{16} \mathrm{Si}$ se acepta un riesgo de 0,05 y se desea una potencia estadística del $90 \%$ para detectar diferencias, y dado que la varianza es el cuadrado de la desviación estándar, se precisan 22 sujetos en cada grupo para detectar una diferencia igual o superior a $0.1378 \mathrm{~mm}$ (un $20 \%$ de la media), cantidad que consideramos clínicamente relevante. Se ha estimado una tasa de pérdidas de seguimiento de 0.1 .

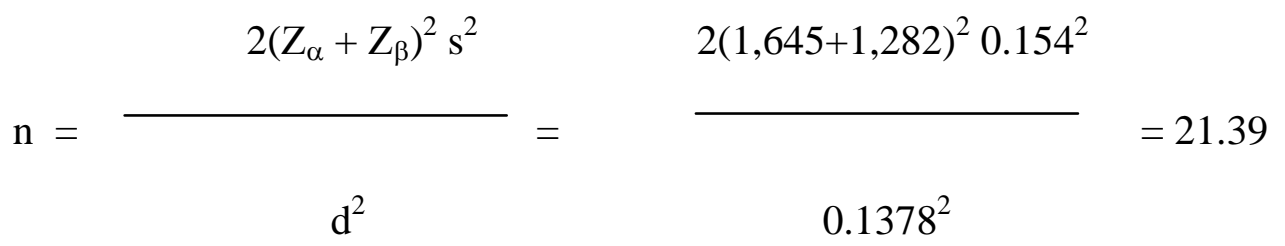

No obstante, al llegar a 12 pacientes en cada brazo del estudio se realizó un estudio piloto para conocer la verdadera desviación estándar en nuestra población y evitar posibles sesgos. De tal forma la desviación estándar en ese momento fue de 0.1266, lo que modificó la fórmula del tamaño muestral a 25.36 pacientes, obligando por ello a incrementar el número de pacientes requeridos en cada grupo a 26. 
5. RESULTADOS 



\section{Características basales}

\begin{tabular}{|lccccc|}
\hline & $\begin{array}{c}\text { Total } \\
(\mathbf{n = 1 4 2})\end{array}$ & $\begin{array}{c}\text { Controles } \\
(\mathbf{n = 6 6})\end{array}$ & $\begin{array}{c}\text { Hemodiálisis } \\
(\mathbf{n = 5 0})\end{array}$ & $\begin{array}{c}\text { Diálisis } \\
\text { peritoneal } \\
(\mathbf{n = 2 6})\end{array}$ & $\boldsymbol{p}$ \\
\hline Edad & $66,86(29-88)$ & $70.79(33-88)$ & $66.80(39-87)$ & $57.00(29-79)$ & 0.000 \\
Sexo (varón) & $78(54.9 \%)$ & $34(51.5 \%)$ & $32(64.0 \%)$ & $12(46.2 \%)$ & 0.249 \\
Tx & $6(4.2 \%)$ & $2(3.0 \%)$ & $4(8.0 \%)$ & $0(0.0 \%)$ & 0.208 \\
HTA & $134(94.4 \%)$ & $64(97.0 \%)$ & $46(92.0 \%)$ & $24(92.3 \%)$ & 0.455 \\
DM & $48(33.8 \%)$ & $32(48.5 \%)$ & $12(24.0 \%)$ & $4(15.4 \%)$ & 0.002 \\
Dislipemia & $78(54.9 \%)$ & $48(72.7 \%)$ & $16(32.0 \%)$ & $14(53.8 \%)$ & 0.000 \\
Tabaco & $16(13.8 \%)$ & $8(12.1 \%)$ & $4(8.0 \%)$ & $4(15.4 \%)$ & 0.251 \\
FA & $14(9.9 \%)$ & $4(6.1 \%)$ & $10(20.0 \%)$ & $0(0.0 \%)$ & 0.008 \\
& & & & & \\
\hline
\end{tabular}

Tabla VIII: Características demográficas antecedentes personales.

Los pacientes del grupo control presentaron una edad mayor que los pacientes incluidos en el grupo de hemodiálisis $(70.79 \pm 13.70$ vs $66.80 \pm 13.94, p=0.242)$ y significativamente mayor que los pacientes en diálisis peritoneal $(70.79+13.70$ vs 57.00 $\pm 15.61, p=0.000$ ). Los pacientes en diálisis peritoneal son significativamente más jóvenes que los pacientes en hemodiálisis $(57.00 \pm 15.61$ vs $66.80 \pm 13.94, p=0.013)$.

También existe una mayor presencia de diabetes mellitus y de dislipemia en los pacientes del grupo control que en los pacientes en hemodiálisis o diálisis peritoneal $(p=0.002$ у $p=0.000$, respectivamente).

Un $20.0 \%$ de los pacientes en hemodiálisis padecen fibrilación auricular, un $6.1 \%$ de los pacientes del grupo control y ninguno de los pacientes en diálisis peritoneal $(p=0.008)$. 


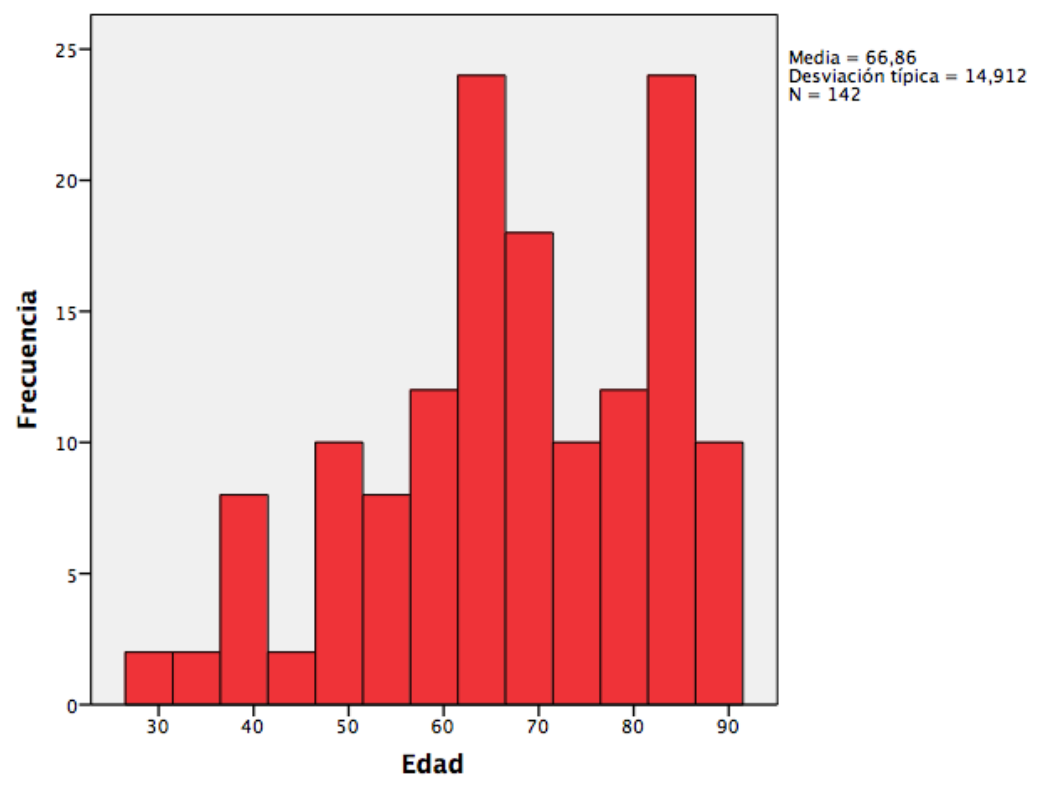

Fig.13: Histograma de la edad de los pacientes de la muestra.

\section{Medicación concomitante}

\begin{tabular}{|c|c|c|c|c|c|}
\hline & $\begin{array}{c}\text { Total } \\
(n=142)\end{array}$ & $\begin{array}{c}\text { Controles } \\
(n=66)\end{array}$ & $\begin{array}{l}\text { Hemodiálisis } \\
\quad(n=50)\end{array}$ & $\begin{array}{c}\text { Diálisis } \\
\text { peritoneal } \\
(n=26)\end{array}$ & $p$ \\
\hline AntiHTA & $128(90.1 \%)$ & $62(93.9 \%)$ & $46(92.0 \%)$ & $20(76.9 \%)$ & 0.061 \\
\hline Estatinas & $64(45.1 \%)$ & $40(60.6 \%)$ & $12(24.0 \%)$ & $12(46.2 \%)$ & 0.000 \\
\hline Quelantes calcio & $64(45.1 \%)$ & $34(51.5 \%)$ & $18(36.0 \%)$ & $12(46.2 \%)$ & 0.249 \\
\hline $\begin{array}{l}\text { Quelantes no } \\
\text { calcio }\end{array}$ & $100(70.4 \%)$ & $36(54.5 \%)$ & $44(88.0 \%)$ & $20(76.9 \%)$ & 0.000 \\
\hline Vitamina D & $20(14.1 \%)$ & $20(30.3 \%)$ & $0(0.0 \%)$ & $0(0.0 \%)$ & 0.000 \\
\hline Cinacalcet & $42(29.6 \%)$ & $10(15.2 \%)$ & $26(52.0 \%)$ & $6(23.1 \%)$ & 0.000 \\
\hline Paricalcitol & $74(52.1 \%)$ & $12(18.2 \%)$ & $38(76.0 \%)$ & $24(92.3 \%)$ & 0.000 \\
\hline Antiagregantes & $28(19.7 \%)$ & $8(12.1 \%)$ & $16(32.0 \%)$ & $4(15.4 \%)$ & 0.024 \\
\hline Anticoagulantes & $12(8.5 \%)$ & $4(6.1 \%)$ & $8(16.0 \%)$ & $0(0.0 \%)$ & 0.037 \\
\hline Hipouricemiantes & $48(33.8 \%)$ & $36(54.5 \%)$ & $6(12.0 \%)$ & $6(23.1 \%)$ & 0.000 \\
\hline ADO/Insulina & $30(21.1 \%)$ & $4(6.1 \%)$ & $8(16.0 \%)$ & $4(15.4 \%)$ & 0.083 \\
\hline
\end{tabular}

Tabla IX: Medicación concomitante.

Los pacientes del grupo control, al presentar una mayor prevalencia de dislipemia, están sujetos a un tratamiento con estatinas significativamente mayor que el resto de grupo $(p=0.000)$. Un $30.3 \%$ de ellos presentan tratamiento con Vitamina D y ninguno en los grupos en diálisis. 
Los pacientes en diálisis presentan una mayor incidencia de medicación con quelantes del calcio, pericalcitol que los pacientes del grupo control ( $p=0.000, p=0.000$ y $p=0.000$, respectivamente). No existen diferencias en el uso de ADO/insulina entre los tres grupos.

Los pacientes en hemodiálisis precisan un mayor tratamiento con antiagregantes $\mathrm{y}$ anticoagulantes que el resto de pacientes de otros grupos $(p=0.024$ y $p=0.037$, respectivamente).

\section{Enfermedad Renal de Base}

La etiología más habitual de la enfermedad renal avanzada es la no filiada (21.1\%), seguida de la nefroangioesclerosis $(19.7 \%)$ y la nefropatía diabética $(8.5 \%)$.

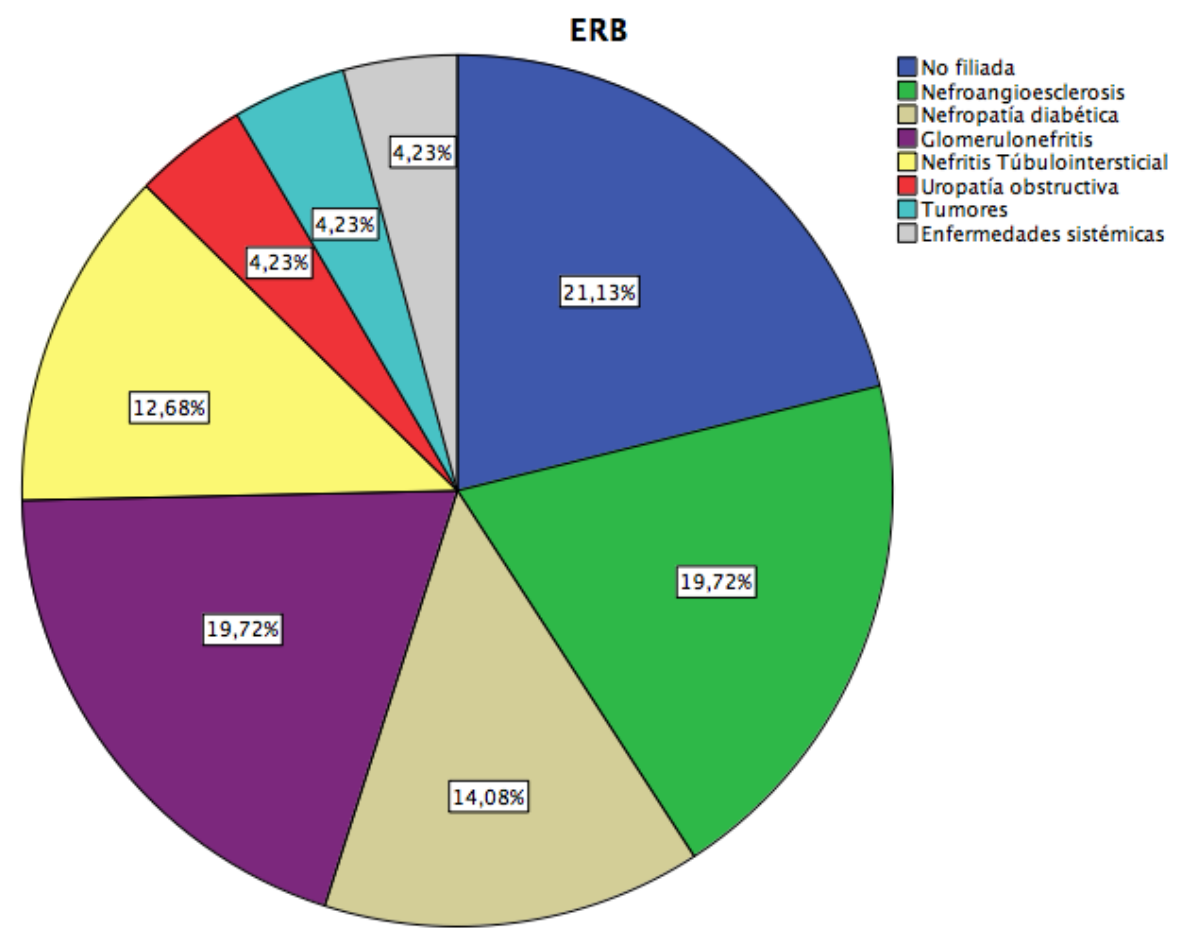

Fig.14: Gráfico de la etiología de la insuficiencia renal avanzada. 


\section{Calcificación}

\begin{tabular}{|c|c|c|c|c|c|c|c|}
\hline & $\begin{array}{c}\text { Total } \\
(n=142)\end{array}$ & $\begin{array}{c}\text { Controles } \\
(n=66)\end{array}$ & $\begin{array}{c}\text { Hemodiálisis } \\
\qquad(\mathbf{n}=50)\end{array}$ & $\begin{array}{c}\text { Diálisis } \\
\text { peritoneal } \\
(\mathbf{n}=26)\end{array}$ & $\begin{array}{c}\text { Levene } \\
p\end{array}$ & $\begin{array}{c}A N O V A \\
P\end{array}$ & $\begin{array}{c}\text { Kruskall- } \\
\text { Wallis } \\
p\end{array}$ \\
\hline Adagrao & $2.07 \pm 2.11$ & $2.10 \pm 2.04$ & $2.56 \pm 2.10$ & $1.08 \pm 2.02$ & 0.412 & & 0.007 \\
\hline Adagrao $>3$ & $39(27,4 \%)$ & $15(22,7 \%)$ & $20(40 \%)$ & $4(15,3 \%)$ & 0.000 & 0.002 & \\
\hline $\begin{array}{l}\text { Adagrao } \\
\text { pelvis }\end{array}$ & $1.10 \pm 1.37$ & $1.23 \pm 1.42$ & $1.24 \pm 1.29$ & $0.54 \pm 1.30$ & 0.116 & & 0.018 \\
\hline $\begin{array}{l}\text { Adagrao } \\
\text { manos }\end{array}$ & $0.99 \pm 1.17$ & $0.87 \pm 1.02$ & $1.36 \pm 1.37$ & $0.54 \pm 0.86$ & 0.002 & 0.007 & \\
\hline $\begin{array}{l}\text { Puntuación } \\
\text { Kauppila }\end{array}$ & $4.99 \pm 5.88$ & $4.44 \pm 5.26$ & $7.40 \pm 6.86$ & $1.69 \pm 2.60$ & 0.000 & 0.000 & \\
\hline Kaupilla $\geq 5$ & $58(41 \%)$ & $27(41 \%)$ & $24(48 \%)$ & $7(28 \%)$ & 0.000 & 0.051 & \\
\hline
\end{tabular}

Tabla X: Parámetros de calcificación.

\begin{tabular}{|lcccc|}
\hline & $\begin{array}{c}\text { Controles } \\
\boldsymbol{v} \\
\text { Hemodiálisis } \\
\boldsymbol{P}\end{array}$ & $\begin{array}{c}\text { Controles } \\
\boldsymbol{v s} \\
\text { Peritoneal } \\
\boldsymbol{p}\end{array}$ & $\begin{array}{c}\text { Hemodiálisis } \\
\boldsymbol{v s} \\
\text { Peritoneal } \\
\boldsymbol{p}\end{array}$ & $\boldsymbol{P}$ \\
\hline Adagrao & 0.404 & 0.068 & 0.009 & 0.007 \\
Adagrao > a 3 & 0.045 & 0.129 & 0.001 & 0.002 \\
Adagrao pelvis & 0.998 & 0.059 & 0.084 & 0.018 \\
Adagrao manos & 0.047 & 0.362 & 0.009 & 0.007 \\
Puntuación Kauppila & 0.011 & 0.067 & 0.000 & 0.000 \\
Kaupilla $\geq \mathbf{5}$ & 0.698 & 0.105 & 0.042 & 0.051 \\
& & & & \\
\hline
\end{tabular}

Tabla XI: Valores de significación estadística de la comparación de los grupos respecto a los parámetros de calcificación.

La puntuación de Adagrao es significativamente mayor en el grupo de hemodiálisis que en el grupo de diálisis peritoneal $(p=0.009)$, de tal forma la presencia de Adagrao> a 3 para los pacientes en el grupo de hemodiálisis es mayor que la del grupo control $(p=0.045)$ o la del grupo de diálisis peritoneal $(p=0.001)$.

La puntuación de Adagrao en pelvis no presenta diferencias entre los diferentes grupos, pero en cambio a nivel de las manos, el grupo de hemodiálisis presenta una mayor puntuación que el grupo control y que el grupo en diálisis peritoneal $(p=0.047 \mathrm{y}$ $p=0.009$, respectivamente).

Respecto a la puntuación de Kauppila, los pacientes en hemodiálisis presentan una mayor puntación que los pacientes del grupo control o de diálisis peritoneal 
( $p=0.011$ y $p=0.000$, respectivamente $)$, pero dichas variaciones sólo se manifiestan en diferencias en un Kauppila $\geq$ a 5 para los grupos en hemodiálisis y en diálisis peritoneal $(p=0.042)$.

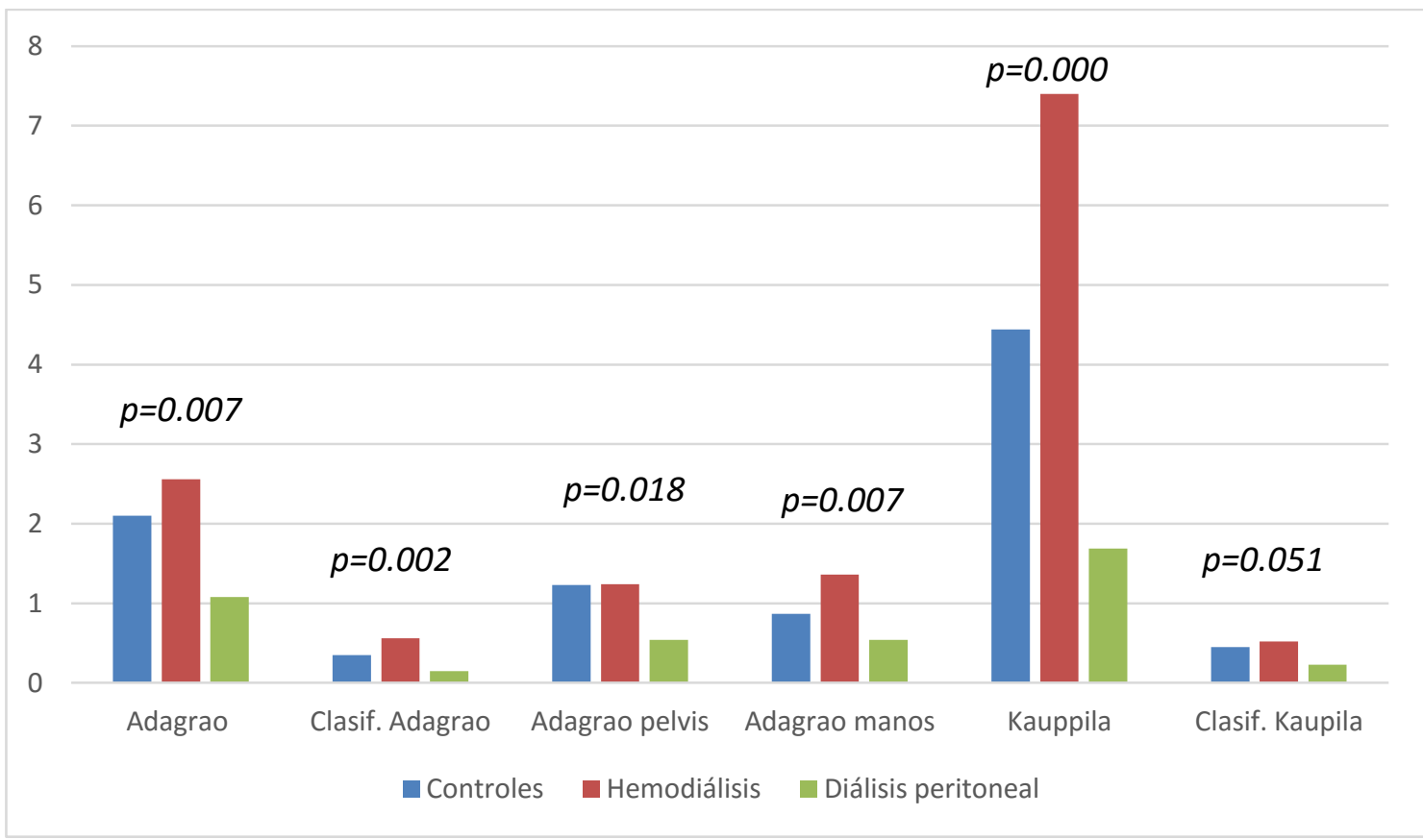

Fig.15: Representación gráfica de la calcificación en los diferentes grupos estudiados.

\begin{tabular}{|lccccccc|}
\hline & $\begin{array}{c}\text { Total } \\
(\mathbf{n = 1 4 2})\end{array}$ & $\begin{array}{c}\text { Controles } \\
(\mathbf{n = 6 6})\end{array}$ & $\begin{array}{c}\text { Hemodiálisis } \\
(\mathbf{n = 5 0})\end{array}$ & $\begin{array}{c}\text { Diálisis } \\
\text { peritoneal } \\
(\mathbf{n = 2 6})\end{array}$ & $\begin{array}{c}\text { Levene } \\
\boldsymbol{p}\end{array}$ & $\begin{array}{c}\text { ANOVA } \\
\boldsymbol{P}\end{array}$ & $\begin{array}{c}\text { Kruskall- } \\
\text { Wallis } \\
\boldsymbol{p}\end{array}$ \\
\hline $\begin{array}{l}\text { Adagrao } \\
\text { Adagrao }>\mathbf{3}\end{array}$ & $2.11 \pm 2.26$ & $2.07 \pm 2.12$ & $2.65 \pm 2.13$ & $1.12 \pm 2.09$ & 0.572 & & 0.011 \\
$\begin{array}{l}\text { Adagrao } \\
\text { pelvis }\end{array}$ & $1.23 \pm 1.42$ & $1.35 \pm 1.64$ & $1.36 \pm 1.35$ & $0.51 \pm 1.45$ & 0.217 & & 0.025 \\
$\begin{array}{l}\text { Adagrao } \\
\text { manos }\end{array}$ & $1.07 \pm 1.11$ & $0.93 \pm 1.04$ & $1.04 \pm 1.63$ & $0.53 \pm 0.68$ & 0.000 & 0.013 & \\
$\begin{array}{l}\text { Puntuación } \\
\text { Kauppila } \\
\text { Kaupilla } \geq 5\end{array}$ & $4.63 \pm 5.67$ & $4.57 \pm 5.37$ & $7.68 \pm 6.56$ & $1.86 \pm 2.53$ & 0.000 & 0.000 & \\
& $61(42,9 \%)$ & $28(42,4 \%)$ & $25(50 \%)$ & $8(22,2 \%)$ & 0.000 & 0.065 & \\
\hline
\end{tabular}

Tabla XII: Parámetros de calcificación tras 1 año de seguimiento. 


\begin{tabular}{|c|c|c|c|c|}
\hline & $\begin{array}{c}\text { Controles } \\
v s \\
\text { Hemodiálisis } \\
p \\
\end{array}$ & $\begin{array}{c}\text { Controles } \\
v s \\
\text { Peritoneal } \\
p \\
\end{array}$ & $\begin{array}{c}\text { Hemodiálisis } \\
v s \\
\text { Peritoneal } \\
p \\
\end{array}$ & $P$ \\
\hline Puntuación Adagrao & 0.645 & 0.102 & 0.028 & 0.011 \\
\hline Adagrao $>3$ & 0.037 & 0.254 & 0.003 & 0.002 \\
\hline Adagrao pelvis & 0.763 & 0.098 & 0.094 & 0.025 \\
\hline Adagrao manos & 0.058 & 0.482 & 0.018 & 0.013 \\
\hline Puntuación Kauppila & 0.34 & 0.186 & 0.002 & 0.000 \\
\hline Kaupilla $\geq 5$ & 0.835 & 0.178 & 0.085 & 0.065 \\
\hline
\end{tabular}

Tabla XIII: Valores de significación estadística de la comparación de los grupos respecto a los parámetros de calcificación tras 1 año de seguimiento.

Dichas diferencias se mantienen tras un año de seguimiento, con escasas variaciones en los valores de las medidas realizadas.

\section{Función cardiaca}

\begin{tabular}{|lccccc|}
\hline & $\begin{array}{c}\text { Total } \\
(\mathbf{n = 1 4 2})\end{array}$ & $\begin{array}{c}\text { Controles } \\
(\mathbf{n = 6 6})\end{array}$ & $\begin{array}{c}\text { Hemodiálisis } \\
(\mathbf{n = 5 0})\end{array}$ & $\begin{array}{c}\text { Diálisis } \\
\text { peritoneal } \\
(\mathbf{n = 2 6})\end{array}$ & $\boldsymbol{p}$ \\
\hline & & & & & \\
Hipertrofia ventrículo izquierdo & $98(69.0 \%)$ & $48(72.7 \%)$ & $38(76.0 \%)$ & $12(46.2 \%)$ & 0.019 \\
$\begin{array}{l}\text { Fracción eyección ventrículo } \\
\text { izquierdo }\end{array}$ & $66.42 \pm 7.30$ & $67.45 \pm 7.13$ & $65.48 \pm 8.00$ & $65.62 \pm 6.11$ & 0.293 \\
\end{tabular}

Tabla XIV: Parámetros de función cardiaca.

\begin{tabular}{|c|c|c|c|c|}
\hline & $\begin{array}{c}\text { Controles } \\
v s \\
\text { Hemodiálisis } \\
p\end{array}$ & $\begin{array}{c}\text { Controles } \\
v s \\
\text { Peritoneal } \\
p\end{array}$ & $\begin{array}{c}\text { Hemodiálisis } \\
\text { vs } \\
\text { Peritoneal } \\
p\end{array}$ & $\begin{array}{c}A N O V A \\
p\end{array}$ \\
\hline $\begin{array}{l}\text { Fracción eyección ventrículo } \\
\text { izquierdo }\end{array}$ & 0.268 & 0.463 & 0.997 & 0.293 \\
\hline
\end{tabular}

Tabla XV: Valores de significación estadística de la comparación de los grupos respecto a los parámetros de función cardiaca.

Los pacientes estudiados presentan una elevada prevalencia de hipertrofia de ventrículo izquierdo (72.7\% el grupo control y 76.0\% los pacientes en hemodiálisis), excepto los pacientes sometidos a diálisis peritoneal $(46.2 \%, p=0.019)$. Sin embargo no 
existieron diferencias respecto a la fracción de eyección del ventrículo izquierdo entre los pacientes de los grupos estudiados, estando la media en los grupos estudiados entre el 65 y el $70 \%$.

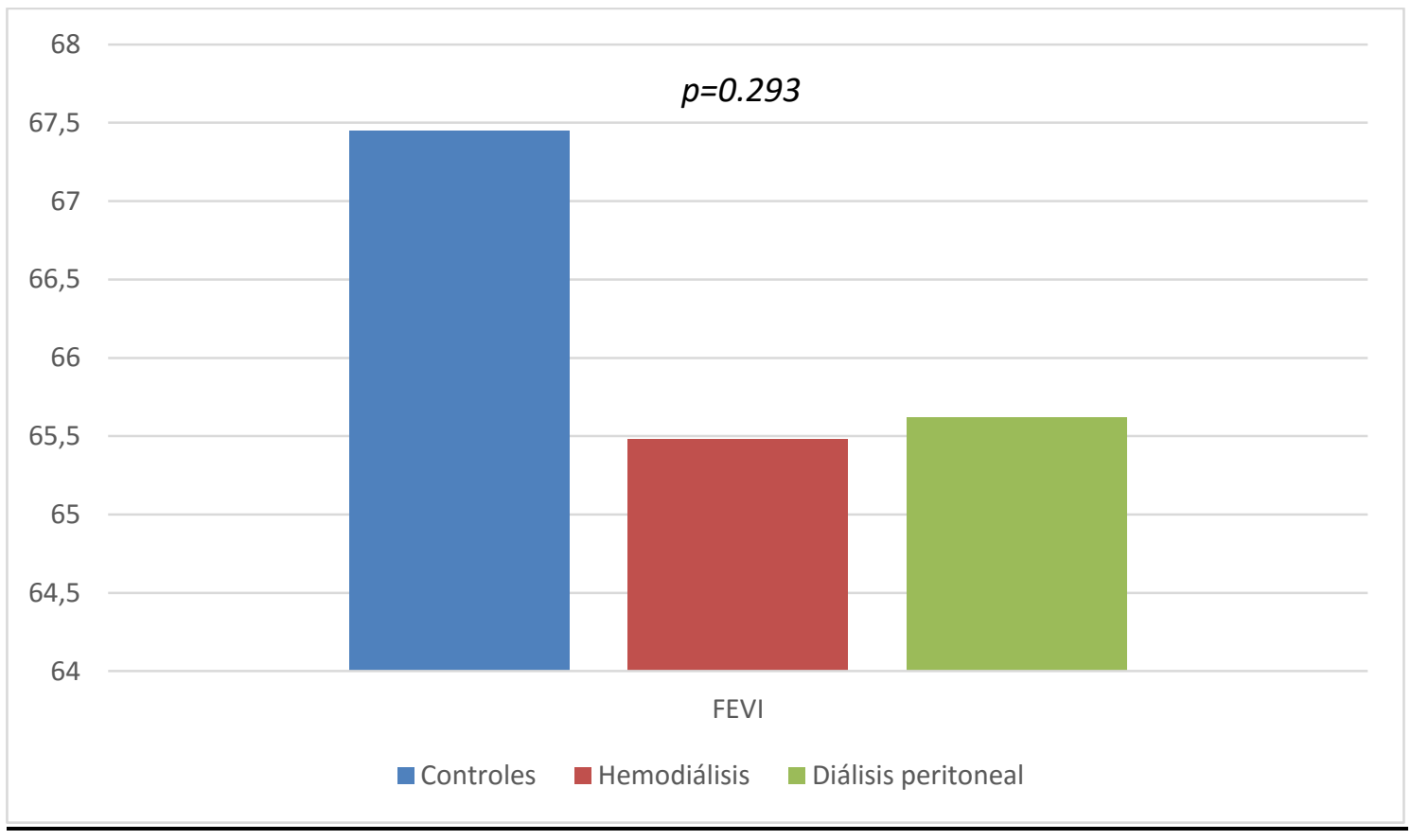

Fig.16: Representación gráfica de la función del ventrículo izquierdo en los diferentes grupos estudiados.

\section{$\underline{\text { Diuresis residual }}$}

\begin{tabular}{|lcccccc|}
\hline & $\begin{array}{c}\text { Total } \\
(\mathbf{n = 1 4 2})\end{array}$ & $\begin{array}{c}\text { Controles } \\
(\mathbf{n = 6 6})\end{array}$ & $\begin{array}{c}\text { Hemodiálisis } \\
(\mathbf{n = 5 0})\end{array}$ & $\begin{array}{c}\text { Diálisis } \\
\text { peritoneal } \\
(\mathbf{n = 2 6})\end{array}$ & $\begin{array}{c}\text { Levene } \\
\boldsymbol{p}\end{array}$ & $\begin{array}{c}\text { Kurskal- } \\
\text { Wallis } \\
\boldsymbol{p}\end{array}$ \\
\hline $\begin{array}{l}\text { Diuresis } \\
\text { residual }\end{array}$ & $1451.61 \pm 952.13$ & $2072.41 \pm 754.47$ & $699.00 \pm 742.12$ & $1224.62 \pm 670.26$ & 0.794 & 0.000 \\
\hline
\end{tabular}

Tabla XVI: Diuresis residual. 


\begin{tabular}{|c|c|c|c|c|}
\hline & $\begin{array}{c}\text { Controles } \\
v s \\
\text { Hemodiálisis } \\
p \\
\end{array}$ & $\begin{array}{c}\text { Controles } \\
v s \\
\text { Peritoneal } \\
p\end{array}$ & $\begin{array}{c}\text { Hemodiálisis } \\
\text { vs } \\
\text { Peritoneal } \\
p\end{array}$ & $p$ \\
\hline Diuresis residual & 0.000 & 0.000 & 0.014 & 0.000 \\
\hline
\end{tabular}

Tabla XVII: Valores de significación estadística de la comparación de los grupos respecto a la diuresis residual.

Los pacientes en el grupo control (2072 \pm 754.47$)$ presentan una mayor diuresis residual que los pacientes en hemodiálisis $(699.00 \pm 742.12)$ o en diálisis peritoneal (1224.62 \pm 670.26$)$ de manera estadísticamente significativa ( $p=0.000$ y $p=0.000$, respectivamente). A su vez, los pacientes en hemodiálisis presentan una diuresis significativamente menor que los pacientes en diálisis peritoneal $(p=0.014)$.

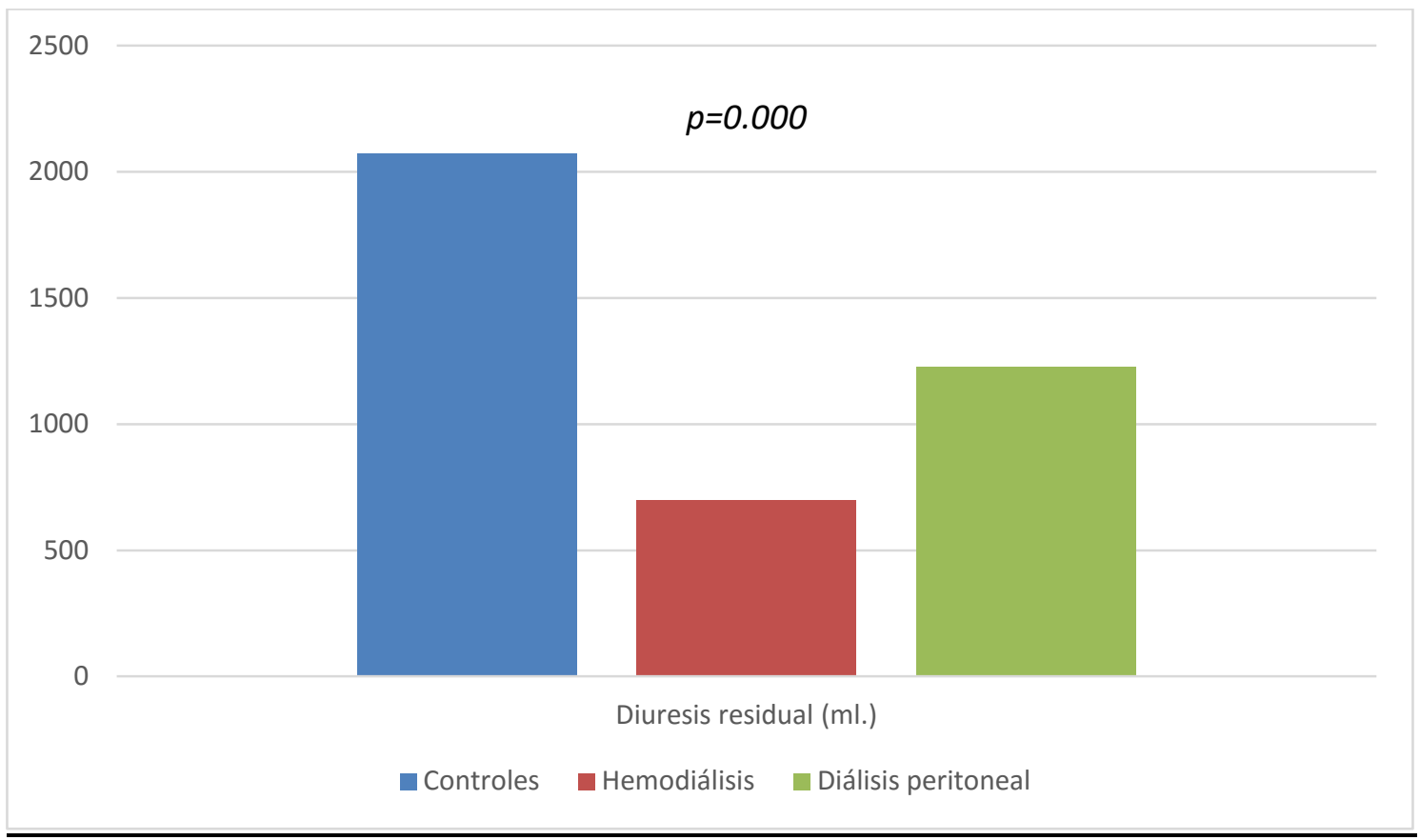

Fig.17: Representación gráfica de la diuresis residual en los diferentes grupos estudiados. 


\section{Índice tobillo-brazo}

\begin{tabular}{|c|c|c|c|c|c|c|c|}
\hline & $\begin{array}{c}\text { Total } \\
(n=142)\end{array}$ & $\begin{array}{c}\text { Controles } \\
(n=66)\end{array}$ & $\begin{array}{l}\text { Hemodiálisis } \\
\quad(n=50)\end{array}$ & $\begin{array}{c}\text { Diálisis } \\
\text { peritoneal } \\
(\mathbf{n}=26)\end{array}$ & $p$ & $\begin{array}{c}\text { Levene } \\
p\end{array}$ & $\begin{array}{c}A N O V A \\
p\end{array}$ \\
\hline $\begin{array}{l}\text { ITB basal } \\
\text { ITB } \\
\text { Patológico } \\
\text { ITB } 1 \text { año } \\
\text { ITB 1año } \\
\text { Patológico }\end{array}$ & $\begin{array}{c}1.189 \pm 0.492 \\
30(21.7 \%)\end{array}$ & $\begin{array}{c}1.038+0.310 \\
16(26.7 \%) \\
1.046+0.368 \\
12(19.4 \%)\end{array}$ & $\begin{array}{c}1.201 \pm 0.403 \\
22(44.0 \%) \\
1.420 \pm 0.544 \\
16(32.0 \%)\end{array}$ & $\begin{array}{c}1.037 \pm 0.184 \\
25.0 \% \\
1.108 \pm 0.515 \\
2(7.7 \%)\end{array}$ & 0.042 & 0.011 & 0.000 \\
\hline
\end{tabular}

Tabla XVIII: Índice tobillo-brazo.

\begin{tabular}{|lcccc|}
\hline & $\begin{array}{c}\text { Controles } \\
\text { vs } \\
\text { Hemodiálisis } \\
\boldsymbol{p}\end{array}$ & $\begin{array}{c}\text { Controles } \\
\text { vs } \\
\text { Peritoneal } \\
\boldsymbol{p}\end{array}$ & $\begin{array}{c}\text { Hemodiálisis } \\
\text { vs } \\
\text { Peritoneal } \\
\boldsymbol{p}\end{array}$ & $\boldsymbol{p}$ \\
\hline ITB basal & & & & 0.102 \\
ITB patológico & 0.000 & 0.801 & 0.116 & 0.000 \\
ITB 1 año & 0.102 & 0.985 & 0.017 & 0.022 \\
ITB patológico 1 año & 0.019 & 1.000 & 0.039 & 0.042 \\
\hline
\end{tabular}

Tabla XIX: Valores de significación estadística de la comparación de los grupos respecto al índice tobillo-brazo.

Los pacientes en hemodiálisis presentaban un mayor ITB en el momento basal (1.201 \pm 0.403$)$ que los pacientes del grupo control $(1.038 \pm 0.310)$, de manera estadísticamente significativa $(p=0.000)$. Dicha diferencia significativa se mantiene con el grupo control tras el año de seguimiento y aparece diferencia entre los pacientes de hemodiálisis $(1.420 \pm 0.544)$ y diálisis peritoneal $(1.108 \pm 0.310)(p=0.017)$.

Dichas diferencias no se objetivan en la clasificación ITB patológico, excepto en las diferencias en cuanto a los grupos de hemodiálisis y diálisis peritoneal al año de seguimiento $(0.320 \pm 0.471$ vs $0.080 \pm 0.272, p=0.039)$. 


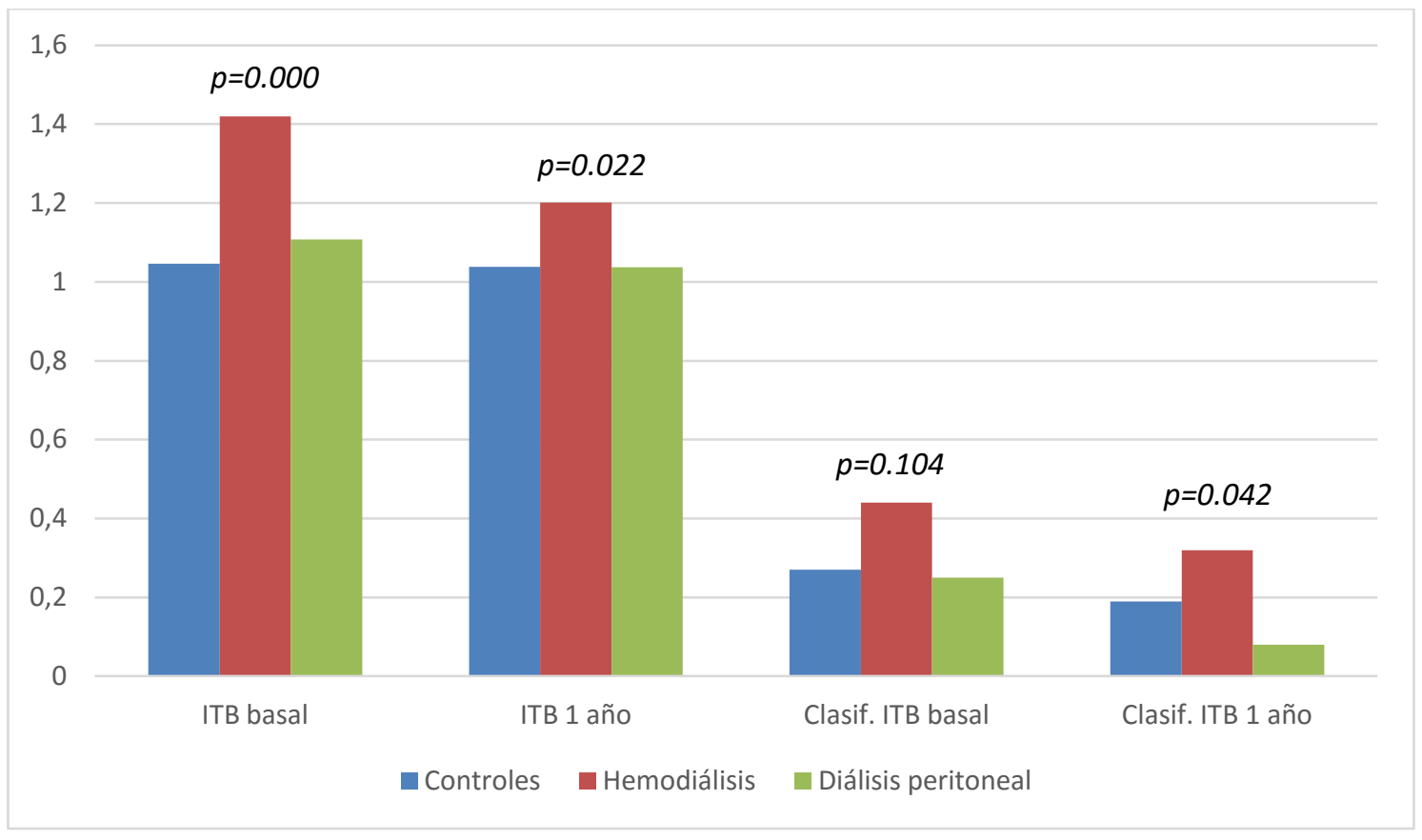

Fig.18: Representación gráfica del índice tobillo-brazo en los diferentes grupos estudiados.

\section{$\underline{\text { Mediciones ecográficas }}$}

En el momento basal existen diferencias en los grosores de la pared del BCD, CID, BCI, CII, siendo mayor en los paciente en hemodiálisis que en los pacientes en diálisis peritoneal $(p=0.042, p=0.027, p=0.004 y p=0.034$, respectivamente). Dichos parámetros de los pacientes en hemodiálisis también son superiores de manera estadísticamente significativa en comparación con los pacientes del grupo control para los grosores del BCI y de la CII ( $p=0.011$ y $p=0.023$, respectivamente). 


\begin{tabular}{|c|c|c|c|c|c|c|c|}
\hline & $\begin{array}{c}\text { Total } \\
(n=142)\end{array}$ & $\begin{array}{c}\text { Controles } \\
(n=66)\end{array}$ & $\underset{(\mathbf{n}=50)}{\text { Hemodiálisis }}$ & $\begin{array}{c}\text { Diálisis } \\
\text { peritoneal } \\
(n=26)\end{array}$ & $\begin{array}{c}\text { Levene } \\
p\end{array}$ & $\begin{array}{c}A N O V A \\
p\end{array}$ & $\begin{array}{c}\text { Kruskal- } \\
\text { Wallis } \\
p\end{array}$ \\
\hline CCD & $0.089 \pm 0.089$ & $0.078 \pm 0.027$ & $0.108 \pm 0.145$ & $0.081 \pm 0.026$ & 0.011 & 0.164 & \\
\hline BCD & $0.142 \pm 0.074$ & $0.120 \pm 0.083$ & $0.147 \pm 0.071$ & $0.109 \pm 0.039$ & 0.065 & & 0.042 \\
\hline CID & $0.087 \pm 0.050$ & $0.082 \pm 0.025$ & $0.100 \pm 0.073$ & $0.070 \pm 0.039$ & 0.000 & 0.027 & \\
\hline CCI & $0.098 \pm 0.059$ & $0.098 \pm 0.055$ & $0.102 \pm 0.064$ & $0.092 \pm 0.062$ & 0.412 & & 0.117 \\
\hline BCI & $0.184 \pm 0.183$ & $0.158 \pm 0.083$ & $0.251 \pm 0.080$ & $0.123 \pm 0.058$ & 0.000 & 0.004 & \\
\hline CII & $0.089 \pm 0.055$ & $0.079 \pm 0.041$ & $0.105 \pm 0.071$ & $0.082 \pm 0.044$ & 0.000 & 0.034 & \\
\hline FCD & $0.118 \pm 0.091$ & $0.127 \pm 0.063$ & $0.106 \pm 0.071$ & $0.089 \pm 0.052$ & 0.001 & 0.176 & \\
\hline FSD & $0.113 \pm 0.121$ & $0.169 \pm 0.073$ & $0.106 \pm 0.071$ & $0.109 \pm 0.138$ & 0.101 & & 0.127 \\
\hline FCI & $0.154 \pm 0.103$ & $0.162 \pm 0.073$ & $0.162 \pm 0.111$ & $0.129 \pm 0.086$ & 0.008 & 0.574 & \\
\hline FSI & $0.099 \pm 0.052$ & $0.100 \pm 0.056$ & $0.098 \pm 0.055$ & $0.099 \pm 0.037$ & 0.261 & & 0.432 \\
\hline GIMC & $0.093 \pm 0.074$ & $0.088 \pm 0.034$ & $0.105 \pm 0.076$ & $0.081 . \pm 0.044$ & 0.000 & 0.004 & \\
\hline GIMC medio & $0.114 \pm 0.085$ & $0.102 . \pm 0.052$ & $0.135 \pm 0.084$ & $0.093 \pm 0.045$ & 0.000 & 0.018 & \\
\hline GIMF & $0.136 \pm 0.097$ & $0.144 \pm 0.068$ & $0.134 \pm 0.091$ & $0.109 \pm 0.069$ & 0.648 & & 0.357 \\
\hline GIMF medio & $0.121 \pm 0.092$ & $0.139 \pm 0.066$ & $0.118 \pm 0.077$ & $0.106 \pm 0.078$ & 0.382 & & \\
\hline GIM Total & $0.114 \pm 0.085$ & $0.116 \pm 0.051$ & $0.119 \pm 0.083$ & $0.09 \pm 0.056$ & 0.000 & 0.005 & \\
\hline
\end{tabular}

Tabla XX: Mediciones ecográficas basales. CCD: carótida común derecha; BCD: bulbo carotídeo derecho; CID: carótida interna derecha; CCI: carótida común izquierda; BCI: bulbo carotídeo izquierdo; CII: carótida interna izquierda; FCD: femoral común derecha; FSD: femoral superficial derecha; FCI: femoral común izquierda; FSI: femoral superficial izquierda. GIMC: grosor íntima-media carotídeo; GIMF: grosor íntima-media femoral.

Dichos valores también hacen que GIMC $(0.170 \pm 0.181$ vs $0.110 \pm 0.040 \mathrm{y}$ $0.093 \pm 0.028, p=0.004)$, GIMC medio $(0.182 \pm 1.021$ vs $0.121+0.037$ y $0.098 \pm 0.032$, $\mathrm{p}=0.018$ ) del grupo en hemodiálisis sea superior de manera que los valores de los pacientes del grupo control y del grupo en diálisis peritoneal. 


\begin{tabular}{|lcccc|}
\hline & $\begin{array}{c}\text { Controles } \\
\boldsymbol{v} \boldsymbol{s} \\
\text { Hemodiálisis } \\
\boldsymbol{p}\end{array}$ & $\begin{array}{c}\text { Controles } \\
\boldsymbol{v s} \\
\text { Peritoneal } \\
\boldsymbol{p}\end{array}$ & $\begin{array}{c}\text { Hemodiálisis } \\
\boldsymbol{v} \boldsymbol{s} \\
\text { Peritoneal } \\
\boldsymbol{P}\end{array}$ & $\boldsymbol{p}$ \\
\hline CCD & & & & \\
BCD & 0.127 & 0.987 & 0.403 & 0.164 \\
CID & 0.972 & 0.032 & 0.041 & 0.042 \\
CCI & 0.098 & 0.460 & 0.030 & 0.027 \\
BCI & 0.900 & 0.907 & 0.781 & 0.117 \\
CII & 0.011 & 0.623 & 0.009 & 0.004 \\
FCD & 0.023 & 0.964 & 0.091 & 0.034 \\
FSD & 0.880 & 0.220 & 0.164 & 0.176 \\
FCI & 0.552 & 0.312 & 0.842 & 0.127 \\
FSI & 0.936 & 0.632 & 0.551 & 0.574 \\
GMIC & 0.951 & 0.995 & 0.991 & 0.432 \\
GMIC medio & 0.009 & 0.748 & 0.013 & 0.004 \\
GIMF & 0.014 & 0.342 & 0.016 & 0.018 \\
GIMF medio & 0.675 & 0.838 & 0.938 & 0.357 \\
Promedio GIMC/GIMF & 0.283 & 0.145 & 0.283 & 0.382 \\
& 0.066 & 0.634 & 0.053 & 0.075 \\
\hline
\end{tabular}

Tabla XXI: Valores de significación estadística de la comparación de los grupos respecto a las mediciones ecográficas basales. CCD: carótida común derecha; $\mathrm{BCD}$ : bulbo carotídeo derecho; CID: carótida interna derecha; CCI: carótida común izquierda; BCI: bulbo carotídeo izquierdo; CII: carótida interna izquierda; FCD: femoral común derecha; FSD: femoral superficial derecha; FCI: femoral común izquierda; FSI: femoral superficial izquierda. GIMC: grosor íntima-media carotídeo; GIMF: grosor íntima-media femoral.

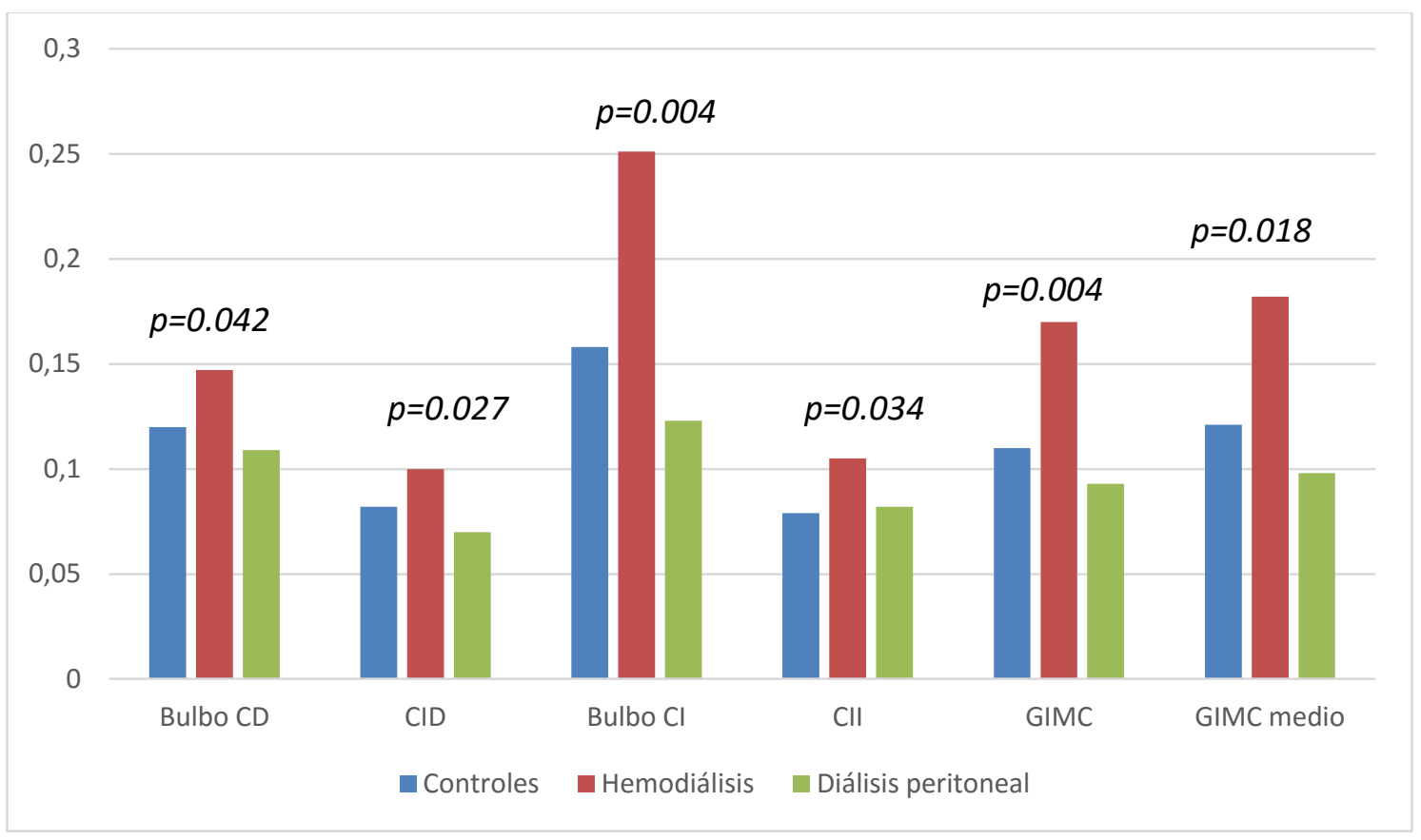

Fig.19: Representación gráfica de los valores ecográficos en el momento basal. 


\begin{tabular}{|c|c|c|c|c|c|c|c|}
\hline & $\begin{array}{c}\text { Total } \\
(n=142)\end{array}$ & $\begin{array}{c}\text { Controles } \\
(n=66)\end{array}$ & $\begin{array}{c}\text { Hemodiálisis } \\
\qquad(\mathrm{n}=50)\end{array}$ & $\begin{array}{c}\text { Diálisis } \\
\text { peritoneal } \\
(\mathbf{n}=26)\end{array}$ & $\begin{array}{c}\text { Levene } \\
\quad p\end{array}$ & $\begin{array}{c}A N O V A \\
p\end{array}$ & $\begin{array}{l}\text { Kruskal- } \\
\text { Wallis p }\end{array}$ \\
\hline CCD & $0.092 \pm 0.042$ & $0.097 \pm 0.039$ & $0.109 \pm 0.048$ & $0.073 \pm 0.030$ & 0.374 & & 0.012 \\
\hline BCD & $0.153 \pm 0.069$ & $0.157 \pm 0.055$ & $0.198 \pm 0.074$ & $0.151 \pm 0.089$ & 0.087 & & 0.047 \\
\hline CID & $0.096 \pm 0.124$ & $0.106 \pm 0.174$ & $0.120 \pm 0.049$ & $0.084 \pm 0.062$ & 0.216 & & 0.037 \\
\hline CCI & $0.101 \pm 0.059$ & $0.098 \pm 0.034$ & $0.104 \pm 0.072$ & $0.097 \pm 0.076$ & 0.023 & 0.590 & \\
\hline BCI & $0.179 \pm 0.129$ & $0.203 \pm 0.161$ & $0.285 \pm 0.098$ & $0.145 \pm 0.068$ & 0.058 & & 0.043 \\
\hline CII & $0.090 \pm 0.071$ & $0.079 \pm 0.025$ & $0.131 \pm 0.107$ & $0.096 \pm 0.060$ & 0.015 & 0.024 & \\
\hline FCD & $0.142 \pm 0.103$ & $0.154 \pm 0.052$ & $0.118 \pm 0.064$ & $0.096 \pm 0.053$ & 0.014 & 0.695 & \\
\hline FSD & $0.188 \pm 0.057$ & $0.176 \pm 0.070$ & $0.207 \pm 0.111$ & $0.170 \pm 0.093$ & 0.001 & 0.223 & \\
\hline FCI & $0.176 \pm 0.092$ & $0.174 \pm 0.081$ & $0.188 \pm 0.118$ & $0.149 \pm 0.122$ & 0.038 & 0.123 & \\
\hline FSI & $0.099 \pm 0.047$ & $0.105 \pm 0.043$ & $0.108 \pm 0.053$ & $0.093 \pm 0.043$ & 0.023 & 0.270 & \\
\hline GIMC & $0.094 \pm 0.050$ & $0.101 \pm 0.071$ & $0.106 \pm 0.060$ & $0.085 \pm 0.053$ & 0.918 & & 0.038 \\
\hline GIMC medio & $0118 . \pm 0.082$ & $0.123 \pm 0.081$ & $0.156 \pm 0.075$ & $0.108 \pm 0.064$ & 0.843 & & 0.023 \\
\hline GIMF & $0.164 \pm 0.097$ & $0.164 \pm 0.066$ & $0.153 \pm 0.091$ & $0.122 \pm 0.087$ & 0.000 & 0.135 & \\
\hline GIMF medio & $0.141 \pm 0.0$ & $0.152 \pm 0.061$ & $0.155 \pm 0.087$ & $0.127 \pm 0.080$ & 0.000 & 0.172 & \\
\hline GIM Total & $0.117 \pm 0.073$ & $0.132 \pm 0.068$ & $0.129 \pm 0.075$ & $0.103 \pm 0.070$ & 0.002 & 0.037 & \\
\hline
\end{tabular}

Tabla XXII: Mediciones ecográficas tras 1 año de seguimiento. CCD: carótida común derecha; BCD: bulbo carotídeo derecho; CID: carótida interna derecha; CCI: carótida común izquierda; BCI: bulbo carotídeo izquierdo; CII: carótida interna izquierda; FCD: femoral común derecha;

FSD: femoral superficial derecha; FCI: femoral común izquierda; FSI: femoral superficial izquierda. GIMC: grosor íntima-media carotídeo; GIMF: grosor íntima-media femoral.

$\mathrm{Al}$ año de seguimiento, el grosor a nivel del BCD (0.198 \pm 0.074 vs $0.151 \pm 0.089)$,

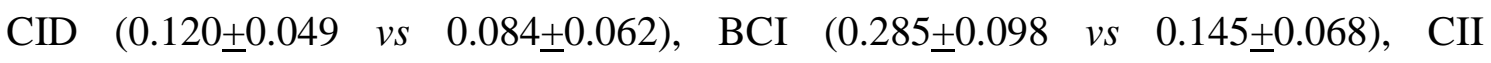
$(0.131 \pm 0.107$ vs $0.096 \pm 0.060)$ en los pacientes en hemodiálisis es mayor que en los pacientes en diálisis peritoneal $(p=0.047, p=0.037, \quad p=0.043$ y $p=0.024$, respectivamente). Además dichas diferencias han aumentado de manera significativa.

El GIMC y el GIMC medio también permanecen más elevados en los pacientes en hemodiálisis que en los pacientes con diálisis peritoneal tras el año de seguimiento $(0.189 \pm 0.049$ vs $0.108 \pm 0.048, \mathrm{p}=0.038$ y $0.193 \pm 0.078$ vs $0.123 \pm 0.089, p=0.023$, respectivamente). 


\begin{tabular}{|lllll|}
\hline & $\begin{array}{l}\text { Controles } \\
\boldsymbol{v} \boldsymbol{S}\end{array}$ & $\begin{array}{l}\text { Controles } \\
\boldsymbol{v} \boldsymbol{s}\end{array}$ & $\begin{array}{l}\text { Hemodiálisis } \\
\boldsymbol{v} \boldsymbol{s}\end{array}$ & $\boldsymbol{P}$ \\
& $\boldsymbol{p}$ & $\boldsymbol{P}$ & $\boldsymbol{p}$ & \\
& & & \\
& $\boldsymbol{p}$ & & \\
\hline CCD & 0.991 & 0.027 & 0.058 & 0.012 \\
BCD & 0.727 & 0.898 & 0.047 & 0.047 \\
CID & 0.738 & 0.672 & 0.044 & 0.037 \\
CCI & 0.556 & 0.999 & 0.717 & 0.590 \\
BCI & 0.206 & 0.092 & 0.042 & 0.043 \\
CII & 0.205 & 0.511 & 0.031 & 0.024 \\
FCD & 0.716 & 0.721 & 0.992 & 0.695 \\
FSD & 0.322 & 0.803 & 0.253 & 0.223 \\
FCI & 0.132 & 0.953 & 0.219 & 0.123 \\
FSI & 0.260 & 0.985 & 0.407 & 0.270 \\
GIMC & 0.833 & 0.289 & 0.037 & 0.038 \\
GIMC medio & 0.234 & 0.156 & 0.025 & 0.023 \\
GIMF & 0.110 & 0.998 & 0.327 & 0.135 \\
GIMF medio & 0.123 & 0.251 & 0.098 & 0.172 \\
GIM Total & 0.577 & 0.711 & 0.342 & 0.037 \\
& & & & \\
\hline
\end{tabular}

Tabla XXIII: Valores de significación estadística de la comparación de los grupos respecto a las mediciones ecográficas tras 1 año de seguimiento. CCD: carótida común derecha; $\mathrm{BCD}$ : bulbo carotídeo derecho; CID: carótida interna derecha; CCI: carótida común izquierda; BCI: bulbo carotídeo izquierdo; CII: carótida interna izquierda; FCD: femoral común derecha; FSD: femoral superficial derecha; FCI: femoral común izquierda; FSI: femoral superficial izquierda.

GIMC: grosor íntima-media carotídeo; GIMF: grosor íntima-media femoral.

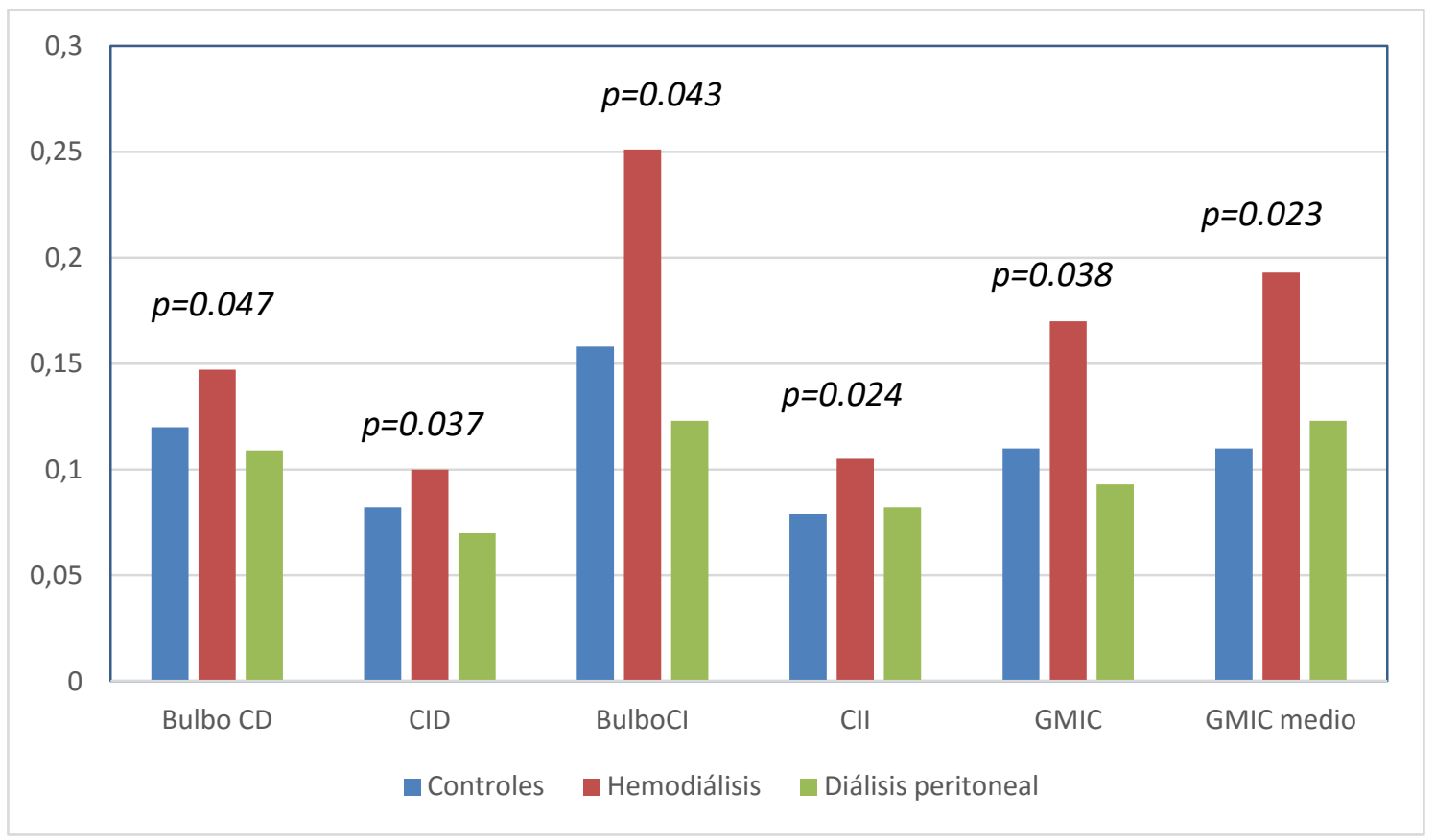

Fig.20: Representación gráfica de los valores ecográficos tras 1 año de seguimiento. 


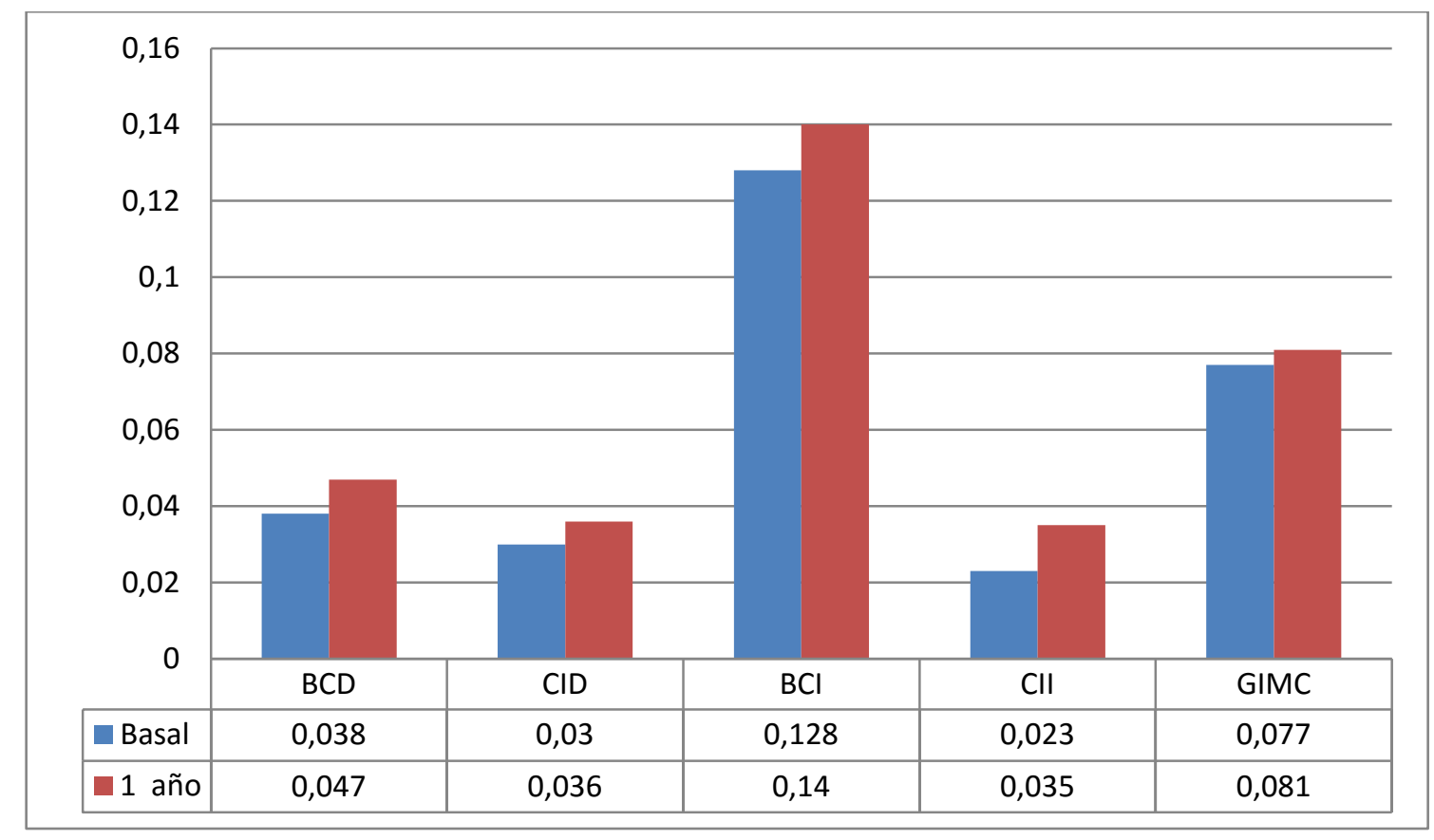

Fig.21: Representación gráfica de las diferencias en las medidas ecográficas entre los pacientes sometidos a hemodiálisis y los pacientes sometidos a diálisis peritoneal.

\section{$\underline{\text { Analítica }}$}

\begin{tabular}{|lccccccc|}
\hline & $\begin{array}{c}\text { Total } \\
(\mathbf{n = 1 4 2})\end{array}$ & $\begin{array}{c}\text { Controles } \\
(\mathbf{n = 6 6})\end{array}$ & $\begin{array}{c}\text { Hemodiálisis } \\
(\mathbf{n = 5 0})\end{array}$ & $\begin{array}{c}\text { Diálisis } \\
\mathbf{p e r i t o n e a l} \\
(\mathbf{n = 2 6})\end{array}$ & $\begin{array}{c}\text { Levene } \\
\boldsymbol{p}\end{array}$ & $\begin{array}{c}\text { ANOVA } \\
\boldsymbol{p}\end{array}$ & $\begin{array}{c}\text { Kruskal- } \\
\text { Wallis } \\
\boldsymbol{p}\end{array}$ \\
\hline Calcio & $9.08 \pm 0.67$ & $9.23 \pm 0.47$ & $8.91 \pm 0.84$ & $9.00 \pm 0.65$ & 0.005 & 0.023 \\
Fósforo & $4.59 \pm 1.28$ & $3.85 \pm 0.50$ & $5.28 \pm 1.44$ & $5.13 \pm 1.38$ & 0.000 & 0.000 \\
Ca x P & $41.38 \pm 10.80$ & $35.49 \pm 4.48$ & $46.68 \pm 11.74$ & $46.16 \pm 12.80$ & 0.000 & 0.000 \\
Vit D & $35.01 \pm 27.86$ & $43.38 \pm 21.00$ & $32.80 \pm 37.05$ & $20.62 \pm 6.65$ & 0.026 & 0.002 & \\
PH & $262.12 \pm 205.17$ & $158.22 \pm 71.14$ & $364.99 \pm 250.86$ & $304.05 \pm 207.65$ & 0.000 & 0.000 & \\
FA & & & & & & 0.000 \\
Hb glic. & $104.34 \pm 46.66$ & $89.58 \pm 40.92$ & $118.92 \pm 43.81$ & $113.77 \pm 55.40$ & 0.345 & & 0.058 \\
Col & $6.19 \pm 1.23$ & $5.97 \pm 0.91$ & $6.76 \pm 1.61$ & $5.40 \pm 0.23$ & 0.000 & 0.035 \\
TGs & $166.03 \pm 41.84$ & $163.61 \pm 41.3$ & $158.48 \pm 38.01$ & $186.69 \pm 45.08$ & 0.252 & & 0.002 \\
LDL & $148.46 \pm 74.60$ & $159.79 \pm 78.37$ & $147.80 \pm 74.76$ & $121.00 \pm 57.79$ & 0.043 & 0.079 \\
HDL & $88.30 \pm 35.06$ & $86.59 \pm 33.66$ & $78.29 \pm 31.12$ & $111.00 \pm 36.39$ & 0.311 & & 0.096 \\
\hline
\end{tabular}

Tabla XXIV: Mediciones analíticas basales. Ca: calcio; P: fósforo; Vit D: vitamina D; PH: parathormona; FA: fosfatasa alcalina; HB glic: hemoglobina glicosilada; Col: colesterol; TGs: triglicéridos. 


\begin{tabular}{|c|c|c|c|c|}
\hline & $\begin{array}{l}\text { Controles } \\
\text { vs } \\
\text { Hemodiálisis } \\
P\end{array}$ & $\begin{array}{l}\text { Controles } \\
v s \\
\text { Peritoneal } \\
p\end{array}$ & $\begin{array}{l}\text { Hemodiálisis } \\
v s \\
\text { Peritoneal } \\
p\end{array}$ & $p$ \\
\hline Calcio & 0.015 & 0.212 & 0.830 & 0.023 \\
\hline Fósforo & 0.000 & 0.000 & 0.828 & 0.000 \\
\hline Ca $\times P$ & 0.000 & 0.000 & 0.970 & 0.000 \\
\hline Vit D & 0.079 & 0.001 & 0.147 & 0.002 \\
\hline PH & 0.000 & 0.002 & 0.356 & 0.000 \\
\hline FA & 0.001 & 0.041 & 0.883 & 0.000 \\
\hline Hb glic. & 0.053 & 0.590 & 0.102 & 0.035 \\
\hline Col & 0.742 & 0.031 & 0.014 & 0.058 \\
\hline TGs & 0.610 & 0.047 & 0.293 & 0.079 \\
\hline LDL & 0.338 & 0.004 & 0.000 & 0.002 \\
\hline HDL & 0.855 & 0.045 & 0.170 & 0.096 \\
\hline
\end{tabular}

Tabla XXV: Valores de significación estadística de la comparación de los grupos respecto a los valores analíticos basales.

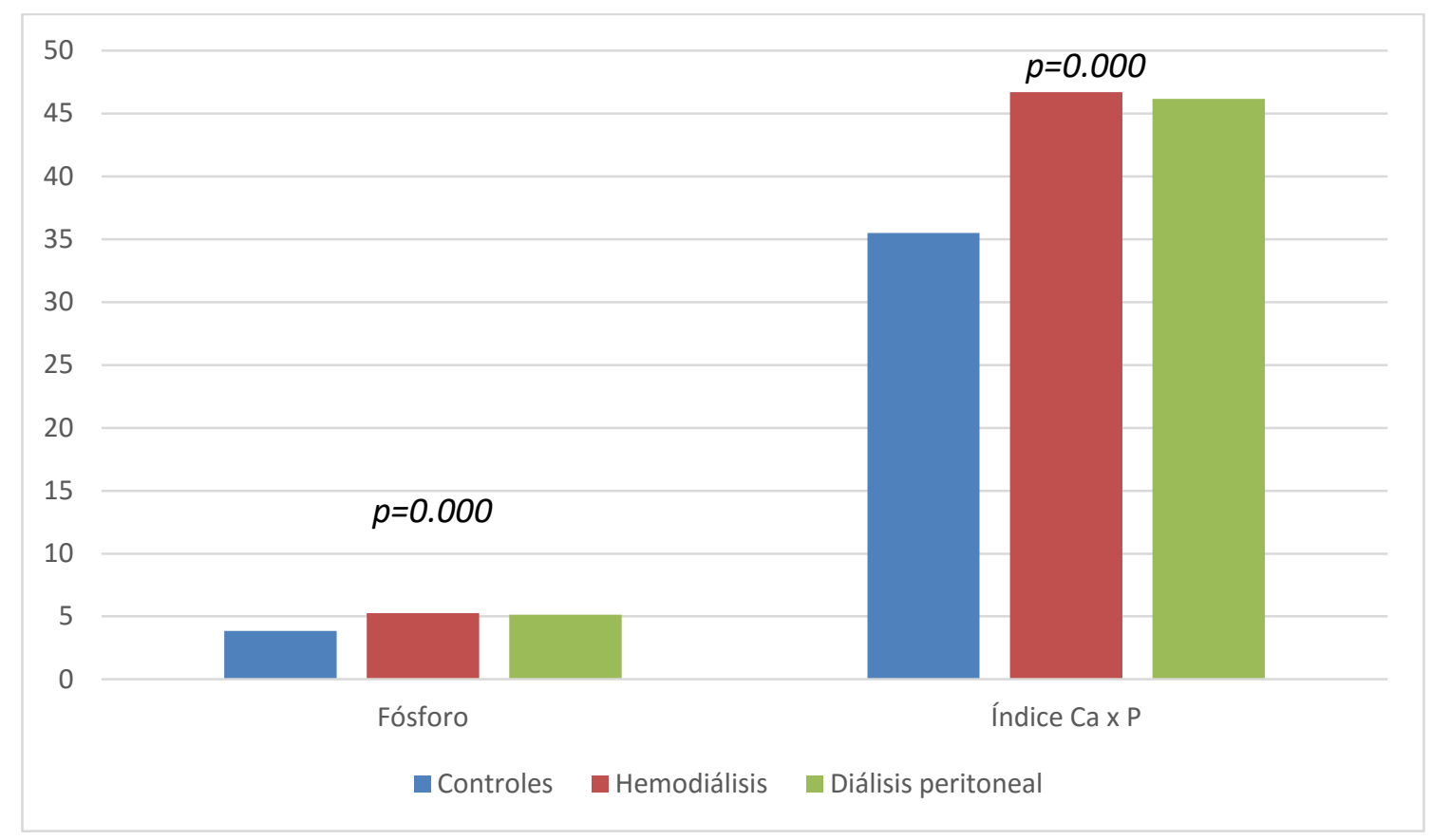

Fig.22: Representación gráfica de los valores analíticos de fósforo y de índice Ca x $\mathrm{P}$ en el momento basal.

En el momento basal los valores de calcio son más elevados en el grupo control $(p=0.023)$, siendo significativamente menores los valores de fósforo en dicho grupo en comparación con los pacientes en hemodiálisis $(3.85 \pm 0.50$ vs 5.28+1.44, $p=0.000)$ o en diálisis peritoneal $(3.85 \pm 0.50$ vs $5.13 \pm 1.38, p=0.000)$. Dicha razón justifica un índice Ca x P también inferior en el grupo control que en los otros dos grupos $(p=0.000)$.

El grupo control presenta niveles significativamente inferiores de parathormona

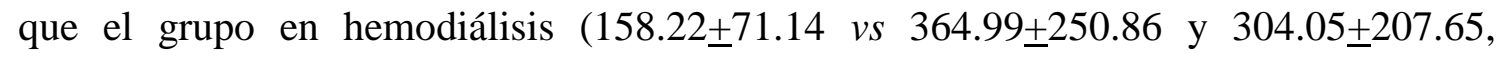


$p=0.000$ ) y del grupo en diálisis peritoneal. De igual forma sucede con los niveles de FA $(89.58 \pm 40.92$ vs $118.92 \pm 42.81$ y $113.77 \pm 55.40, p=0.000)$.

Los pacientes en diálisis peritoneal presentan unos niveles significativamente más elevados de colesterol $(186.69 \pm 45.08$ vs $158.48 \pm 38.01, p=0.014)$ y de LDL (111.00 \pm 36.39 vs 78.29 $\pm 31.12, p=0.000)$ que los pacientes en hemodiálisis.

\begin{tabular}{|lccccccc|}
\hline & $\begin{array}{c}\text { Total } \\
(\mathbf{n = 1 4 2})\end{array}$ & $\begin{array}{c}\text { Controles } \\
(\mathbf{n = 6 6})\end{array}$ & $\begin{array}{c}\text { Hemodiálisis } \\
(\mathbf{n = 5 0})\end{array}$ & $\begin{array}{c}\text { Diálisis } \\
\text { peritoneal } \\
(\mathbf{n = 2 6})\end{array}$ & $\begin{array}{c}\text { Levene } \\
\boldsymbol{p}\end{array}$ & $\begin{array}{c}\text { ANOVA } \\
\boldsymbol{p}\end{array}$ & $\begin{array}{c}\text { Kruskal- } \\
\text { Wallis } \\
\boldsymbol{p}\end{array}$ \\
\hline Calcio & $9.05 \pm 0.64$ & $9.19 \pm 0.52$ & $8.83 \pm 0.80$ & $9.06 \pm 0.52$ & 0.025 & 0.012 \\
Fósforo & $4.45 \pm 1.45$ & $3.94 \pm 0.60$ & $4.97 \pm 2.03$ & $4.80 \pm 1.31$ & 0.000 & 0.000 \\
Ca x P & $40.11 \pm 12.27$ & $36.33 \pm 5.86$ & $43.45 \pm 16.62$ & $43.55 \pm 12.55$ & 0.000 & 0.002 & 0.000 \\
Vit D & $30.26 \pm 21.79$ & $34.44 \pm 16.91$ & $31.63 \pm 29.50$ & $20.23 \pm 12.55$ & 0.240 & & \\
PH & $221.62 \pm 202.76$ & $159.07 \pm 86.67$ & $332.86 \pm 300.69$ & $177.71 \pm 75.64$ & 0.000 & 0.000 & 0.011 \\
FA & $97.21 \pm 40.42$ & $86.70 \pm 34.62$ & $109.04 \pm 39.79$ & $102.08 \pm 49.04$ & 0.060 & & 0.006 \\
Hb glic. & $6.33 \pm 1.24$ & $5.98 \pm 0.98$ & $7.40 \pm 1.43$ & $6.20 \pm 1.09$ & 0.108 & 0.014 \\
Col & $165.96 \pm 39.74$ & $157.91 \pm 33.83$ & $166.00 \pm 41.25$ & $186.31 \pm 39.58$ & 0.057 & & 0.640 \\
TGs & $144.00 \pm 71.05$ & $138.27 \pm 57.36$ & $153.75 \pm 85.22$ & $140.54 \pm 74.71$ & 0.118 & & 0.031 \\
LDL & $91.11 \pm 31.65$ & $83.63 \pm 27.40$ & $94.82 \pm 34.74$ & $103.00 \pm 32.09$ & 0.619 & & 0.023 \\
HDL & $45.75 \pm 12.28$ & $47.13 \pm 11.67$ & $41.59 \pm 11.56$ & $49.92 \pm 13.32$ & 0.877 & & \\
\hline
\end{tabular}

Tabla XXVI: Mediaciones analíticas tras 1 año de seguimiento. Ca: calcio; P: fósforo; Vit D: vitamina D; PH: parathormona; FA: fosfatasa alcalina; HB glic: hemoglobina glicosilada; Col: colesterol; TGs: triglicéridos.

\begin{tabular}{|lcccc|}
\hline & $\begin{array}{c}\text { Controles } \\
\text { Hemodiálisis }\end{array}$ & $\begin{array}{c}\text { Controles } \\
\text { Ps } \\
\text { Peritoneal }\end{array}$ & $\begin{array}{c}\text { Hemodiálisis } \\
\boldsymbol{v s} \\
\text { Peritoneal } \\
\boldsymbol{p}\end{array}$ & $\boldsymbol{p}$ \\
\hline Calcio & $\boldsymbol{p}$ & $\boldsymbol{p}$ & 0.300 & 0.012 \\
Fósforo & 0.006 & 0.585 & 0.875 & 0.000 \\
Ca x P & 0.000 & 0.015 & 0.999 & 0.002 \\
Vit D & 0.004 & 0.018 & 0.093 & 0.000 \\
PH & 0.775 & 0.013 & 0.003 & 0.000 \\
FA & 0.000 & 0.886 & 0.748 & 0.011 \\
Hb glic. & 0.006 & 0.172 & 0.076 & 0.006 \\
Col & 0.000 & 0.876 & 0.072 & 0.014 \\
TGs & 0.435 & 0.003 & 0.727 & 0.640 \\
LDL & 0.429 & 0.987 & 0.552 & 0.031 \\
HDL & 0.021 & 0.132 & 0.019 & 0.023 \\
\hline
\end{tabular}

Tabla XXVII: Valores de significación estadística de la comparación de los grupos respecto a los valores analíticos tras 1 año de seguimiento. 


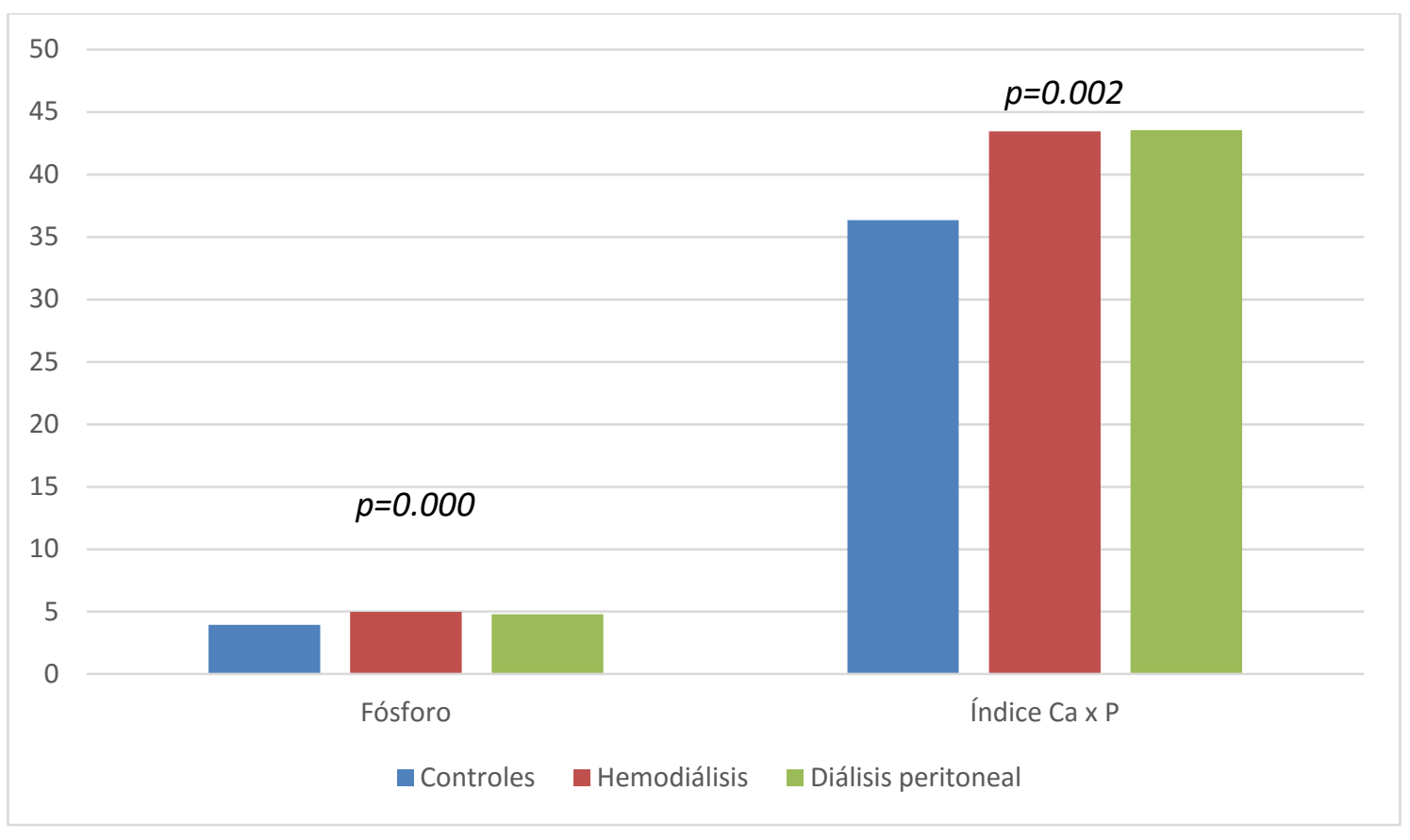

Fig.23: Representación gráfica de los valores analíticos de fósforo y de índice Ca x P tras 1 año de seguimiento.

Tras el año de seguimiento continua existiendo diferencias en los niveles de fósforo en el grupo control, siendo significativamente inferiores en dicho grupo que en los pacientes en hemodiálisis $(3.94 \pm 0.60$ vs $4.97 \pm 2.03, p=0.000)$ o en diálisis peritoneal (3.94 \pm 0.60 vs 4.80 $\pm 1.31, p=0.015)$. Dicha razón sigue justificando un índice $\mathrm{Ca} \times \mathrm{P}$ también inferior en el grupo control que en los otros dos grupos $(p=0.002)$.

El colesterol total y el LDL en el grupo de pacientes en diálisis peritoneal continua siendo mayor, pero ha perdido la significación estadística. No obstante, los niveles de HDL en dicho grupo son estadísticamente superiores a los del grupo de pacientes en hemodiálisis $(49.92 \pm 13.32$ vs $41.59 \pm 11.56, p=0.019)$.

Tras el año de seguimiento, los niveles de parathormona en el grupo continuaban siendo estadísticamente inferiores que en el grupo en hemodiálisis $(159.07 \pm 86.67$ vs $332.86 \pm 300.69, p=0.000)$. No existía dicha diferencia con los pacientes en diálisis peritoneal.

Tanto en el momento basal como tras 1 año de seguimiento, más de la mitad de los pacientes presentaban niveles de Vitamina D inferiores a la normalidad. Dichos niveles no se modificaron significativamente tras el año de seguimiento. 


\section{VITAMINA D BASAL}

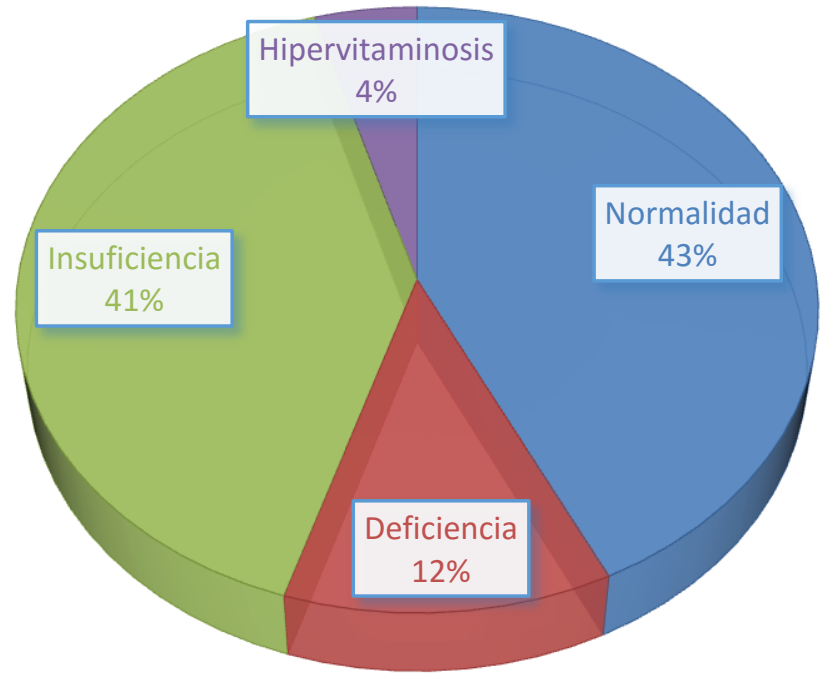

Fig.24: Representación gráfica de los niveles de Vitamina D en el momento basal.

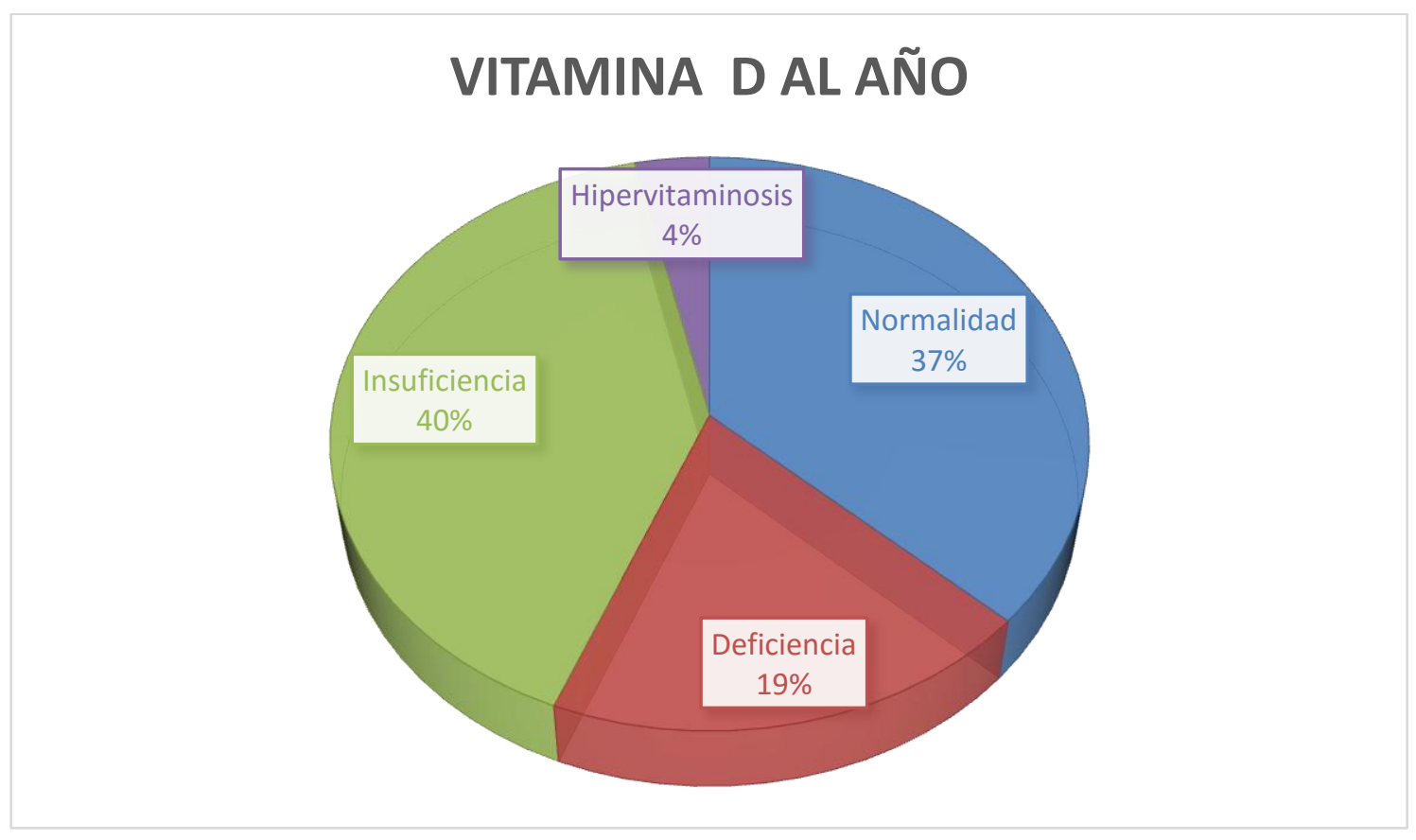

Fig.25: Representación gráfica de los niveles de Vitamina D tras 1 año de seguimiento. 



\section{DISCUSIÓN}



En nuestro estudio se evalúa la prevalencia y evolución de la ateromatosis subclínica en los pacientes con enfermedad renal en estadios avanzados que se encuentran con tratamiento sustitutivo de HD o DP. Además de valorar el papel de los diferentes tests no invasivos de cribado de enfermedad cardiovascular en esta población.

La enfermedad cardiovascular es la principal causa de morbimortalidad en los pacientes renales, y continúa siéndolo a pesar del mayor conocimiento de la fisiopatología de la arterioesclerosis y de la mejora de los tratamientos ${ }^{(48,138)}$. Una adecuada evaluación del riesgo cardiovascular es esencial, los métodos no invasivos y de fácil utilización, como el ecodoppler están teniendo una gran repercusión.

En la muestra analizada, nos encontramos diferencias significativas respecto a la edad entre los diferentes grupos. Los pacientes del grupo control presentaron una edad mayor que los pacientes incluidos en el grupo de hemodiálisis $(70.79 \pm 13.70$ vs $66.80 \pm 13.94, p=0.242)$ y significativamente mayor que los pacientes en diálisis peritoneal $(70.79+13.70$ vs $57.00 \pm 15.61, p=0.000)$. Esto puede ser debido a que los pacientes elegidos en el grupo control son aquellos que aun teniendo enfermedad renal avanzada con estadios 4 y 5 no son candidatos o ellos mismos han renunciado al tratamiento de HD o DP. Muchas veces la causa del rechazo de estos tratamientos es la edad, aunque actualmente no hay consenso sobre la edad límite para la realización del tratamiento renal sustitutivo.

Esta mayor edad en el grupo control, puede justificar que exista una mayor presencia de diabetes mellitus y de dislipemia que en los pacientes en HD o DP ( $p=0.002$ у $p=0.000$, respectivamente), ya que la prevalencia de ambas patologías aumenta con la edad.

Por otro lado, los pacientes en DP son significativamente más jóvenes que los pacientes en HD $(57.00 \pm 15.61$ vs $66.80 \pm 13.94, p=0.013)$. Esta diferencia en la población se puede explicar porque es el propio paciente quien elige el modo de TRS. En el caso de la diálisis peritoneal, el paciente debe ser capaz de realizar el intercambio del catéter así como mantener la asepsia del mismo. Por normal general, los pacientes más jóvenes, eligen la DP, ya que es una técnica que realizan ellos mismos de forma domiciliaria. El paciente más anciano, bien sea por inseguridad o por la merma de sus 
facultades, prefiere ser tratado, aunque esto suponga acudir al hospital varias veces por semana $^{(139)}$.

En el único registro llevado a cabo en la población española se describe que de media, en el $80 \%$ de los casos, la DP es elegida libremente por los pacientes, en el $20 \%$ restante media una causa médica, predominando los problemas en el acceso vascular (imposibilidad o agotamiento) y las cardiopatías ${ }^{(137)}$.

La edad media global de la población en DP en España es de 54.7 años, mientras que en nuestra muestra la edad media era de 57 años. En cuanto a la distribución por edades, prevalecen los grupos entre 40-60 y 60-80 años, como ocurre en el resto de los registros nacionales e internacionales ${ }^{(137)}$.

En el estudio de Wólfgram et al. ${ }^{(140)}$ en el que se compara 121.623 pacientes de los cuales 112.960 pertenecen al grupo de hemodiálisis y 8.663 al grupo de diálisis peritoneal encuentra una media de 69.9 para en grupo de hemodiálisis y de 60.4 para el grupo de peritoneal (la edad media de toda la muestra es 69.2), en otros estudios analizados también se encuentran diferencias entre las edades medias de los pacientes de hemodiálisis y diálisis peritoneal al menos de 5 años, siendo siempre mayor en el grupo de hemodiálisis ${ }^{(141-142)}$.

La dislipemia es un factor de riesgo cardiovascular conocido, frecuentemente presente en los pacientes con insuficiencia renal. Sin embargo, el papel de la dislipemia en la progresión de esta enfermedad no es del todo conocido. En los estudios realizados sobre la relación entre dislipemia y enfermedad renal crónica los pacientes son muy heterogéneos e incluyen desde aquellos que presentan proteinuria hasta los que tiene un bajo filtrado glomerular, en nuestro caso todos los pacientes se engloban en el estadio 4-5 de enfermedad renal ${ }^{(143)}$.

Otra consecuencia de la mayor prevalencia de dislipemia en el grupo control es que estos pacientes, están sujetos a un tratamiento con estatinas significativamente mayor que el resto de grupo $(p=0.000)$.

Hay que tener en cuenta que el uso de agentes hipolipemiantes parece que está indicado en las etapas tempranas de la insuficiencia renal para prevenir el riesgo de 
arterioesclerosis. Sin embargo, no queda claro el manejo de las estatinas en estadios avanzados de la enfermedad $\operatorname{renal}^{(144)}$.

La eficacia del tratamiento varía con el estadio de la enfermedad renal. En personas que no están en diálisis, las estatinas reducen todas las causas de muerte (RR, $0.81,95 \% \mathrm{IC}, 0.74-0.88)$, las muertes por causa cardiovascular $(0.78,0.68-0.89)$ y los eventos cardiovasculares $(0.76,0.73-0.80)$ con una moderada-alta evidencia. En las personas en diálisis, las estatinas tienen un pequeño efecto o incluso no tienen ningún efecto sobre la mortalidad por cualquier causa $(0.96,0.88-1.04)$, mortalidad relacionada por causa cardiovascular $(0.94,0.82-1.07)$ y eventos cardiovasculares $(0.95,0.87-1.03)$ con una moderada-alta evidencia ${ }^{(145)}$.

El efecto de las estatinas en pacientes que han sido recientemente trasplantados no se conoce muy bien.

La fibrilación auricular (FA) es la arritmia más frecuente en los pacientes con enfermedad renal y es más prevalente en ERCA que en la población general. La literatura ha revelado que el impacto que tiene la FA sobre el organismo en pacientes con ERCA es relevante ya que tiene importantes implicaciones pronósticas, provocando un aumento de riesgo de ictus y mortalidad ${ }^{(146)}$.

Se ha descrito que la prevalencia de FA aumenta con la edad, este aumento puede estar en relación con el aumento de otros factores de riesgo cardiovascular ${ }^{(147)}$.

La prevalencia de FA descrita en los distintos estudios varía entre el 7 y el $27 \%$ $(\text { Tabla } 1)^{(14-16,19-29) .}$ La variabilidad de la prevalencia puede ser explicada, al menos en parte, por la diferencia de la población, la duración del tiempo en diálisis, las comorbilidades o la forma de registrar y/o diagnosticar la FA. Por ejemplo el estudio de Genovesi et al. ${ }^{(148)}$ así como otro estudio de Tsagilis et al. ${ }^{(149)}$, presentan una prevalencia del 27 y $23.2 \%$ respectivamente, estos estudios incluyen pacientes más mayores, describiendo una edad media de sus muestras de 66+/-13.4 en el caso de Genovesi y de 65+/-14.4 en la muestra de Tsagilis.

Zimmerman et al. realizaron una revisión sobre la incidencia de la FA en pacientes en diálisis, obtiene cifras de incidencia de 2.7/100 pacientes año, y lo que es más importante, el riesgo de mortalidad e ictus se incrementó en un 26.9 y 5.2/100 
pacientes-año versus 13.4 y 1.9/100 pacientes-año comparado con pacientes con enfermedad renal avanzada sin $\mathrm{FA}^{(150)}$.

En nuestra población de hemodiálisis la prevalencia de FA se sitúa en un 20\%, cifra que concuerda con la de la literatura.

Un factor a tener en cuenta es que en la mayoría de los estudios no se distingue entre los distintos tipos de diálisis e incluso engloban varios estadios de insuficiencia renal.

Entre los pacientes con insuficiencia renal crónica que no requieren diálisis, hay varios estudios que describen una alta prevalencia de FA, 2.3 veces más elevada que en la población general. En los pacientes con moderada-avanzada enfermedad renal del estudio Chronic Renal Insufficiency Cohort (CRIC), la prevalencia de FA se sitúa en el $18 \%$ y en pacientes mayores de 70 años por encima del $25 \%{ }^{(146)}$.

La prevalencia de FA entre los pacientes de nuestro grupo control es sólo del $6.1 \%$, esta cifra difiere con la que ofrecen algunas series en la literatura. Este grupo control tiene una edad media es de 70 años y presentan enfermedad renal avanzada y otros factores de riesgo cardiovascular como son la diabetes y la dislipemia. La disparidad en las cifras se puede explicar por un error de selección, ya que en nuestros criterios de inclusión se encontraban los pacientes sin antecedentes de cardiopatía isquémica. Es sabido que la FA es una de las arritmias que puede aparecer asociada a un evento cardiaco. Además hay que tener en cuenta el error de supervivencia, ya que un paciente mayor de 70 sin antecedentes de cardiopatía isquémica y con una enfermedad renal avanzada se puede denominar "cardiovascular survivor".

La prevalencia exacta de FA en pacientes en diálisis peritoneal no se ha calculado, pero se presupone más alta que en la población normal ${ }^{(151)}$.

En nuestro caso, la no aparición de ningún caso de FA en el grupo de diálisis peritoneal puede deberse a un error de selección ya que se excluyen a los pacientes con antecedentes de cardiopatía isquémica y a un pequeño tamaño muestral $(n=26)$.

El tratamiento anticoagulante está en debate dado que aporta riesgos y beneficios, riesgo de sangrado y beneficio frente al embolismo. Se precisan estudios 
randomizados para determinar si la anticoagulación es una terapia adecuada en este tipo de pacientes. La mayoría de los estudios no respalda el efecto protector de la anticoagulación en pacientes de enfermedad renal avanzada con $\mathrm{FA}^{(150)}$.

Según uno de los últimos metanálisis publicados en CHEST concluye que el uso de warfarina para la FA tiene un desfavorable riesgo-beneficio en los pacientes con estadios avanzados de enfermedad ${ }^{(152)}$.

Existe escasez de datos sobre la eficacia y seguridad de los nuevos anticoagulantes orales en pacientes con insuficiencia renal y en insuficiencia renal avanzada $^{(146)}$. Los nuevos anticoagulantes como apixaban, dabigatran, edoxaban y rivaroxaban tienen aclaramiento renal. Estos fármacos se pueden usar en pacientes con ERC ajustando la dosis, aunque actualmente ninguno de ellos está recomendado en ERCA. El estudio RELY con dabigatran, AVERROES y ARISTOTLE con apixaban, ROCKET con rivaroxaban mostraron que con la dosis ajustada son tan eficaces y seguros como la warfarina para pacientes con ERC. Sin embargo en ninguno de estos estudios se incluyeron pacientes con aclaramiento de creatinina $<25-30 \mathrm{ml} / \mathrm{min}^{(91)}$.

Por lo mencionado anteriormente, nos encontramos que, a pesar de existir un $20 \%$ de prevalencia de FA en el grupo de hemodiálisis, sólo existe tratamiento anticoagulante en el 16\% (8 pacientes) de los pacientes, de los cuales uno estaba sometido a tratamiento anticoagulante por presentar síndrome antifosfolípido con manifestaciones neurológicas y varios episodios trombosis de accesos vasculares.

Respecto al grupo de diálisis peritoneal al no existir ningún paciente con el diagnóstico de FA tampoco existen pacientes anticoagulados. Además, la presencia de FA complica de forma notable el manejo de estos pacientes. Hoy día se desconoce el papel que el tratamiento antiarrítmico profiláctico, la cardioversión eléctrica o las técnicas de ablación puede tener en el manejo clínico de pacientes en $\mathrm{DP}^{(151)}$.

La HVI es común en los pacientes con ERCA y se ha planteado como objetivo terapéutico. Los cambios subyacentes en el miocardio cuando existe hipertrofia de VI son un sustrato ideal para que ocurra una arritmia y también para provocar una muerte súbita. La HVI está presente entre el 68-89\% de los pacientes en HD y frecuentemente progresa, sin embargo, en algunos pacientes se ha observado la regresión. Alto grado de 
HVI en el momento del diagnóstico, así como el incremento de la masa de VI a lo largo del tiempo, están asociados con una disminución de la supervivencia, sin embargo esta asociación causa-efecto no está todavía claramente definida ${ }^{(153)}$.

Colbert et al. define a la HVI como un factor independiente de riesgo para todas las causas de muerte y muerte cardiovascular en pacientes en diálisis ${ }^{(154)}$.

La HVI es altamente prevalente en los pacientes de diálisis presentando cifras cercanas al $75 \%$ en el estudio de Foley realizado en $1998^{(48)}$. Cifras similares, al estudio realizado en Japón en la que la cifra se situó en un $68 \%{ }^{(155)}$. Más recientemente el análisis realizado por la CRIC (Chronic Renal Insufficiency Cohort) describe una cifra del $79 \%$ en pacientes que comienzan por primera vez su tratamiento de diálisis ${ }^{(146)}$. La incidencia varía según los estudios en un rango entre 36\%-74\% en muestras sin seleccionar, cuando existe una selección de pacientes que incluyen pacientes diagnosticados de enfermedad cardiovascular probablemente la incidencia sea superior $^{(153)}$.

En nuestro estudio los pacientes del grupo control (72.7\%) y el grupo de HD (76\%) presentan una mayor prevalencia de HVI que los del grupo de DP (46.2\%) con una $p=0.019$.

Las guía internacional de manejo cardiovascular y metabólico del paciente en $\mathrm{DP}^{(156)}$ sugieren que los pacientes en diálisis peritoneal con Hipertrofia de VI o fallo cardiaco se considere el tratamiento con IECas o ARAs (Evidencia 2D). Así mismo, sugieren que los pacientes en DP con HVI, cardiomiopatía dilatada o fallo cardiaco sistólico se considere el tratamiento con $\beta$-bloqueantes (evidencia 2C).

Aunque el tratamiento con ARAS y la frecuencia de la diálisis pueden reducir la hipertrofia, a pesar de esta disminución no se han observado mejoras en la supervivencia y/o en la aparición de complicaciones $\mathrm{CV}^{(153)}$ por ello, se necesitan futuros estudios para analizar como los cambios en el VI y la función cardiaca puede ser útil en el pronóstico de estos pacientes.

Aunque se encontraron diferencias en la HVI entre los distintos grupos no existieron diferencias respecto a la fracción de eyección del ventrículo izquierdo. La 
media en los grupos estudiados estaba entre el 65 y el 70\%. Lo que representa que estos pacientes se encuentran en rangos de normalidad.

Los pacientes en HD precisan un mayor tratamiento con antiagregantes que pacientes de otros grupos $(p=0.024)$. Esto se debe en su mayoría a la presencia de un acceso vascular para la realización de la hemodiálisis. En la revisión de la Cochrane sobre los tratamientos en los accesos vasculares concluye que el tratamiento antiagregante protege a la Fistula Arteriovenosa de la trombosis y de la pérdida de permeabilidad, pero este tratamiento tiene un poco o nulo efecto sobre los accesos protésicos. También afirma que el tratamiento antiagregante tiene un efecto incierto sobre la maduración del acceso vascular y la existencia de sangrado mayor ${ }^{(157)}$.

En los pacientes con ERCA existe un 50-80\% de respuesta disminuida al clopidogrel, lo que se denomina en la literatura como hiperreactividad plaquetaria residual.

La actual evidencia sugiere que los pacientes con ERCA no obtienen los mismos beneficios con el tratamiento con clopidogrel que la población general y esta terapia puede estar asociada a un posible efecto dañino. Se necesitan estudios prospectivos randomizados para establecer el papel del clopidogrel en los pacientes con ERCA y analizar asimismo el papel de los nuevos antiagregantes como prasugrel o ticagrelor en pacientes en los que exista una alta tasa de hiperreactividad plaquetaria residual ${ }^{(158)}$.

Otra de las indicaciones de la terapia antiagregante es la prevención de la enfermedad cerebrovascular. La recurrencia de ictus es más alta en los pacientes que presentan ERC. Sin embargo, no hay recomendaciones específicas de la terapia antiagregante en los pacientes con ictus e insuficiencia renal. Los pacientes con insuficiencia renal poseen características diferentes a la población general como son la alta tasa de sangrado, la pobre respuesta a antiagregantes, la selección, por tanto el tratamiento antiplaquetario debe ser individualizado. Además, no hay que olvidar que el ácido acetil salicílico puede agravar la enfermedad renal.

Los inhibidores de la fosfodiesterasa restauran la disfunción endotelial y puede servir como un objetivo para la prevención del ictus en los pacientes con enfermedad renal $^{(159)}$. 
La AHA recomienda la terapia antitrombótica en la prevención primaria de ictus sólo en los pacientes que se consideran de alto riesgo ${ }^{(160)}$. Sin embargo una reciente revisión de la Cochrane evalúa el efecto de la terapia antiagregante sobre los eventos cardiovasculares, muerte, sangrado en 11.701 pacientes con insuficiencia renal y enfermedad cardiovascular y ha encontrado que la terapia antiagregante está asociada con incierto efecto sobre el ictus y el incremento del riesgo de sangrado menor ${ }^{(161)}$. Teniendo en cuenta el beneficio poco claro de la antiagregación en la prevención primaria de ictus y el aumento del riesgo en los pacientes con enfermedad renal, no se recomienda la antiagregación de rutina en los pacientes en $\mathrm{DP}^{(156)}$.

Los pacientes del grupo control, como ya se ha comentado anteriormente, presentan una mayor prevalencia de dislipemia, por lo tanto, están sujetos a un tratamiento con estatinas significativamente mayor que el resto de grupos $(p=0.000)$.

El tratamiento antihipertensivo, antidiabético e hipolipemiante es más frecuente en estadios 4-5 que en estadio 3 de ERC. En pacientes en diálisis estos tratamientos son menos frecuentes. Esta tendencia puede ser explicada por las diferencias entre grupos, pero también es conocido los pacientes en diálisis suelen presentar unos niveles de LDL-colesterol más bajos y por ello se prescriben menos estatinas ${ }^{(137)}$.

Como ya se ha comentado anteriormente las estatinas en pacientes con TRS no han demostrado mejoría de la morbimortalidad cardiovascular. Se han publicado datos de resultados dispares en estadio renal avanzados, como ya hemos comentado anteriormente $^{(144,162)}$.

La alteración en el metabolismo de la Vit D juega un papel principal en la patogenia del Hiperparatiroidismo secundario (HPTS) y también se asocia con el aumento de la morbimortalidad cardiovascular en pacientes con ERC.

Durante más de sesenta años, la Vit D, los metabolitos de Vit D (ergocalciferol, colecalciferol o calciferol) y los activadores de receptores no selectivos de Vit D (VDR) como el calcitriol o alfacalcidol han sido usados en la prevención y tratamiento del HPTS. En los últimos 20 años, los activadores selectivos de VDR (paricalcitol, maxacalcitol) han sido usados para el HPTS. 
Las guías K/DOQUI y KDIGO recomiendan analizar si existe deficiencia o insuficiencia de Vit D en los pacientes renales pero actualmente no existe consenso para definir estos términos ${ }^{(41,163)}$. Debido a esta falta de consenso, la prevalencia de insuficiencia o deficiencia de Vit D varía. La mayoría de los estudios define deficiencia como niveles de 25(OH)D (calcidiol) $<15 \mathrm{ng} / \mathrm{ml}$ e insuficiencia valores de 15 $30 \mathrm{ng} / \mathrm{ml}^{(41)}$. Tampoco hay acuerdo para definir los niveles que se consideran tóxicos.

Algunos autores creen que los valores normales son aquellos que están asociados a un nivel adecuado de PTH en la población general, mientras que otros lo definen como el nivel por encima del cual no hay una reducción recíproca de la PTH en suero por la suplementación con vit $\mathrm{D}^{(164)}$.

En nuestro estudio se han considerado valores de VitD $<15 \mathrm{mcg} / \mathrm{L}$ como deficiencia, 15-30mcg/L insuficiencia y > 30mcg/L como normal.

Numerosas publicaciones han encontrado asociación de deficiencia de Vit D, con diversas enfermedades. En la población general y en pacientes con enfermedad renal $^{(45)}$ existe asociación de bajos niveles de Vit D y mortalidad ${ }^{(165)}$. Sin embargo, no hay datos que demuestren que la suplementación con Vit D reduzca la mortalidad en pacientes con $\mathrm{ERC}^{(41)}$.

Otras cuestiones abiertas son, por ejemplo, cual es el mejor metabolito de Vit D, que dosis y si hay que asociar los activadores de VDR. Teniendo en cuenta que el tratamiento con activadores de VDR se requiere en la mayoría de los pacientes con ERC y particularmente en los pacientes de diálisis ${ }^{(166)}$.

En nuestra muestra un $30,3 \%$ de los pacientes del grupo control toman Vit D, por el contrario nos encontramos que ningún paciente estaba tomando Vit $\mathrm{D}$ en el grupo de HD y DP, este fenómeno también se ha descrito en el estudio NEFRONA ${ }^{(137)}$. Los facultativos responsables de la Unidad de Hemodialisis y Dialisis Peritoneal no consideran necesario la suplementación con Vit D por el riesgo de hipervitaminosis hasta que la evidencia científica sea clara.

Wang et al. ${ }^{(165)}$ analiza la población en HD estratificándola en dos categorías, el primer grupo incluye a los pacientes con niveles séricos de Vit $\mathrm{D} \leq$ a $30 \mathrm{mcg} / \mathrm{L}$ y un segundo grupo con niveles superiores a $30 \mathrm{mcg} / \mathrm{L}$. El autor llega a la conclusión de que 
en los pacientes en HD, los niveles de Vit D suelen estar bajos incluso en los aquellos que reciben suplemento de Vit $\mathrm{D}$, además, hay una alta incidencia de calcificación vascular entre ellos.

Los pacientes con deficiencia de Vit D tienen mayor incidencia de calcificación, y la severidad de ésta aumenta cuando disminuyen los valores de Vit D. Por lo tanto, recomienda que la deficiencia de Vit D en paciente en HD sea corregida. No obstante, se necesitan estudios prospectivos randomizados para evaluar el impacto de la Vit D sobre la supervivencia de pacientes en $\mathrm{HD}^{(165)}$.

Al inicio de nuestro estudio se observa que más de la mitad de los pacientes presentaban niveles de Vit D inferiores a la normalidad (41\% insuficiencia y $12 \%$ deficiencia de Vit D). En el control que se realizó al año, los niveles no se modificaron, por lo tanto se mantuvo el porcentaje de pacientes con niveles inferiores a la normalidad. Analizándolo por grupos, los valores de los pacientes control y de HD están en el rango deseado (>30mcg/L), en cambio los pacientes en DP se sitúan por debajo; aún así, este grupo no toma complementos de Vit D.

$\mathrm{Al}$ año observamos que las cifras se mantienen excepto en el grupo control que a pesar de estar con suplementación de VitD los valores son inferiores. Circunstancia no extraña ya que en los pacientes con ERCA a veces presentan bajos niveles de Vit D a pesar del tratamiento ${ }^{(167)}$.

En cambio observamos que el uso de paricalcitol (VDR), es significativamente mayor en los grupos de HD (76\%) y DP (92\%) respecto al grupo control (18\%), la evidencia científica indica como ya hemos mencionado anteriormente el uso de VDR como un tratamiento muy eficaz para el control del HPTS en los pacientes en diálisis. El HPTS es de difícil manejo cuando el aclaramiento renal es menor, por ello en los pacientes en diálisis está más extendido su uso. En la práctica clínica, casi la totalidad de los pacientes lo toman, a no ser que exista alguna contraindicación, como por ejemplo, la enfermedad ósea adinámica que se observa en pacientes añosos y que se presenta con unas cifras bajas de PTH.

Un alto porcentaje de pacientes en ERCA reciben quelantes de fósforo, cálcicos y no cálcicos, a pesar del alto riesgo de calcificación vascular que provocan estos 
fármacos. En los pacientes en diálisis al existir un HPTS de difícil control a veces se requieren doble terapia de quelantes de fósforo, usándose en un mismo paciente dos fármacos o incluso más.

En nuestra serie nos encontramos que casi el $45 \%$ del total de la muestra está tomando quelantes de fosforo de tipo cálcico, porcentaje que disminuye al $36 \%$ en los pacientes en HD que son los que a priori tienen mayor riesgo de calcificación vascular. En el estudio español de prevalencia FRCV y epidemiologia, encuentran que el 43,8\% de los pacientes en estadio 5D están tomando quelantes de fósforo de tipo cálcico ${ }^{(137)}$.

Respecto a los quelantes no cálcicos de fósforo, nos encontramos diferencias estadísticamente significativas entre grupos, apareciendo más su uso en los pacientes de HD $(88 \%)$ y DP (76.9\%) respecto al grupo control (54.5\%), diferencias que también se observan en otros registros publicados ${ }^{(137)}$.

El cinacalcet es un medicamento calcimimético que actúa sobre el receptor sensible al calcio situado en la superficie de la célula principal de la paratiroides. Este fármaco incrementa la sensibilidad de dicho receptor al calcio, reduciendo así las concentraciones de PTH. Esta reducción se asocia a un descenso paralelo de las concentraciones séricas de calcio.

En nuestra serie casi el 30\% de la muestra toma cinacalcet, nos encontramos que existen diferencias estadísticamente significativas entre los grupos, siendo el mayor porcentaje en HD (52\%), DP (23.1\%) y el grupo control (29.6\%). Al igual que en el caso de los quelantes de fósforo, la explicación se debe a que el manejo de HPTS es más difícil a medida que avanza la enfermedad renal. Hay que tener en cuenta que los pacientes en DP mantienen una mayor diuresis residual, factor que influye en la excreción de calcio, de esta forma estos pacientes poseen un mejor manejo que los pacientes en HD.

Dos recientes estudios han evaluado respectivamente la eficacia del cinacalcet en la mejoría de calcificación cardiovascular (ADVANCE trial), y su impacto en el seguimiento clínico, incluyendo todas las causas de muerte y eventos cardiovasculares (EVOLVE trials). El estudio ADVANCE evidencia que el cinacalcet puede mejorar la calcificación de las grandes arterias y válvulas cardiacas. Sin embargo, el estudio 
EVOLVE no demuestra que el cinacalcet disminuya los eventos cardiovasculares ${ }^{(168-}$ 170)

Durante casi una década el cinacalcet ha sido considerado un elemento muy importante en el arsenal terapéutico en el tratamiento de los pacientes en diálisis, mejorando los parámetros analíticos (PTH, Ca sérico), el metabolismo mineral-óseo y la calcificación vascular. La evidencia actual, no ha demostrado mejora en la supervivencia y aparición de eventos cardiovasculares ${ }^{(168)}$.

Los requerimiento de Antidiabéticos orales (ADO) o Insulina disminuyen en los pacientes con muy bajo filtrado glomerular, ya que tanto la insulina como los ADO son de excreción renal, a veces cuando el filtrado glomerular es muy pequeño con la poca insulina que genera el paciente se puede realizar un control correcto de la DM. Además, una sobredosificación de ADO o insulina en un paciente renal puede conllevar una severa hipoglucemia que es una complicación grave. Por ello, en ocasiones, en pacientes muy mayores compensa dejar de tratar la DM ante el riesgo de hipoglucemias.

En nuestro estudio se observa que no todos los pacientes que están diagnosticados de DM reciben tratamiento y eso se traduce que aun existiendo diferencias de DM entre el grupo control y los grupos de HD y DP no existen diferencias cuando medimos los tratamientos insulínicos o de ADO.

Los niveles de calcio sérico son medidos de rutina en los laboratorios clínicos usando métodos colorimétricos en máquinas automatizadas. En individuos sanos, el calcio sérico está controlado en un rango estrecho, normalmente 8.5-10.00 o $10.5 \mathrm{mg} / \mathrm{dl}$ (2.1-2.5 o $2.6 \mathrm{mmol} / \mathrm{l})$, con alguna variación diurna ${ }^{(41)}$.

Sin embargo, el rango normal puede variar ligeramente de un laboratorio a otro, depende del tipo de medida que se use. En pacientes con ERC, los niveles de calcio fluctúan más, por la alteración de la homeostasis y los tratamientos que reciben. En aquellos con ERC en estadio 5D, hay una fluctuación adicional en asociación con los cambios inducidos por la diálisis, la hemoconcentración y la consecuente hemodilución.

Las muestras recogidas antes de diálisis y después de un largo intervalo entre 
sesiones como puede ser el fin de semana, comparadas con las muestras obtenidas en un periodo corto entre sesiones durante la semana, presentan mayor nivel de calcio. En el International Dialysis Outcomes and Practice Pattern Study, el calcio medido inmediatamente antes de la sesión del Lunes o Martes fue un $0.01 \mathrm{mg} / \mathrm{dl}(0.0025$ mmol/l) más alto que el medido antes de la sesión del Miércoles o Jueves ${ }^{(171)}$.

La fórmula corregida de calcio es usada de rutina en muchos laboratorios y estudios clínicos. Estima el calcio iónico a partir del calcio total, sumando $0.8 \mathrm{mg} / \mathrm{dl}$ $(0.2 \mathrm{mmol} / \mathrm{l})$ por cada gramo que disminuye la albúmina por debajo de $4 \mathrm{~g} / \mathrm{dl}(4 \mathrm{~g} / \mathrm{l})$. Datos recientes han demostrado que no ofrece superioridad sobre el calcio total y es menos específico que las medidas directas de calcio iónico. En nuestro caso nuestro laboratorio realiza mediciones del calcio total ${ }^{(172)}$.

En el momento basal los valores de calcio son más elevados en el grupo control $(p=0.023)$ sin diferencia estadísticamente significativas, estudiando estas diferencias entre los distintos grupos, nos encontramos que la única que alcanza significación estadística es la comparación entre el grupo control, y los pacientes en HD.

La cifra media de calcio en nuestra muestra es de 9.08+0.67, analizando este valor en los distintos grupos nos encontramos $9.23 \pm 0.47,8.91 \pm 0.84$ y $9.00 \pm 0.65$ para los grupos de control, HD y DP respectivamente.

Estas cifras son equivalentes a las descritas en la literatura ${ }^{(137,173)}$, estos valores se encuentran por debajo de los niveles de calcio sérico recomendados por las guías K/DOQUI para el metabolismo óseo y la enfermedad renal crónica ${ }^{(172)}$, niveles superiores a $9.45 \mathrm{mg} / \mathrm{dL}$ ha demostrado un aumento de la aparición y progresión de la calcificación vascular ${ }^{(173)}$.

Analizando el Ca sérico pasado un año, nos encontramos que no existe variación estadísticamente significativa respecto a los valores basales, encontrándose un buen control de este parámetro en nuestra muestra ya que siempre se mantienen por debajo de los niveles recomendados por las guías de referencia en la ERC. Por lo tanto, observamos que sigue existiendo diferencia estadísticamente significativa del nivel de Calcio entre los pacientes control y los pacientes de HD, diferencia que se puede explicar en la alimentación que llevan, ya que en HD la dieta es mucho más estricta. 
Otro factor que nos ayuda a explicar esta diferencia es que en los pacientes con TRS son sometidos a frecuentes controles analíticos (normalmente una analítica al mes) pudiendo modificar el tratamiento si fuese necesario.

El fósforo es fundamental para numerosas funciones fisiológicas como el desarrollo del esqueleto, el metabolismo mineral, el contenido fosfolipídico de la membrana celular, la agregación plaquetaria y trasferencia de energía a través del metabolismo mitocondrial. Debido a su importancia, en individuos sanos la concentración normal se debe mantener entre 2.5-4.5 mg/dl (0.81-1.45 mmol/l).

Los términos, fósforo y fosfatos, a menudo son intercambiables, pero hablando estrictamente, el término fosfato significa la suma de dos partículas inorgánicas en el suero.

A diferencia del calcio, el mayor componente de fósforo es intracelular, y factores como el $\mathrm{pH}$ y la glucosa modifican el intercambio de fósforo entre los medios intra y extracelular, de este modo alteran la concentración del fósforo sérico sin cambiar el fósforo total del organismo.

El fósforo es medido de rutina en los laboratorios con técnicas colorimétricas con maquinas automáticas. Los niveles pueden resultar falseados con la hemólisis en el momento de obtención de la muestra. En individuos sanos, existe una variación diurna en los niveles séricos de fósforo y en los niveles de secreción urinaria del mismo. Llegan a su punto más bajo en las primeras horas de la mañana, alcanzan la meseta a las 16:00 h y muestran su pico de 1:00 a 3:00 horas $^{(41)}$.

Un metaanálisis de pacientes con ERCA mostró que por cada $1 \mathrm{mg} / \mathrm{dL}$ más de fósforo existía un $18 \%$ más de probabilidad de mortalidad y que era un factor de riesgo independiente de mortalidad ${ }^{(174)}$.

En las cifras observadas en nuestros grupos son: control $(3.85 \pm 0.50)$, grupo de HD (5.28 \pm 1.44$)$ y en el grupo DP (5.13+1.38). En el estudio OSERCE, basado en pacientes renales en estadio 3-5 que no se encuentran en diálisis, es decir que están en un equivalente estadio renal que nuestro grupo control describe una cifra muy similar a la nuestra ${ }^{(95)}$. OSERCE $(3,9 \pm 0.9)$ vs nuestro grupo control $(3.85 \pm 0.5)$. En el estudio de Kalanter-Zahed et al. donde analiza 58.000 pacientes describe cifras de fósforo de 
$5.5 \pm 0.3$, este mismo autor concluye que unos valores mayores de $6 \mathrm{mg} / \mathrm{dl}$ están relacionados con el aumento de la mortalidad ${ }^{(98)}$.

Nuestras cifras son superiores al estudio realizado en la población española ${ }^{(137)}$. Al igual que ocurría con las cifras de calcio, aunque aparezcan algo elevadas respecto a la literatura siempre se encuentran en el rango deseado $(3.5-5.5 \mathrm{mg} / \mathrm{dl})^{(175-176)}$.

La salida de fósforo de la célula implica la entrada de calcio a la misma, a través de los canales Ca-Fosforo. Por ello se ha utilizado el producto CaxP. La cifra objetivo del producto Calcio-Fósforo es un valor menor de $\left.55 \mathrm{mg}^{2} / \mathrm{dl}^{2}\right)^{(177)}$.

En nuestro caso las cifras en los tres grupos se encuentran dentro del límite de la normalidad. Se observa una diferencia entre grupos, en el grupo control el producto Calcio-Fósforo es menor, lo que se traduce en que existe una menor tasa de desequilibrio del metabolismo mineralo-óseo, esto implica menor aparición de Hiperparatiroidismo y en caso de existir, un mejor control terapéutico.

La limitación del uso del producto Calcio-Fósforo es que el los valores de fósforo fluctúan más que los valores de calcio. La fórmula de CaxP depende en gran medida del fósforo y en general, no proporciona ninguna información más allá que la medida de calcio y fósforo por separado. Aunque se sigue realizando en los estudios de investigación, las últimas guías internacionales no lo aconsejan para la práctica clínica $^{(41)}$.

$\mathrm{Al}$ año los niveles se mantienen en el rango deseado y la diferencia observada en el inicio del estudio se mantiene.

Diferentes estudios han demostrado un incremento de la mortalidad en pacientes con niveles alterados de PTH, bien sean altos o bajos. Sin embargo, no hay una relación causal directa e inequívoca entre la PTH y las lesiones cardiovasculares ${ }^{(178)}$.

Observamos que en nuestros pacientes con TRS presentan diferencias respecto al grupo control, diferencias que también se describen en la literatura ${ }^{(137,177)}$. Se observa que las cifras tanto de los grupos de HD como de DP se encuentran por encima de los objetivos marcados por las guías KDOQUI (150-300 pg/ml $)^{(172)}$. Hecho frecuente en la literatura, en las guías internacionales sobre el manejo del metabolismo mineralo-óseo 
describen que hasta un $80 \%$ de los pacientes presentan alteraciones en los niveles de $\mathrm{PTH}^{(172)}$.

$\mathrm{Al}$ año observamos en los pacientes de nuestro estudio, un descenso de las cifras de PTH tanto en el grupo de HD y DP, consiguiendo el rango deseado en estos últimos. Esta corrección en los niveles puede ser debida a la mayor concienciación del control de estos parámetros por parte de los facultativos responsables.

Las cifras elevadas de fosfatasa alcalina son una variable independiente asociada al aumento de riesgo relativo de mortalidad en los pacientes en diálisis ${ }^{(41)}$. Regidor et al. describe que unos niveles superiores a $120 \mathrm{U} / \mathrm{L}$ o el incremento de $10 \mathrm{U} / \mathrm{L}$ en seis meses, son marcadores de mal pronóstico y asocian mayor mortalidad en los pacientes con $\mathrm{ERCA}^{(179)}$. Sin embargo, no existe evidencia de que reduciendo estos niveles se mejore la supervivencia.

Al contrario que ocurre con la PTH, las cifras de fosfatasa alcalina en nuestros pacientes se sitúa en el rango deseado, sin existir diferencias estadísticamente significativas entre los distintos grupos. Al año se mantiene este buen control e incluso se observa un descenso de las cifras globales.

La etiología más habitual de la enfermedad renal avanzada es la no filiada $(21.1 \%)$, seguida de la nefroangioesclerosis $(19.7 \%)$ y la nefropatía diabética $(8.45 \%)$. En nuestro caso es difícil de definir el origen de la nefropatía ya que son pacientes diagnosticados hace mucho tiempo y se hace difícil indagar cuál fue el origen de la enfermedad renal al no existir un registro sistematizado.

Debido a la elevada media de edad de la población analizada nos encontramos que la nefroangioesclerosis es la causa conocida de enfermedad renal de base, y la nefropatía diabética se sitúa como segunda causa. Datos que coinciden con el estudio NEFRONA ${ }^{(137)}$.

En el registro español de pacientes en DP, se observa una gran variabilidad entre las distintas comunidades autónomas pero en el conjunto del país las causas vascular y diabética, se sitúan en los dos primeros puestos de causa conocida, siendo siempre la primera causa la desconocida ${ }^{(139)}$. 
Para la valoración de las calcificaciones hemos realizado el test de Adragao y Kauppila, ambos útiles para estadios subclínicos de la enfermedad vascular. El test de Adragao valora las calcificaciones mediante radiografía de ambos manos y de pelvis, está diseñado para identificar las calcificaciones vasculares sólo en las arterias musculares como son las iliacas, femoral, radial y digital. Las arterias musculares son más propensas a la calcificación lineal, al contrario que las arterias elásticas que son más propensas a la calcificación intimal.

La aparición de enfermedad vascular en el seguimiento de los pacientes con ERC está claramente asociada con la puntuación de los tests de calcificación ${ }^{(180)}$.

El sexo masculino, la diabetes, la edad, la duración de la hemodiálisis y la tensión arterial media, se asocian independientemente con una puntuación mayor de 3 en el test de Adragao. La puntuación mayor o igual a tres es un predictor independiente de muerte cardiovascular, hospitalizaciones por causa cardiovascular, eventos cardiovasculares $^{(181)}$.

La puntuación de Adagrao es significativamente mayor en el grupo de HD que en el grupo de DP $(p=0.009)$. Una puntuación mayor de 3 en el test de Adragao aparece más frecuentemente en los pacientes de HD, que en el grupo control $(p=0.045)$ o el grupo de DP $(p=0.001)$.

Esta diferencia de puntuación en el test de Adragao es a expensas de las puntuaciones obtenidas en las radiografías de las manos $(p=0.047$ grupo control y $p=0.009$ para DP), no encontrando diferencias en la puntuación de Adragao para la calcificación de las arterias del sector iliofemoral. Dichas diferencias se mantienen tras un año de seguimiento, con escasas variaciones en los valores de las medidas realizadas.

Según Adragao et al., puntuaciones mayores de 3 se asocian a enfermedad coronaria y enfermedad arterial periférica. Esta puntuación es un factor de riesgo independiente para lo anteriormente mencionado. Pacientes con un Adragao mayor de 3 tienen 3.9 más de riesgo de muerte por causa cardiovascular, un 2.8 mayor de riesgo de hospitalización por causa vascular y un 2.3 más de riesgo de evento cardiovascular fatal o no fatal ${ }^{(96)}$. 
Esta misma autora describe en su muestra casi un $47.1 \%$ de puntuaciones mayores de 3, en nuestra muestra el único que se aproxima a esas cifras es el grupo de HD que presenta un $40 \%$ de pacientes con puntuaciones mayores de 3, (en DP 14\% y en Controles 23\%). Lee et al. sin embargo, refiere cifras algo más bajas encontrando un $23.3 \%$ en pacientes de ERCA sin TRS y un $30.2 \%$ en pacientes en diálisis ${ }^{(152)}$.

Llama la atención el pequeño porcentaje de Adragao mayor de 3 que presentan los pacientes en DP, se debe al sesgo de edad, la poca incidencia de DM, ya que se ha descrito que estos factores junto con otros por ejemplo la TA media, sexo masculino se asocian independientemente a puntuaciones mayores de 3 en el test de Adragao.

A pesar de que el test de Adragao es una escala no cuantitativa y por lo tanto no es adecuada para evaluar la progresión de la calcificación, en nuestro estudio se ha repetido al año. Este test ha sido utilizado en algunos estudios como método para evaluar la progresión o regresión de las calcificaciones, comparando las puntuaciones obtenidas en radiografías realizadas en el pasado con radiografías actuales ${ }^{(182)}$. Un año es un periodo de tiempo corto, por lo tanto es normal las puntuaciones de Adragao apenas se modificaran.

El test de Kauppila es un método útil para detectar la calcificación vascular y predecir eventos cardiovasculares. La ventaja que ofrece sobre el test de Adragao es que sirve para valorar la progresión de las calcificaciones ${ }^{(135)}$. El test se basa en la medición de las calcificaciones aórticas (en el segmento de L1 a L4) que se observan en la radiografía lateral de abdomen.

Al igual que para el test de Adragao, la puntuación de Kauppila en nuestra muestra, es mayor en los pacientes en HD que los pacientes del grupo control o de DP $(p=0.011$ y $p=0.000$, respectivamente).

Existen discrepancias de cuál es la puntuación que significa un aumento en la morbimortalidad cardiovascular. En los primeros estudios los pacientes se clasificaban en dos categorías, presencia o ausencia de calcificación ${ }^{(133,183)}$. Estudios posteriores han mostrado que una puntuación de 5 es el punto que aumenta el riesgo de mortalidad $^{(132,}$ 135). 
Para Kwon et al, el punto de corte para la predicción de mortalidad se sitúa en 7.75 con una $\mathrm{S}$ de $61 \%$ y una $\mathrm{E}$ del $81 \%$, por lo que divide a los pacientes en dos grupos, puntuaciones mayores y menores a $8^{(184)}$.

En nuestro estudio las puntuaciones medias de Kauppila al inicio del periodo de recogida de datos fueron de 4.99 para el total de la muestra, en el grupo control fue de 4.44, donde mayor puntuación media se observó fue en el grupo de HD (7.40) y por el contrario donde menor cifra se registro fue en el grupo de DP 1.69.

El valor medio obtenido en el grupo de HD está bastante por encima del punto de corte deseado $(<5)$ por eso, es interesante analizar dentro de este grupo cuántos de estos pacientes están por encima de esta cifra.

Teniendo en cuenta lo anterior, en nuestro estudio hemos analizado cuántos pacientes poseen una puntuación mayor de 4 en el test de Kauppila. Presentan una puntuación mayor de 4 en el test de Kauppila el $48 \%$ de los pacientes en HD, el 28\% en DP y un $41 \%$ del grupo control, encontrando diferencias estadísticamente significativa entre en grupo de HD y DP $(p=0.0 .42)$.

\section{Porcentaje de pacientes con test de calcificación patológicos}

\begin{tabular}{|lcccc|} 
Test & Población total & Grupo control & Grupo HD & Grupo DP \\
\hline Adragao $>\mathbf{3}$ & $27 \%$ & $23 \%$ & $40 \%$ & $14 \%$ \\
Kauppila $\geq \mathbf{5}$ & $41 \%$ & $41 \%$ & $48 \%$ & $28 \%$ \\
ITB $(<\mathbf{0 , 9}$ ó $>\mathbf{1 , 3})$ & $27 \%$ & $17 \%$ & $44 \%$ & $28 \%$ \\
ITB 1 año & & $26 \%$ & $44 \%$ & $42 \%$ \\
$(<\mathbf{0 , 9 0}>\mathbf{1 , 3})$ & & & & \\
\hline
\end{tabular}

Tabla XXVIII: Porcentajes pacientes con tests patológicos de calcificaciones

Vannini et al. ${ }^{(135)}$ describen en su serie, que el $65.3 \%$ de los pacientes presentan calcificación vascular con una puntuación media de $\geq 5$ puntos.

En nuestra muestra la menor puntuación la presenta el grupo de DP. Existen pocos estudios que diferencien entre HD y DP, en los que hacen referencia a estos parámetros describen unas cifras medias de Kauppila de 8.5-9 para los grupos de $\mathrm{DP}^{(185-}$ 186). 
Medias muy superiores a la nuestra, es difícil comparar estos datos, ya que en la mayoría de bibliografía consultada no concretan cuanto tiempo llevan estos pacientes en DP.

Dichas diferencias se mantienen tras un año de seguimiento, con escasas variaciones en los valores de las medidas realizadas. Se observa un aumento de pacientes que presentan índice de Kauppila patológico. Aunque un año parece poco tiempo para medir la progresión de la calcificación en los grandes vasos, Vannini et al. realizó un estudio en el que demostró que la escala Kauppila puede ser útil para la valoración de la progresión de las calcificaciones, obteniendo lo que él denominó incremento de calcificación (puntuación final menos la puntuación inicial) y además encontró que este incremento en un factor independiente de predicción de eventos cardiovasculares $^{(135,184,186)}$.

El Índice Tobillo/ Brazo es un método muy útil para el diagnóstico de la enfermedad arterial periférica incluso en estadios precoces. Es una herramienta ampliamente utilizada y validada para los estudios clínicos y en la práctica médica ${ }^{(187)}$. Un ITB $<0.9$ o $>1.3$ son predictores independientes de muerte por cualquier causa y de muerte por causa cardiovascular ${ }^{(96)}$.

Los pacientes en HD presentaban un mayor ITB en el momento basal $(1.420 \pm 0.544)$ que los pacientes del grupo control $(1.046 \pm 0.368)$ y que los pacientes en DP (1.108 \pm 0.515$)$, de manera estadísticamente significativa $(p=0.000$ y $p=0.017$, respectivamente), esto se explica por la mayor presencia de pacientes con calcinosis en dicho grupo. Dicha diferencia significativa se mantiene con el grupo control tras el año

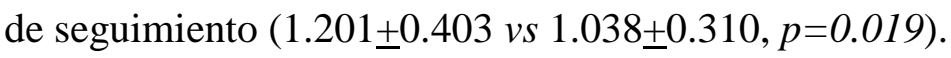

Estas diferencias no se objetivan en la clasificación del ITB, excepto cuando se compara los grupos de HD y DP al año de seguimiento $(0.320 \pm 0.471$ vs $0.080 \pm 0.272$, $p=0.039)$.

En nuestra serie nos encontramos altos porcentajes de ITB patológico (controles 17\%, HD 44\%, DP 21\%), a pesar de que uno de los criterios de exclusión es la enfermedad arterial periférica sintomática. Aun así son cifras concordantes con el 
estudio de Adragao et al. que también se llevó a cabo en pacientes asintomáticos desde el punto de vista de enfermedad arterial periférica ${ }^{(96)}$.

La diferencia entre nuestro grupo de HD y DP puede deberse a la distinta edad media. Se ha demostrado que la edad y la calcificación vascular está directamente asociada con un ITB patológico.

Respecto a las cifras del grupo control (17\% de ITB patológico) concuerdan con las descritas por la NHNES (National Health and Nutrition Examination Survey), en el análisis de 3627 pacientes sin clínica de enfermedad arterial periférica encuentra que un $15 \%$ tiene un ITB $<0.9$; un $83 \%$ un ITB entre $0-9$ y 1.4 y sólo un $2 \%$ presenta un ITB $>14^{(187)}$. El estudio español de Guerrero et al. con pacientes en estadio renal 4-5 que no estaban en TRS ofrece cifras del 19\% de pacientes con EAP; e indica que la mortalidad a 5 años era más alta en pacientes con enfermedad arterial periférica que los pacientes que no la tenían $(64 \% \text { vs } 20 \%)^{(188)}$.

De los pocos estudios que analizan la aparición de enfermedad arterial periférica (ITB anormal) dividiendo a sus pacientes en HD y DP encuentran unas cifras en HD de casi el $22 \%$ frente a $4.8 \%$ en el grupo de DP. Existe diferencia de edad entre los grupos HD y DP, en nuestro estudio también encontramos diferencias entre los grupos de HD y DP aunque no son tan marcadas como en nuestro estudio ${ }^{(189)}$.

El distinto porcentaje al año en la clasificación de ITB, que se observa en los pacientes de DP puede deberse a que existe un sesgo por el pequeño tamaño muestral (basal $7.7 \%$ y al año 25\%), al ser un tamaño muestral pequeño cualquier pequeña variación se traduce en un cambio significativo en el porcentaje.

La ecografía carotídea se utiliza para detectar la enfermedad ateroesclerosa en estadios subclínicos, ya que proporciona medidas del grosor íntima-media (GIM) y determina la presencia de placas de aterosclerosis. Entre las ventajas que encontramos en la ecografía carotídea están que es una técnica no invasiva, relativamente barata y que no comporta irradiación; así pues, esta exploración puede realizarse de manera repetida sin que ello tenga efectos adversos para el sujeto ${ }^{(128,190)}$.

En estudios previos se ha demostrado la asociación del GIM carotídeo con los factores de riesgo cardiovascular y con la incidencia de eventos cardiovasculares ${ }^{(191)}$. 
Concretamente, los resultados de un metaanálisis han mostrado que para una diferencia absoluta del GIM carotídeo de $0.1 \mathrm{~mm}$, el riesgo de un futuro infarto de miocardio aumentaba en un $10-15 \%$ y el riesgo de ictus, un $13-18 \%{ }^{(192)}$.

En nuestro estudio se han medido los siguientes parámetros, GIM en carótida común, bulbo carotídeo y carótida interna, para posteriormente calcular el GIM carotideo (GIM calculado en Carótida Común) y GIM carotideo medio (promedio de los GIM de los seis sectores medidos). También hemos analizado si los pacientes tienen placa o no. La exploración ecográfica se ha realizado al inicio y final del estudio. Definiendo placa como la protusión de la luz de $\geq$ a 0.15 según recomienda la American Society of Echocardiography ${ }^{(190)}$.

Obteniendo unos resultados en el momento basal para el GIM carotídeo en los grupo control, HD y DP de $0.088 \pm 0.034 ; 0.105 \pm 0.034$ y $0.81 \pm 0.044$ respectivamente. Podemos observar que son valores elevados sobretodo en el grupo de HD, superiores a los descritos por el estudio NEFRONA que describe una media de GIM para estadios 45 y $5 \mathrm{D}$ de 0.705 y 0.695 . En este estudio epidemiológico realizado en España la edad media de sus grupos (estadio 4-5: 58.7 \pm 12.3 años y 5D: 53.2 \pm 13 años), es muy inferior a la nuestra (grupo control: 70.79 años y estadio 5D: 66.8 años) ${ }^{(137)}$.Lo mismo ocurre en la revisión que realiza Kokubo et al., donde los estudios que analizan presentan una edad media menor a 64 años, por lo tanto también observa valores de GIM inferiores a los nuestros ${ }^{(193)}$. Sin embargo el GIM medio del grupo de HD coincide con las cifras obtenidas en los estudios de Shi y Yerly ${ }^{(194-195)}$. Por el contrario la cifra que obtenemos en el grupo de DP y la descrita en la literatura es similar ${ }^{(196-197)}$.

Entre nuestros grupos de HD y DP no encontramos diferencias significativas tanto en la medición del GIM, como en la presencia de placas, Shi et al. en su estudio compara pacientes en distintas modalidades de TRS y tampoco encuentra diferencias entre grupos ${ }^{(195)}$.

Respecto a la presencia de placas de ateroma en el sector carotideo, en nuestra muestra más de la mitad del grupo control (55\%) y del grupo de HD (56\%) tienen placa en el momento basal. En el grupo de DP también se observa una cifra cercana al $50 \%$ aunque es algo inferior respecto a los otros grupos (42\%). Cifras tan elevadas o incluso 
mayores aparecen descritas en la literatura ${ }^{(198-199)}$, aunque la mayoría de las series presentan cifras menores ${ }^{(137,196)}$.

En el control al año vemos que existe un aumento tanto en las medidas de GIM como en las de GIM medio, diferencias que son mayores en el grupo de HD.

La mayor variación del GIM medio está en el grupo de HD, a pesar de que el número de pacientes que presentan placas en el territorio carotideo al año es similar al del inicio del estudio. Lo que significa que las placas han ido creciendo pero no han aparecido de novo en aquellos pacientes que no las tenían.

El porcentaje de pacientes con placas carotideas en el momento del inicio del estudio en el grupo de DP es un $42 \%$, pero al año este porcentaje se incrementó hasta situarse en el 57\%. En el grupo control y en HD se mantuvo estable. Es como si los pacientes de HD y grupo control hubieran alcanzado el techo de calcificación y los pacientes de DP que son más jóvenes estuvieran todavía en pleno proceso ateroescleroso.

El GIM femoral se ha investigado menos, pero también se ha asociado con los factores de riesgo tradicionales y con la existencia de EC, con un valor predictivo superior al del GIM carotídeo ${ }^{(200-201)}$.

El GIM Femoral que obtenemos en el inicio del estudio es de $0.136 \mathrm{~mm}$. Analizando por grupos nos encontramos que los pacientes del grupo control $(0.144 \mathrm{~mm})$ y HD $(0.134 \mathrm{~mm})$ poseen cifras más elevadas que el grupo de DP $(0.109 \mathrm{~mm})$. Cifras que comparadas con el estudio de distribución de los valores de GIM F en la población española se sitúan ligeramente por encima. Esto es debido a que nuestra medición se realiza en pacientes renales y no en población general ${ }^{(116)}$. Este mismo estudio analiza el GIM femoral medio y obtiene un valor de $0.166 \mathrm{~mm}$ en la población mayor de 65 años. Valor algo mayor que el obtenido nosotros en nuestra población.

Existen muy poco estudios publicados que utilicen la arteria femoral superficial para valorar la calcificación vascular ${ }^{(202)}$. El estudio NEFRONA ha analizado el porcentaje de personas que tiene placas en el territorio femoral, carotideo y la combinación de ambos. Describen que un $70 \%$ de los pacientes en estadios 4-5 o 5D presentan placas en algún territorio. Los pacientes en diálisis presentan sólo un $20 \%$ de 
placas en carótida y un $11 \%$ en femoral ${ }^{(137)}$.Cifras muy inferiores a las obtenidas en nuestro estudio, que se sitúan en porcentajes mayores al 50\% en ambos territorios, cifras más parecidas a las observadas por Yerly et al. (70\% en carótida y $67.5 \%$ en femoral $)^{(194)}$.

\begin{tabular}{|lcccc|}
\hline Territorio con Placa & Total & Controles & HD & DP \\
\hline Carótida & $53 \%$ & $55 \%$ & $56 \%$ & $42 \%$ \\
Femoral & $65 \%$ & $64 \%$ & $68 \%$ & $64 \%$ \\
En ambos & $45 \%$ & $41 \%$ & $52 \%$ & $42 \%$ \\
Carótida 1 año & $57 \%$ & $58 \%$ & $56 \%$ & $57 \%$ \\
Femoral 1 año & $76 \%$ & $76 \%$ & $84 \%$ & $64 \%$ \\
En ambos 1 año & $50 \%$ & $50 \%$ & $56 \%$ & $42 \%$ \\
\hline
\end{tabular}

Tabla XIX: Lugares en los que se ha encontrado placa

Al año se observa un aumento de los valores de GIM F y de GIM medio en todos los grupos estudiados sin existir diferencias significativas.

\section{Limitaciones del estudio}

Entre las limitaciones de nuestro estudio se encuentra que es unicéntrico observacional, con un tamaño muestral pequeño y un periodo de seguimiento relativamente breve. En la selección de la muestra existe un sesgo debido a que los pacientes en HD pertenecen al ámbito hospitalario; esto implica que estos presentan mayor comorbilidad y edad que aquellos pacientes que realizan la HD en centros no hospitalarios. Otro aspecto que puede condicionar los resultados es que los pacientes control y HD presentaban una mayor edad que los pacientes DP.

Existen muy pocos grupos de trabajo que diferencien entre las distintas modalidades de TRS y estudien la calcificación vascular, por ello se hace difícil compara nuestros resultados con la literatura. 


\section{Futuros estudios}

El estudio continúa abierto realizando el seguimiento de los pacientes. Se repetirán las exploraciones a los 3 años y se incluirán datos de supervivencia. En el momento del análisis de los datos de nuestro estudio no había registrado ningún evento cardiovascular o muerte. Seis meses después ya se han registrado 2 éxitus en el grupo DP y 4 en el grupo HD.

Sería interesante ampliar la muestra incluyendo más centros, y el estudio de un nuevo grupo como son los pacientes trasplantados renales.

Como prueba de diagnóstico precoz de enfermedad ateroesclerosa se puede añadir al estudio pruebas de la rigidez arterial como la Velocidad de la onda de pulso aórtica (PWV). 


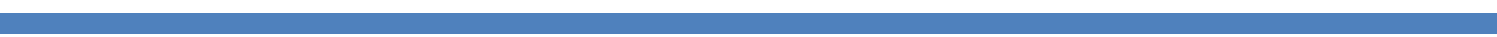


7. CONCLUSIONES 

1. Los pacientes con enfermedad renal avanzada sin enfermedad cardiovascular sintomática presentan una gran prevalencia de HTA, dislipemia y diabetes mellitus.

2. La fracción de eyección de ventrículo izquierdo se encuentra deprimida en los pacientes con enfermedad renal avanzada sin enfermedad cardiovascular sintomática, presentando una elevada prevalencia de hipertrofia del mismo. Esta última es más frecuente en los pacientes en terapia renal sustitutiva con hemodiálisis que en los pacientes en diálisis peritoneal.

3. Las calcificaciones vasculares aórticas, en vasos de pelvis y vasos de las manos son mayores en los pacientes con enfermedad renal terminal sin enfermedad cardiovascular sintomática en terapia renal sustitutiva con hemodiálisis en el momento basal y al año de seguimiento, que en los pacientes en terapia sustitutiva con diálisis peritoneal.

4. Los pacientes con enfermedad renal avanzada sin enfermedad cardiovascular sintomática en terapia renal sustitutiva con hemodiálisis presentan un índices de riesgo de eventos cardiovasculares (Adagrao y Kauppila) más elevados que los tratados con diálisis peritoneal.

5. El índice tobillo-brazo es mayor en los pacientes con enfermedad renal avanzada sin enfermedad cardiovascular sintomática en terapia renal sustitutiva con hemodiálisis en el momento basal y al año de seguimiento que en los pacientes en terapia sustitutiva con diálisis peritoneal.

6. Las mediciones ecográficas (grosor de bulbo carotídeo derecho, grosor de carótida interna derecha, grosor de bulbo carotídeo izquierdo, grosor de carótida interna izquierda, GIMC y GIMC medio) son mayores en los pacientes con enfermedad renal avanzada sin enfermedad cardiovascular sintomática en terapia renal sustitutiva con hemodiálisis en el momento basal y al año de seguimiento, que en los pacientes en terapia sustitutiva con diálisis peritoneal. Además, dichas diferencias aumentan con el seguimiento. 
7. Los parámetros analíticos del metabolismo mineralo-óseo Fósforo e Índice Calcio/Fósforo son menores en los pacientes con enfermedad renal avanzada sin enfermedad cardiovascular sintomática sin terapia renal sustitutiva que en los pacientes en hemodiálisis o en diálisis peritoneal.

8. Los niveles de parathormona en los en los pacientes con enfermedad renal avanzada sin enfermedad cardiovascular sintomática sin terapia renal sustitutiva eran menores que en los pacientes en hemodiálisis o en diálisis peritoneal. Tras un año de seguimiento, dicha diferencia se mantenía exclusivamente en el grupo de pacientes en hemodiálisis.

9. Más de la mitad de los pacientes con enfermedad renal terminal sin enfermedad cardiovascular sintomática presentaban niveles de Vitamina D inferiores a la normalidad en el momento basal y tras un año de seguimiento. 


\section{BIBLIOGRAFÍA}



1. Hoystad M. Historia del corazón: desde la antigüedad hasta hoy. Trapo Ld, editor. Madrid, 2007.

2. Allam A, Mandour A, Wann L, Thompson R, Sutherland M, Sutherland J. Atherosclerosis in ancient and modern Egyptians: the Horus study. Glob Heart 2014;9(2):197-202.

3. O'Donnel C, Elosua R. Factores de riesgo cardiovascular. Perspectivas derivadas del Framingham Heart Study. Rev Esp Cardiol. 2008;61(3):699-310.

4. Oppenheimer GM. Profiling risk: the emergence of coronary heart disease epidemiology in the United States (1947-70). Int J Epidemiol 2006;35(3):720-30.

5. Tendera M. Grupo de Trabajo de Diagnóstico y Tratamiento de las Enfermedades Arteriales Periféricas de la Sociedad Europea de Cardiología.Guía de práctica clínica de la ESC sobre diagnóstico y tratamiento de las enfermedades arteriales periféricas. Rev Esp Cardiol. 2012;65(2):1-57.

6. Cho K, Kim B, Kim H, Heo J. Low Carotid Artery Wall Shear Stress is Associated with Significant Coronary Artery Disease in Patients with Chest Pain. J Atheroscler Thromb. 2015;Epub ahead of print.

7. Steg P, Bhatt D, Wilson P, D'Agostino R, Ohman E, Rother J. Oneyear cardiovascular event rates in outpatients with atherothrombosis. JAMA. 2007;297(11):1197-206.

8. Fuster J, González-Navarro H, A AV, Molina-Sànchez P, Andrés-Manzano M, Nakayama K. Deficient p27 phosphorylation at serine 10 increases macrophage foam cell formation and aggravates atherosclerosis through a proliferation-independent mechanism. Arterioscler Thromb Vasc Biol. 2011;31(11):2455-63.

9. Fernández G, Tardáguila F, López C, Velasco M, Miguel PS, Fuente Adl. Fisiopatología de la placa de ateroma y sus implicaciones en la imagen. Radiología 2003;45(3):107-14. 
10. Stary H, Blankenhorn D, Chandler A, Glagov S, Insull W, Richardson M. A definition of the intima of human arteries and of its atherosclerosis-prone regions. A report from the Committee on Vascular Lesions of the Council on Arteriosclerosis, American Heart Association. Arterioscler Thromb. 1992;12(1):120-34.

11. Helft G, Worthley S, Fuster V, Fayad Z, Zaman A, Corti R. Progression and regression of atherosclerotic lesions. Monitoring with serial noninvasive magnetic resonance imaging. Circulation. 2002;105(8):993-8.

12. Zhao X, Yuan C, Hatsukami T. Effects of prolonged intensive lipid-lowering therapy on the characteristics of carotid atherosclerotic plaques in vivo by MRI. Arterioscler Thromb Vasc Biol. 2001;21(10):1623-29.

13. Rašić S, Rebić D, Hasić S, Rašić I, Šarac MD. Influence of Malondialdehyde and Matrix Metalloproteinase-9 on Progression of Carotid Atherosclerosis in Chronic Renal Disease with Cardiometabolic Syndrome. Mediators Inflamm 2015;2015(1):614357.

14. Yuan C, Zhang S, Polissar N, Echelard D, Ortiz G, Davis J, et al. Identification of fibrous cap rupture with magnetic resonance imaging is highly associated with recent transient ischemic attack or stroke. Circulation. 2002;105(2):181-5.

15. Giachelli C. Vascular calcification mechanisms. J Am Soc Nephrol. 2004;15(12):2959-64.

16. Burke A, Taylor A, Farb A, Malcom G, Virmani R. Coronary calcification: insights from sudden coronary death victims. Z Kardiol 2000;89(Suppl 2):49-53.

17. Edmonds M, Morrison N, Laws J, Watkins P. Medial arterial calcification and diabetic neuropathy. Br Med J (Clin Res Ed). 1982;284(6320):928-30

18. Schwarz U, Buzello M, Ritz E, Stein G, Raabe G, Wiest G, et al. Morphology of coronary atherosclerotic lesions in patients with end-stage renal failure. Nephrol Dial Transplant. 2000;15(2):218-23. 
19. Ibels L, Alfrey A, Huffer W, Craswell P, Anderson J, Weil R. Arterial calcification and pathology in uremic patients undergoing dialysi. Am $\mathrm{J}$ Med. 1979;66(5):790-6.

20. McCullough P, Chinnaiyan K, Agrawal V, Danielewicz E, Abela G. Amplification of atherosclerotic calcification and Monckeberg's sclerosis: a spectrum of the same disease process. Adv Chronic Kidney Dis. 2008;15(4):396-412.

21. Mönckeberg J. Ueber die reine Mediaverlakalkung der Extremitaetenarterien und ihr Verhalten zur Arteriosklerose. Virchows Arch A Pathol Anat Histol. 1903;171(2):141-67.

22. Schoppet M, Fakhri NA, Franke F, Katz N, Barth P, Maisch B, et al. Localization of osteoprotegerin, tumor necrosis factor-related apoptosis-inducing ligand, and receptor activator of nuclear factor-kappa B ligand in Monckeberg's sclerosis and atherosclerosis. J Clin Endocrinol Metab. 2004;89(8):4104-12.

23. Micheletti R, Fishbein G, Currier J, Singer E, Fishbein M. Calcification of the internal elastic lamina of coronary arteries. Mod Pathol. 2008;21(8):1019-28.

24. Valdivielso J. Vascular calcification: types and mechanisms. Nefrologia. 2011;31(2):142-7.

25. Speer M, Giachelli C. Regulation of cardiovascular calcification. Cardiovascular Pathology. 2004;13(2):63-70.

26. Block G, Hulbert-Shearon T, Levin N, Port F. Association of serum phosphorus and calcium $\mathrm{x}$ phosphate product with mortality risk in chronic hemodialysis patients: A national study. Am J Kidney Dis. 1998;31(4):607-17.

27. Proudfoot D, Skepper J, Hegyi L, Bennett M, Shanahan C, Weissberg P. Apoptosis regulates human vascular calcification in vitro - Evidence for initiation of vascular calcification by apoptotic bodies. Circ Res. 2000;87(11):1055-62.

28. Moe S, Duan D, Doehle B, O'Neill K, Chen N. Uremia induces the osteoblast differentiation factor Cbfa1 in human blood vessels. Kidney Int. 2003;63(3):1003-11. 
29. Budoff M, Young R, Lopez V, Kronmal R, Nasir K, Blumenthal R. Progression of coronary calcium and incident coronary heart disease events: the Multi-Ethnic Study of Atherosclerosis. J Am Coll Cardiol. 2013;61(12):1231-39.

30. Budoff M, Hokanson J, Nasir K, Shaw L, Kinney G, D DC. Progression of coronary artery calcium predicts all-cause mortality. JACC Cardiovasc Imaging. 2010;3(12):1229-36.

31. Gassett A, Sheppard L, McClelland R, Olives C, Kronmal R, Blaha M. Risk Factors for Long-Term Coronary Artery Calcium Progression in the Multi-Ethnic Study of Atherosclerosis. J Am Heart Assoc. 2015;4(8).

32. Lahoz C, Mostaza J. La aterosclerosis como enfermedad sistémica. Rev Esp Cardiol. 2007;60(2):184-95.

33. Grau M, Elosua R, León ACd, Guembe M, Baena-Díez JM, al TVAe. Cardiovascular Risk Factors in Spain in the First Decade of the 21st Century,a Pooled Analysis With Individual Data From 11 Population-Based Studies:the DARIOS Study. Rev Esp Cardiol. 2011;64(4):295-304.

34. Serrano FJ, Martín A. Enfermedad arterial periférica: aspectos fisiopatológicos,clínicos y terapéuticos Rev Esp Cardiol. 2007;60(9):969-82.

35. Norgren L, Hiatt W, Dormandy J, Nehler M, Harris K, Fowkes F. Inter-Society Consensus for the Management of Peripheral Arterial Disease (TASC II). J Vasc Surg. 2007;45(Suppl):S5-67.

36. Grau A, Weimar C, Buggle F, Heinrich A, Goertler M, Neumaier S. Risk factors, outcome, and treatment in subtypes of ischemic stroke: the German stroke data bank. Stoke. 2001;32(11):2559-66.

37. Inzitari D, Eliasziw M, Gates P, Sharpe B, Chan R, Meldrum H. North American Symptomatic Carotid Endarterectomy Trial Collaborators. The causes and risk of stroke in patients with asymptomatic internal-carotid-artery stenosis. $\mathrm{N}$ Engl $\mathrm{J}$ Med 2000;342(23):1693-700. 
38. Ferguson G, Eliasziw M, Barr H, Clagett P, Barnes R, Wallace C. The North American Symptomatic Carotid Endarterectomy Trial : surgical results in 1415 patients. Stroke. 1999;30(9):1751-8.

39. Halliday A, Mansfield A, Marro J, Peto C, Peto R, Potter J. Prevention of disabling and fatal strokes by successful carotid endarterectomy in patients without recent neurological symptoms: randomised controlled trial. Lancet. 2004;363(9420):1491-502.

40. Levey A, Coresh J. Chronic kidney disease. Lancet. 2012;379(9811):165-18.

41. KDIGO 2012 Clinical Practice Guideline for the Evaluation and Management of Chronic Kidney Disease. Kidney Int. 2013;3(1):1-308.

42. Gorostidi M, Santamaría R, Alcázar R, Fernández-Fresnedo G, Galcerán J, Goicoechea M. Documento de la Sociedad Española de Nefrología sobre las guías KDIGO para la evaluación y el tratamiento de la enfermedad renal crónica. Nefrologia. 2014;34(3):302-16.

43. Levey A, Coresh J, Balk E, AT AK, A AL, Steffes M. National Kidney Foundation practice guidelines for chronic kidney disease: evaluation, classification, and stratification. Ann Intern Med. 2003;139(2):137-47.

44. Otero A, Gayoso P, Garcia F. Prevalence of chronic renal disease in Spain: results of the EPIRCE study. Nefrologia. 2010;30(1):78-86.

45. Keith D, Nichols G, Gullion C, Brown J, Smith D. Longitudinal follow-up and outcomes among a population with chronic kidney disease in a large managed care organization. Arch Intern Med. 2004;164(6):659-63.

46. Martínez-Castelao A, Górriz-Teruel J, Bover-Sanjuán J, Morena JS-dl, Cebollada J, Escalada J. Documento de consenso para la detección y manejo de la enfermedad renal crónica. Nefrologia. 2014;34(2):243-62.

47. Lorenzo V, Perestelo L, Barroso M, Torres A, Nazco J. Economic evaluation of haemodialysis. Analysis of cost components based on patientspecific data. Nefrologia. 2010;30(4):403-12. 
48. Foley R, Parfrey P, Sarnak M. Epidemiology of cardiovascular disease in chronic renal disease. J Am Soc Nephrol. 1998;9(12 Suppl):S16-23.

49. Herzog C, Asinger R, Berger A, Charytan D, Díez J, RG RH. Cardiovascular disease in chronic kidney disease. A clinical update from Kidney Disease: Improving Global Outcomes (KDIGO). Kidney Int 2011;80(6):572-86.

50. Gluba-Brzózka A, Michalska-Kasiczak M, Franczyk B, Nocuń M, Toth P, Banach M, et al. Markers of increased atherosclerotic risk in patients with chronic kidney disease: a preliminary study. Lipids Health Dis. 2016;15(1):22.

51. Vanholder R, Massy Z, Argiles A, Spasovski G, Verbeke F, N NL. Chronic kidney disease as cause of cardiovascular morbidity and mortality. Nephrol Dial Transplant. 2005;20(6):1048-56.

52. Hyre A, Fox C, Astor B, AJ AC, Muntner P. The impact of reclassifying moderate $\mathrm{CKD}$ as a coronary heart disease risk equivalent on the number of US adults recommended lipid-lowering treatment. Am J Kidney Dis. 2007;49(1):37-45.

53. López-Gómez J, Jofré R, Cases A. Cardiovascular risk factors in chronic renal failure. Nefrologia. 2002;22(Suppl 1):59-67.

54. Shinaberger J. Quantitation of dialysis: historical perspective. Semin Dial. 2001;14(4):238-45.

55. Sellarés L. Principios físicos: definiciones y conceptos. Nefrología. 2012;6(1):355-67.

56. Gibney R, Kimmel P, Lazarus M. The Acute Dialysis Quality Initiative--part I: definitions and reporting of CRRT techniques. Adv Ren Replace Ther. 2002;9(4):252-4.

57. Struijk D. Peritoneal Dialysis in Western Countries. Kidney Dis. 2015;1(3):15764.

58. Rabindranath K, Adams J, Ali T, Daly C, Vale L, Macleod A. Automated vs continuous ambulatory peritoneal dialysis: a systematic review of randomized controlled trials. Nephrol Dial Transplant. 2007;22(10):2991-8. 
59. Cnossen T, Smit W, Konings C, Kooman J, Leunissen K, Krediet R. Quantification of free water transport during the peritoneal equilibration test. Perit Dial Int. 2009;29(5):523-7.

60. Grothe C, Taminato M, Belasco A, Sesso R, Barbosa D. Prophylactic treatment of chronic renal disease in patients undergoing peritoneal dialysis and colonized by Staphylococcus aureus: a systematic review and meta-analysis. BMC Nephrol. 2016;17(1):115.

61. Jager K, Korevaar J, Dekker F, Krediet R, Boeschoten E. The effect of contraindications and patient preference on dialysis modality selection in ESRD patients in The Netherlands. Am J Kidney Dis. 2004;43(5):891-9.

62. Kaul P, McAlister F, Ezekowitz J, Grover V, Quan H. Ethnic differences in 1year mortality among patients hospitalised with heart failure. Heart. 2011;97(13):104853.

63. Chaturvedi N. Ethnic differences in cardiovascular disease. Heart. 2003;89(6):681-6.

64. arterial Geh. Estratificación y valoración del riesgo cardiovascular. Hipertensión 2005;22(Supl 2):9-15.

65. Hirsch A, Haskal Z, Hertzer N, Bakal C, Creager M, Halperin J. ACC/AHA 2005 Practice Guidelines for the management of patients with peripheral arterial disease (lower extremity, renal, mesenteric, and abdominal aortic): a collaborative report from the American Association for Vascular Surgery/Society for Vascular Surgery, Society for Cardiovascular Angiography and Interventions, Society for Vascular Medicine and Biology, Society of Interventional Radiology, and the ACC/AHA Task Force on Practice Guidelines (Writing Committee to Develop Guidelines for the Management of Patients With Peripheral Arterial Disease): endorsed by the American Association of Cardiovascular and Pulmonary Rehabilitation; National Heart, Lung, and Blood Institute; Society for Vascular Nursing; TransAtlantic Inter-Society Consensus; and Vascular Disease Foundation. Circulation. 2006;113(11):e463-654. 
66. Khosla S, Laddu A, Ehrenpis S. Cardiovascular effects of nicotine: Relation to deleterious effects of cigarette smoking. Am Heart J. 1994;127(6):1669-72.

67. Craig W, Palomaki G, Haddow J. Cigarette smoking and serum lipid and lipoprotein concentration; an analysis of published data. BMJ. 1989;298(6676):784-8.

68. Yarnell J, Baker I, Sweetnam P. Fibrinogen, viscosity and white blood cell count are major risk factors for ischemic heart disease. The Caerphilly and Speedwell Collaborative Heart Disease Studies. Circulation. 1991;83(3):836-44.

69. Tonnesen P, Carrozzi L, Fagerström K, Gratziou C, Jimenez-Ruiz C, Nardini S. Task Force recommendations smoking cessation in patients with respiratory diseases: a high priority, integral component of therapy. Eur Respir J. 2007;29(2):390-427.

70. Expert, Panel, on, Detection, Evaluation. And Treatment of High Blood Cholesterol In Adults. Executive Summary of The Third Report of The National Cholesterol Education Program (NCEP). JAMA. 2001;285(19):2486-97.

71. Sánchez-Recalde A, Kaski JC. Diabetes mellitus, inflammation and coronary atherosclerosis: current and future perspectives. Rev Esp Cardiol. 2001;54(6):751-63.

72. Park G, An H, Lee S, Cho Y, Gil E, Her S. Impact of Metabolic Syndrome on Subclinical Atherosclerosis in Asymptomatic Individuals. Circ J. 2015;79(8):1799-806.

73. Selvin E, Marinopoulos S, Berkenblit G, Rami T, Brancari F, Powe N. Metaanalysis glycosylated hemoglobin and cardiovascular disease in diabetes mellitus. Ann Intern Med. 2004;141(6):421-31.

74. Muntner P, Wildman R, Reynolds K, Desalvo K, Chen J, Fonseca V. Relationship between HbA1c level and peripheral arterial disease. Diabetes care. 2005;28(8):1981-7.

75. American, Diabetes, Association. Peripheral arterial disease in people with diabetes. Diabetes care 2003;26(12):3333-41. 
76. Lloyd-Jones J, Hong Y, Labarthe D, Mozaffarian D, Appel L, Hon LV. Defining and Setting National Goals for Cardiovascular Health Promotion and Disease Reduction and disease reduction: the American Heart Association's strategic Impact Goal through 2020 and beyond. Circulation. 2010;2(4):586-613.

77. Yusuf S, Sleight P, Pogue J, Bosch J, Davies R, Dagenais G. Effects of an angiotensinconverting-enzyme inhibitor, ramipril, on cardiovascular events in high-risk patients. The Heart Outcomes Prevention Evaluation Study Investigators. N Engl J Med. 2000;342(3):145-53.

78. Yusuf S, Teo K, Pogue J, Dyal L, Copland I, Schumacher H. Telmisartan,ramipril, or both in patients at high risk for vascular events. . N Engl J Med. 2008;358(15):1547-59.

79. Poldermans D, Bax J, Boersma E, Hert SD, Eeckhout E, Fowkes G. Guidelines for preoperative cardiac risk assessment and perioperative cardiac management in noncardiac surgery: the Task Force for Preoperative Cardiac Risk Assessment and Perioperative Cardiac Management in Non-cardiac Surgery of the European Society of Cardiology (ESC) and European Society of Anaesthesiology (ESA). . Eur Heart J 2009;30(22):2769-812.

80. Radack K, Deck C. Beta-adrenergic blocker therapy does not worsen intermittent claudication in subjects with peripheral arterial disease. A meta-analysis of randomized controlled trials. Arch Intern Med. 1991;151(9):1769-76.

81. Aronow W, Ahn C. Effect of beta blockers on incidence of new coronary events in older persons with prior myocardial infarction and symptomatic peripheral arterial disease. Am J Cardiol. 2001;87(11):1284-6.

82. Mascarenhas J, Albayati M, Shearman C, Jude E. Peripheral arterial disease. Endocrinol Metab Clin North Am. 2014;43(1):149-66.

83. Grundy S, Pasternak R, Greenland P, Smith S, Fuster V. Assessment of cardiovascular risk by use of multiple-risk-factor assessment equations: a statement for healthcare professionals from the American Heart Association and the American College of Cardiology. Circulation. 1999;100(13):1481-92. 
84. Collins R, Armitage J, Parish S, Sleigh P, Peto R. MRC/BHF Heart Protection Study of cholesterol-lowering with simvastatin in 5963 people with diabetes: a randomised placebo-controlled trial. Lancet. 2003;361(9374):2005-16.

85. Reiner Z, Catapano A, Backer GD, Graham I, Taskinen M, Wiklund O, et al. ESC/EAS Guidelines for the management of dyslipidaemias: the Task Force for the management of dyslipidaemias of the European Society of Cardiology (ESC) and the European Atherosclerosis Society (EAS). Eur Heart J. 2011;32(14):1769-818.

86. Engeland A, Bjorge T, Sogaard A, Tverdal A. Body mass index in adolescence in relation to total mortality: 32-year follow up of 227,000 Norwegian boys and girls. Am J Epidemiol. 2003;157:517-23.

87. Smulders Y, Heijer Md, Blom H. Homocysteine levels: measure or not? Ned Tijdschr Geneeskd. 2013;157(44):A6265.

88. O'Hare A, Vittinghoff E, Hsia J, Shlipak M. Renal insufficiency and the risk of lower extremity peripheral arterial disease: results from the Heart and Estrogen/Progestin Replacement Study (HERS). J Am Soc Nephrol. 2004;15(4):104651.

89. Anavekar N, McMurray J, Velazquez E, Solomon S, Kobert L, Rouleau J, et al. Relation between renal dysfunction and cardiovascular outcomes after myocardial infarction. N Engl J Med. 2004;351(13):1285-95.

90. Gorostidi. M. La insuficiencia renal como nuevo factor de riesgo cardiovascular. Riesgo vascular ligado a la microalbuminuria. Nefrologia. 2004;24(Supl 6):47-61.

91. Kahn M, Robbins M, Kim M, Fuster V. Management of cardiovascular disease in patients with kidney disease. Nat Rev Cardiol. 2013;10(5):261-73.

92. Krintus M, Kozinski M, Kubica J, Sypniewska G. Critical appraisal of inflammatory markers in cardiovascular risk stratification. Crit Rev Clin Lab Sci. 2014;51(5):263-79. 
93. Liu Y, Zhang H, Zhang K, Liu J, Zhou L, Liao X, et al. Metabolic status and personality affect the prognosis of patients with continuous ambulatory peritoneal dialysis. Int J Clin Exp Med. 2015;8(1):440-7.

94. Puz P, Lasek-Bal A, Ziaja D, Kazibutowska Z, Ziaja K. Inflammatory markers in patients with internal carotid artery stenosis. Arch Med Sci. 2013;9(2):254-60.

95. Górriz J, Molina P, Bover J, Barril G, Francisco AM-d, Caravaca F, et al. Characteristics of bone mineral metabolism in patients with stage 3-5 chronic kidney disease not on dialysis: results of the OSERCE study. Nefrologia. 2013;33(1):46-60.

96. Adragao T, Pires A, Branco P, Castro R, Oliveira A, Nogueira C, et al. Ankle-brachial index, vascular calcifications and mortality in dialysis patients. Nephrol Dial Transplant 2012;27(1):318-2.

97. Gioia MCD, Gascuena R, Gallar P, Cobo G, Camacho R, Acosta N, et al. Echocardiographic findings in haemodialysis patients according to their state of hydration. Nefrologia. 2016;16(5):1-7.

98. Kalantar-Zadeh K, Block G, Humphreys M, Kopple J. Reverse epidemiology of cardiovascular risk factors in maintenance dialysis patients. Kidney Int. 2003;63(3):793808.

99. Iimori S, Naito S, Noda Y, Nishida H, Kihira H, Yui N, et al. Anaemia management and mortality risk in newly visiting patients with chronic kidney disease in Japan: The CKD-ROUTE study. Nephrology 2015;20(9):601-8.

100. Kramann R, Floege J, Ketteler M, Marx N, Brandenburg V. Medical options to fight mortality in end-stage renal disease: a review of the literature. Nephrol Dial Transplant. 2012;27(12):4298-307.

101. Fouque D, Kalantar-Zadeh K, Kopple J, Cano N, Chauveau P, Cuppari L, et al. A proposed nomenclature and diagnostic criteria for protein-energy wasting in acute and chronic kidney disease. Kidney Int. 2008;73(4):391-8. 
102. As'habi A, Tabibi H, Hedayati M, Mahdavi-Mazdeh M, Nozary-Heshmati B. Association of malnutrition-inflammation score, dialysis-malnutrition score and serum albumin with novel risk factors for cardiovascular diseases in hemodialysis patients. Ren Fail. 2015;37(1):113-6.

103. Bonanni A, Mannucci I, Verzola D, Sofia A, Saffioti S, Gianetta E, et al. Protein-energy wasting and mortality in chronic kidney disease. Int $\mathbf{J}$ Environ Res Public Health. 2011;8(5):1631-54.

104. Wachtell K, Hornestam B, Lehto M, Slotwiner D, Gerdts E, Olsen M. Cardiovascular morbidity and mortality in hypertensive patients with a history of atrial fibrillation: The Losartan Intervention For End Point Reduction in Hypertension (LIFE) study. J Am Coll Cardiol. 2005;45(5):705-11.

105. Minguela JI, Hernando A, Gallardo I, Martínez I, García P, Muñoz R. La hiperuricemia como factor de riesgo cardiovascular y renal. Dial Traspl. 2011;32(2):57-61.

106. Perlstein T, Gumieniak O, Williams G, Sparrow D, Vokonas P, Gaziano M. Uric Acid and the Development of Hypertension - The Normative Aging Study. Hypertension. 2006;48(6):1031-6.

107. Høieggen A, Alderman M, Kjeldsen S, Julius S, Devereux R, Faire UD. The impact of serum uric acid on cardiovascular outcomes in the LIFE study. Kidney Int. 2004;65(3):1041-9.

108. Alegría E, Alijarde M, Cordo J, Chorro F, Pajarón A. Utilidad de la prueba de esfuerzo y de otros métodos basados en el electrocardiograma en la cardiopatía isquémica crónica. Rev Esp Cardiol. 1997;50(1):6-14.

109. Vlachopoulos C, Xaplanteris P, Aboyans V, Brodmann M, Cífkov R, Cosentino F. The role of vascular biomarkers for primary and secondary prevention.A position paper from the European Society of Cardiology Working Group on peripheral circulation. Atherosclerosis. 2015;241(2):507-32. 
110. Narula A, Benenstein R, Duan D, Zagha D, Li L, Choy-Shan A. Ankle-Brachial Index Testing at the Time of Stress Testing in Patients Without Known Atherosclerosis. Clin Cardiol. 2016;39(1):24-9.

111. Fortuñoa J, Perendreua J, Falcoa J, Canovas D, Branera J. Estenosis carotídea: cómo se diagnostica y se trata adecuadamente. Radiología. 2006;48(3):119-36.

112. Qu B, Qu T. Causes of changes in carotid intima-media thickness: a literature review. Cardiovasc Ultrasound. 2015;13(1):46.

113. Bedi U, Singh M, Singh P, Bhuriya R, Bahekar A, Molnar J. Effects of statins on progression of carotid atherosclerosis as measured by carotid intimal--medial thickness: a meta-analysis of randomized controlled trials. J Cardiovasc Pharmacol Ther. 2010;15(3):268-73.

114. Niu L, Zhang Y, Qian M, Meng L, Xiao Y, Wang Y. Impact of multiple cardiovascular risk factors on carotid intima-media thickness and elasticity. PLoS One. 2013;8(7):e67809.

115. Yerly P, Rodondi N, Viswanathan B, Riesen W, Vogt P, Bovet P. Association between conventional risk factors and different ultrasound-based markers of atherosclerosis at carotid and femoral levels in a middle-aged population. Int $\mathrm{J}$ Cardiovasc Imaging. 2013;29(3):589-99.

116. Junyent M, Gilabert R, Núñez I, Corbell E, Cofána M, Zambón D, et al. Ecografía femoral en la evaluación de la aterosclerosis preclínica. Distribución de valores del grosor íntima-media y frecuencia de placas de ateroma en una cohorte comunitaria española Med Clin. 2008;131(15):566-71.

117. Mancia G, Fagard R, Narkiewicz K, Redon J, Zanchetti A, Böhm M, et al. Task Force for the Management of Arterial Hypertension of the European Society of Hypertension and the European Society of Cardiology. 2013 ESH/ESC Practice Guidelines for the Management of Arterial Hypertension. Blood Press. 2014;23(1):3-16. 
118. Greenland P, Alpert J, Beller G, Benjamin E, Budoff M, Fayad Z. 2010 ACCF/AHA guideline for assessment of cardiovascular risk in asymptomatic adults: a report of the American College of Cardiology Foundation/American Heart Association Task Force on Practice Guidelines. Circulation. 2010;122(25):e584-636.

119. Muñoz J, Aranda P. Técnicas de imagen en la enfermedad aórtica. Cir Cardiov. 2009;16(4):299-304.

120. Ruehm S, Goyen M, Barkhausen J, Kroger K, BosK S, Ladd M. Rapid magnetic resonance angiography for detection of atherosclerosis. Lancet. 2001;357(9262):108691.

121. Goyen M, Quick H, Debatin J, Ladd M, Barkhausen J, Herborn C, et al. Wholebody three-dimensional MR angiography with a rolling table platform: initial clinical experience. Radiology. 2002;224(1):270-7.

122. Gotschy A, Niemann M, Kozerke S, Lüscher T, Manka R. Cardiovascular magnetic resonance for the assessment of coronary artery disease. Int $\mathrm{J}$ Cardiol. 2015;193:84-92.

123. Leskinen Y, Groundstroem K, Virtanen V, Lehtimäki T, Huhtala H, Saha H. Prediction of coronary artery disease by transesophageal echocardiographic detection of thoracic aortic plaque in patients with chronic kidney disease. Nephron Clin Pract. 2006;103(4):c157-61.

124. Szmigielski C, Styczyński G, Sobczyńska M, Milewska A, Placha G, KuchWocial A. Pulse wave velocity correlates with aortic atherosclerosis assessed with transesophageal echocardiography. J Hum Hypertens. 2016;30(2):90-4.

125. Unagami K, Nitta K, Tago K, Matsushita K. Relationship Between Diastolic Dysfunction and Atherosclerosis and Vascular Calcification in Hemodialysis Patients: Diagnostic Potential of the Cardio-Ankle Vascular Index. Ther Apher Dial. 2016:Epub ahead of print.

126. Noce J. Fundamentals of diagnostic ultrasonography. Biomed Instrum Technol. 1990;24(6):456-9. 
127. Paspulati R, Bhatt S. Sonography in benign and malignant renal masses. Radiol Clin North Am. 2006;44(6):787-803.

128. Grau M, Subiran I, Agis D, Ramos R, Basagan X, Martí R, et al. Grosor íntimamedia carotídeo en población española : valores de referencia y asociación con los factores de riesgo cardiovascular. Rev Esp Cardiol. 2012;65(12):1086-93.

129. Suurküla M, Fagerberg B, Wendelhag I, Agewall S, Wikstrand J. Atherosclerotic disease in the femoral artery in hypertensive patients at high cardiovascular risk. The value of ultrasonographic assessment of intima-media thickness and plaque occurrence. Risk Intervention Study (RIS) Group. Arterioscler Thromb Vasc Biol. 1996;16(8):971-7.

130. Chasco J. El ecocardiograma. Imagen Diagn 2010;1(1):14-8.

131. Kauppila L, Polak J, Cupples L, Hannan M, Kiel D, Wilson P. New indices to classify location, severity and progression of calcific lesions in the abdominal aorta: a 25-year follow-up study. Atherosclerosis. 1997;132(2):245-50.

132. Verbeke F, Biesen WV, Honkanen E, Wikström B, Jensen P, Krzesinski J, et al. Prognostic value of aortic stiffness and calcification for cardiovascular events and mortality in dialysis patients: outcome of the calcification outcome in renal disease (CORD) study. Clin J Am Soc Nephrol. 2011;6(1):153-9.

133. Okuno S, Ishimura E, Kitatani K, Fujino Y, Kohno K, Maeno Y, et al. Presence of abdominal aortic calcification is significantly associated with all-cause and cardiovascular mortality in maintenance hemodialysis patients. Am J Kidney Dis. 2007;49(3):417-25.

134. Prados-Garrido M, Bover J, González-Álvarez M, Hervás J, Ocharan-Corcuera J, Foraster A, et al. 2010 - Guía de práctica clínica de la Sociedad Española de Diálisis y Trasplante de las alteraciones del metabolismo mineral y óseo de la enfermedad renal crónica (CKD-MBD). Dial Traspl 2011;32(3):108-18.

135. Vannini F, Teixeira A, Caramori J, Martin L, Barretti P. Is Kauppila method able to detect the progression of vascular calcification and predict cardiovascular events in patients undergoing hemodialysis? Clin Nephrol. 2016 85(2):84-91. 
136. Adragao T, Pires A, Lucas C, Birne R, Magalhaes L, Gonçalves M, et al. A simple vascular calcification score predicts cardiovascular risk in haemodialysis patients. Nephrol Dial Transplant. 2004;19(6):1480-8.

137. Arroyo D, Betriu A, Martinez-Alonso M, Vidal T, Valdivielso J, Fernández E, et al. Observational multicenter study to evaluate the prevalence and prognosis of subclinical atheromatosis in a Spanish chronic kidney disease cohort: baseline data from the NEFRONA study. BMC Nephrol. 2014;15(168):1-10.

138. Go A, Chertow G, Fan D, McCulloch C, Hsu C. Chronic kidney disease and the risks of death, cardiovascular events, and hospitalization. $\mathrm{N}$ Engl $\mathrm{J}$ Med. 2004;351(13):1296-305.

139. Remón-Rodríguez C, Quirós-Ganga P, Portolés-Pérez J, Gómez-Roldán C, Miguel-Carrasco A, Borràs-Sans M, et al. Results of the cooperative study of Spanish peritoneal dialysis registries: analysis of 12 years of follow-up. Nefrologia. 2014;34(1):18-33.

140. Wolfgram D, Szabo A, Murray A, Whittle J. Risk of dementia in peritoneal dialysis patients compared with hemodialysis patients. Perit Dial Int. 2015;35(2):18998.

141. Fu J, Huang J, Lei M, Luo Z, Zhong X, Huang Y, et al. Prevalence and Impact on Stroke in Patients Receiving Maintenance Hemodialysis versus Peritoneal Dialysis: A Prospective Observational Study. PLoS One. 2015 10(10):1-10.

142. Wu B, Wang M, Gan L, Zhao H. Comparison of patient survival between hemodialysis and peritoneal dialysis in a single Chinese center. Int Urol Nephrol. 2014;46(12):2403-7.

143. Iseki K. Epidemiology of dyslipidemia in chronic kidney disease. Clin Exp Nephrol 2014;18(2):185-8.

144. Massy Z, Zeeuw Dd. LDL cholesterol in CKD--to treat or not to treat? Kidney Int 2013;84(3):451-6. 
145. Palmer S, Craig J, Navaneethan S, Tonelli M, Pellegrini F, Strippoli G. Benefits and harms of statin therapy for persons with chronic kidney disease: a systematic review and meta-analysis. Ann Intern Med. 2012;157(4):263-75.

146. Bansal N, Hsu C, Go A. Intersection of cardiovascular disease and kidney disease: atrial fibrillation. Curr Opin Nephrol Hypertens. 2014;23(3):275-82.

147. Korantzopoulos P, Liu T, Letsas K, Fragakis N, Kyrlas K, Goudevenos J. The epidemiology of atrial fibrillation in end-stage renal disease. J Nephrol. 2013 26(4):61723.

148. Genovesi S, Vincenti A, Rossi E, Pogliani D, Acquistapace I, Stella A, et al. Atrial fibrillation and morbidity and mortality in a cohort of long-term hemodialysis patients. Am J Kidney Dis. 2008;51(2):255-62.

149. Tsagalis G, Bakirtzi N, Manios E, Chouliaras I, Papagiannidou P, Stamellou E, et al. Atrial fibrillation in chronic hemodialysis patients: prevalence, types, predictors, and treatment practices in Greece. Artif Organs. 2011;35(10):916-92.

150. Zimmerman D, Sood M, Rigatto C, Holden R, Hiremath S, Clase C. Systematic review and meta-analysis of incidence, prevalence and outcomes of atrial fibrillation in patients on dialysis. Nephrol Dial Transplant. 2012 27(10):3816-2.

151. Alonso, Gómez. What should nephrologists know about cardiac illnesses in patients on peritoneal dialysis? Nefrologia. 2008;28(Suppl 6):105-12.

152. Dahal K, Kunwar S, Rijal J, Schulman P, Lee J. Stroke, Major Bleeding, and Mortality Outcomes in Warfarin Users With Atrial Fibrillation and Chronic Kidney Disease: A Meta-Analysis of Observational Studies. Chest. 2016;149(4):951-9.

153. Charytan D. Is left ventricular hypertrophy a modifiable risk factor in end-stage renal disease. Curr Opin Nephrol Hypertens 2014;23(6):578-85.

154. Colbert G, Jain N, Lemos Jd, Hedayati S. Utility of traditional circulating and imaging-based cardiac biomarkers in patients with predialysis CKD. Clin J Am Soc Nephrol. 2015;10(3):515-29. 
155. Takeda A, Toda T, Iwamoto H, Watanabe K, Matsui N. Long-term evolution and changing associations of left ventricular hypertrophy after starting hemodialysis. Nephron Clin Pract. 2008;110(2):126-32.

156. Wang A, Brimble $\mathrm{K}$, Brunier G, Holt S, Jhan V, Johnson D, et al. ISPD Cardiovascular and Metabolic Guidelines in Adult Peritoneal Dialysis Patients Part II Management of Various Cardiovascular Complications. Perit Dial Int. 2015;35(4):38896.

157. Palmer S, Micco LD, Razavian M, Craig J, Ravani P, Perkovic V, et al. Antiplatelet therapy to prevent hemodialysis vascular access failure: systematic review and meta-analysis. Am J Kidney Dis. 2013;61(1):112-22.

158. Tanios B, Itani H, Zimmerman D. Clopidogrel use in end-stage kidney disease. Semin Dial. 2015;28(3):276-81.

159. Kim S, Bang O. Antiplatelet therapy for preventing stroke in patients with chronic kidney disease. Contrib Nephrol. 2013;179(3):119-29.

160. Goldstein L, Bushnell C, Adams R, Appel L, Braun L, Chaturvedi S. Guidelines for the primary prevention of stroke: a guideline for healthcare professionals from the American Heart Association/American Stroke Association. Stroke. 2011;42:517-84.

161. Palmer S, Micco LD, Razavian M, Craig J, Perkovic V, Pellegrini F. Effects of antiplatelet therapy on mortality and cardiovascular and bleeding outcomes in persons with chronic kidney disease: a systematic review and meta-analysis. . Ann Intern Med. 2012;156(4):445-59.

162. Palmer S, Craig J, Navaneethan S, Tonelli M, Pellegrini F, Strippoli G. Benefits and harms of statin therapy for persons with chronic kidney disease: a systematic review and meta-analysis. Ann Intern Med. 2012;157(4):263-75.

163. Taler S, Agarwal R, Bakris G, Flynn J, Nilsson P, Rahman M. KDOQI US commentary on the 2012 KDIGO clinical practice guideline for management of blood pressure in CKD. Am J Kidney Dis. 2013;62(2):201-13. 
164. Heaney R, Davies K, Chen T, Holick M, Barger-Lux M. Human serum 25hydroxycholecalciferol response to extended oral dosing with cholecalciferol. Am J Clin Nutr. 2003;77(1):204-10.

165. Wang F, Wu S, Ruan Y, Wang L. Correlation of serum 25-hydroxyvitamin D level with vascular calcification in hemodialysis patients. Int J Clin Exp Med. 2015;8(9):15745-51.

166. Pavlovic D, Katicic D, Gulin T, Josipovic J. Vitamin d in the patients with chronic kidney disease: when, to whom and in which form. Mater Sociomed. 2015 27(2):122-4.

167. Jean G, Chazot C. The French clinician's guide to the Kidney disease: Improving global outcomes (KDIGO) for chronic kidney disease-mineral and bone disorders (CKD-MBD). Nephrol Ther. 2010;6(3):151-7.

168. Vervloet M, Buf-Vereijken Pd, Loon BPv, Manamley N, Reichert L, Gregoor PS. Cinacalcet for secondary hyperparathyroidism: from improved mineral levels to improved mortality? Neth J Med. 2013;71(7):348-54.

169. Wheeler D, London G, Parfrey P, Block G, Correa-Rotter R, Dehmel B, et al. Effects of cinacalcet on atherosclerotic and nonatherosclerotic cardiovascular events in patients receiving hemodialysis: the EValuation Of Cinacalcet $\mathrm{HCl}$ Therapy to Lower CardioVascular Events (EVOLVE) trial. J Am Heart Assoc. 2014;3(6):1363-74.

170. Raggi P, Chertow G, Torres P, Csiky B, Naso A, Nossuli K, et al. The ADVANCE study: a randomized study to evaluate the effects of cinacalcet plus lowdose vitamin D on vascular calcification in patients on hemodialysis. Nephrol Dial Transplant. 2011;26(4):1327-39.

171. Tentori F, Blayney M, Albert J. Mortality risk for dialysis patients with different levels of serum calcium, phosphorus, and PTH: the Dialysis Outcomes and Practice Patterns Study (DOPPS). Am J Kidney Dis 2008;52(3):519-30. 
172. Uhlig K, Berns J, Kestenbaum B, Kumar R, Leonard M, Martin K. KDOQI US commentary on the 2009 KDIGO Clinical Practice Guideline for the Diagnosis, Evaluation, and Treatment of CKD-Mineral and Bone Disorder (CKD-MBD). Am J Kidney Dis. 2010;55(5):773-99.

173. Noordzij M, Korevaar J, Dekker F, Boeschoten E, Bos W, Krediet R, et al. Mineral metabolism and mortality in dialysis patients: a reassessment of the K/DOQI guideline. Blood Purif. 2008;26(3):231-7.

174. Palmer S, Hayen A, Macaskill P, Pellegrini F, Craig J, Elder G, et al. Serum levels of phosphorus, parathyroid hormone, and calcium and risks of death and cardiovascular disease in individuals with chronic kidney disease: a systematic review and meta-analysis. JAMA. 2011;305(11):1119-27.

175. Evenepoel P, Meijers B, Bammens B, Viaene L, Claes K, Sprangers B. Phosphorus metabolism in peritoneal dialysis- and haemodialysis-treated patients. Nephrol Dial Transplant. 2016 31(9):1508-14.

176. Rhee C, Molnar M, Lau W, Ravel V, Kovesdy C, Mehrotra R, et al. Comparative mortality-predictability using alkaline phosphatase and parathyroid hormone in patients on peritoneal dialysis and hemodialysis. Perit Dial Int. 2014;34(7):732-48.

177. Moe S, Drüeke T. Management of secondary hyperparathyroidism: the importance and the challenge of controlling parathyroid hormone levels without elevating calcium, phosphorus, and calcium-phosphorus product. Am J Nephrol. 2003;23(6):369-79.

178. Rodríguez N, Jiménez I, Méndez C, Canal C, Lloret M, Pozo MD, et al. Diagnóstico y tratamiento de las alteraciones oseominerales asociadas a la enfermedad renal crónica. Dial Traspl. 2010;3(31):79-85.

179. Regidor D, Kovesdy C, Mehrotra R, Rambod M, Jing J, McAllister C, et al. Serum alkaline phosphatase predicts mortality among maintenance hemodialysis patients. J Am Soc Nephrol. 2008;19(11):2193-203. 
180. Adragao T, Pires A, Lucas C, Birne R, Magalhaes L, Gonçalves M, et al. A simple vascular calcification score predicts cardiovascular risk in haemodialysis patients. Nephrol Dial Transplant. 2004;19(6):1480-8.

181. Adragao T, Pires A, Birne R, Dias J, Lucas C, Goncalves M, et al. A plain X-ray vascular calcification score is associated with arterial stiffness and mortality in dialysis patients. Nephrol Dial Transplant. 2009;24(3):997-1002.

182. Goldsmith D, Covic A, Sambrook P, P PA. Vascular calcification in long-term haemodialysis patients in a single unit: a retrospective analysis. Nephron. 1997;77(1):37-43.

183. Honkanen E, Kauppila L, Wikström B, Rensma P, Krzesinski J, Aasarod K, et al. Abdominal aortic calcification in dialysis patients: results of the CORD study. Nephrol Dial Transplant. 2008;23(12):4009-15.

184. Kwon H, Lee O, Kim M, Joo W, Lee S, Kim M, et al. The association between mortality and abdominal aortic calcification and relation between its progression and serum calcium concentration in chronic hemodialysis patients. Kidney Res Clin Pract. 2014;33(2):95-102.

185. Martino F, Loreto PD, Giacomini D, Kaushik M, Rodighiero M, Crepaldi C, et al. Abdominal aortic calcification is an independent predictor of cardiovascular events in peritoneal dialysis patients. Ther Apher Dial Aug;():. 2013;17(4):448-53.

186. Peride I, Checheriţă I, Smarandache D, Rădulescu D, Sinescu R, Niculae A, et al. Vascular calcification in continuous ambulatory peritoneal dialysis patients. Rom $\mathbf{J}$ Morphol Embryol. 2015;56(2 Suppl):777-80.

187. Chen J, Mohler E, Garimella P, Hamm L, Xie D, Kimmel S, et al. Ankle Brachial Index and Subsequent Cardiovascular Disease Risk in Patients With Chronic Kidney Disease. J Am Heart Assoc. 2016;5(6):3-15.

188. Guerrero A, Montes R, Muñoz-Terol J, Gil-Peralta A, Toro J, Naranjo M, et al. Peripheral arterial disease in patients with stages IV and $\mathrm{V}$ chronic renal failure. Nephrol Dial Transplant. 2006;21(12):3525-31. 
189. Lee C, Wu C, Chou L, Shen S, Chiang S, Jen P, et al. Peripheral artery disease in peritoneal dialysis and hemodialysis patients: single-center retrospective study in Taiwan. BMC Nephrol. 2012;13(5):100-5.

190. Stein J, Korcarz C, Hurst R, Lonn E, Kendall C, Mohler E, et al. Use of carotid ultrasound to identify subclinical vascular disease and evaluate cardiovascular disease risk: a consensus statement from the American Society of Echocardiography Carotid Intima-Media Thickness Task Force. Endorsed by the Society for Vascular Medicine. J Am Soc Echocardiogr. 2008;21(2):93-111.

191. Whitman I, Feldman H, Deo R. CKD and sudden cardiac death: epidemiology, mechanisms, and therapeutic approaches. J Am Soc Nephrol. 2012;23(12):1929-39.

192. Lorenz M, Markus H, Bots M, Rosvall M, Sitzer M. Prediction of clinical cardiovascular events with carotid intima-media thickness: a systematic review and meta-analysis. Circulation. 2007;115(4):459-67.

193. Kokubo Y. Carotid Atherosclerosis in Kidney Disease. Contrib Nephrol. 2013;179(3):35-41.

194. Yerly P, Rodondi N, Viswanathan B, Riesen W, Vogt P, Bovet P. Association between conventional risk factors and different ultrasound-based markers of atherosclerosis at carotid and femoral levels in a middle-aged population. Int $\mathbf{J}$ Cardiovasc Imaging 2013;29(3):589-99.

195. Shi Z, Zhu M, Guan J, Chen J, He Q, Zhang X, et al. Dialysis methods may affect carotid intima-media thickness in Chinese end-stage renal disease patients. Ren Fail. 2012;34(10):1206-11.

196. Caliskan Y, Ozkok A, Akagun T, Alpay N, Guz G, Polat N, et al. Cardiac biomarkers and noninvasive predictors of atherosclerosis in chronic peritoneal dialysis patients. Kidney Blood Press Res. 2012;35(5):340-8.

197. Mutluay R, Degertekin C, Poyraz F, Yılmaz M, Yücel C, Turfan M, et al. Dialysis type may predict carotid intima media thickness and plaque presence in endstage renal disease patients. Adv Ther. 2012;29(4):370-82. 
198. Betriu A, Martinez-Alonso M, Arcidiacono M, Cannata-Andia J, Pascual J, Valdivielso $\mathrm{J}$, et al. Prevalence of subclinical atheromatosis and associated risk factors in chronic kidney disease: the NEFRONA study. Nephrol Dial Transplant. 2014;29(7):1415-22.

199. Leskinen Y, Lehtimäki T, Loimaala A, Lautamatti V, Kallio T, Huhtala H, et al. Carotid atherosclerosis in chronic renal failure-the central role of increased plaque burden. Atherosclerosis. 2003;171(2):295-302.

200. Paul T, Chen W, Srinivasan S, Ahmet-Toprak J, He J, Berenson G. Framingham risk score is associated with femoral artery intima-media thickness in asymptomatic young adults (The Bogalusa Heart Study). Atherosclerosis. 2010;213(2):627-31.

201. Protogerou A, Fransen J, Zampeli E, Argyris A, Aissopou E, Arida A, et al. The Additive Value of Femoral Ultrasound for Subclinical Atherosclerosis Assessment in a Single Center Cohort of 962 Adults, Including High Risk Patients with Rheumatoid Arthritis, Human Immunodeficiency Virus Infection and Type 2 Diabetes Mellitus. PLoS One. 2015;10(7):132-45.

202. Marinelli A, Pistolesi V, Pasquale L, Lullo LD, Ferrazzano M, Baudena G, et al. Diagnosis of Arterial Media Calcification in Chronic Kidney Disease Cardiorenal Med 2013;3(2):89-95. 

9. ANEXO 

Anexo 1: Hoja de recogida de datos. 



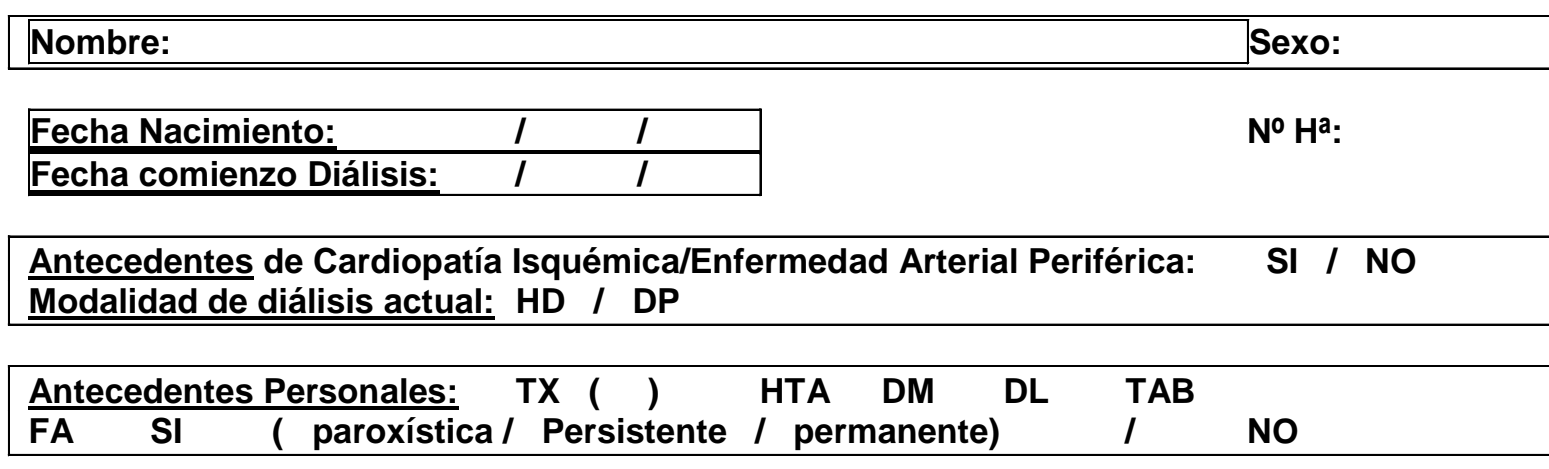

\begin{tabular}{|llllll|}
\hline \multicolumn{4}{l}{ Tratamiento Farmacológico Actual: } & & \\
\hline Antihipertensivos & Estatinas & Antidiabéticos Orales & Insulina \\
Quelantes Cálcicos & Quelantes No Cálcicos & Vitamina D & & \\
Paricalcitol & Cinacalcet & Hipouricemiantes & Anticoagulación & Antiagrega. \\
\hline
\end{tabular}

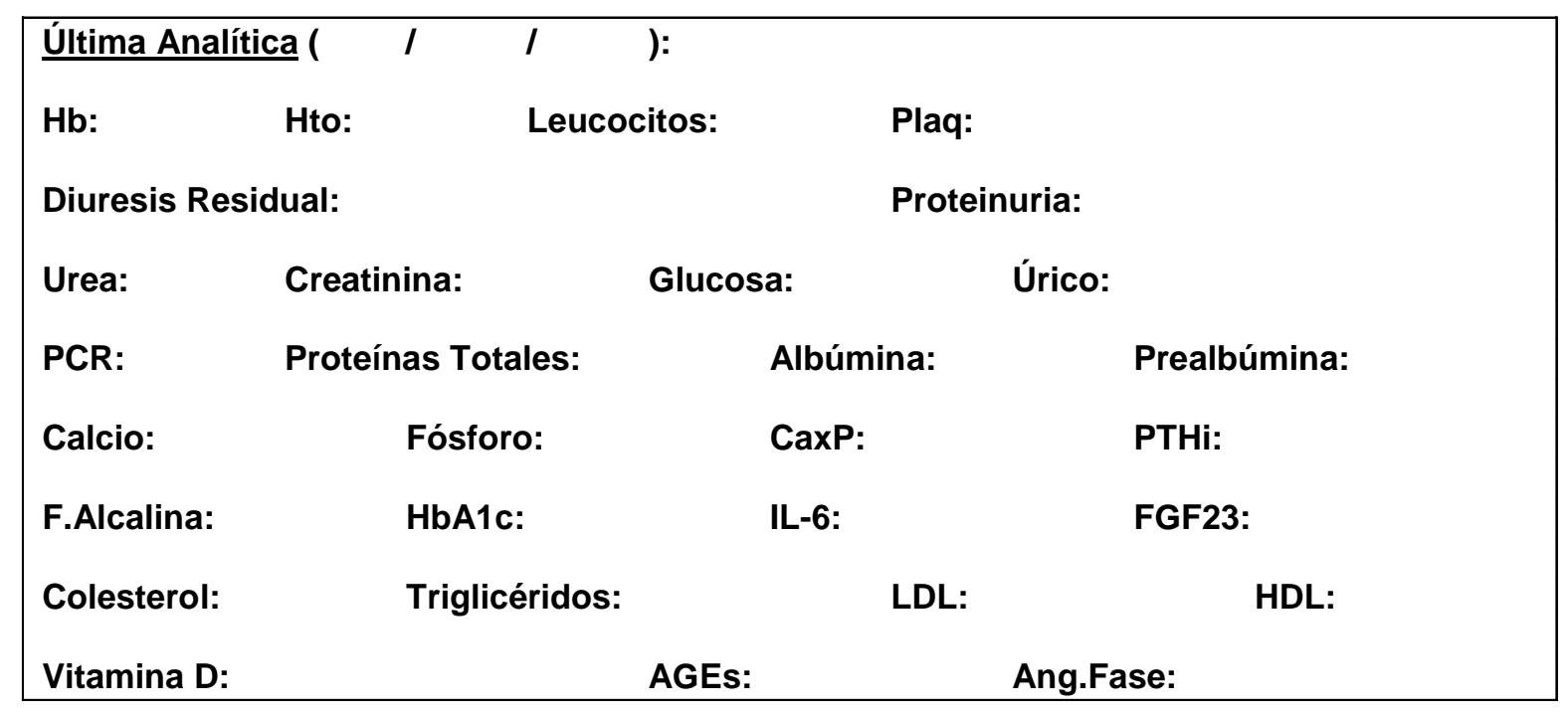

\begin{tabular}{lll}
\hline Adragao: & \\
Pelvis: & Manos: & Total: \\
\hline
\end{tabular}

\begin{tabular}{|l|}
\hline Kauppila: \\
\hline
\end{tabular}

\begin{tabular}{|llll|}
\hline GIM: & & & \\
CCD: & Placa Bulbo D: & Placa CID: & Placa \\
CCI: & Placa Bulbo I: & Placa CII: & Placa \\
Fem CD: & Placa Femo SD: & Placa & \\
Femo Cl: & Placa Femo SI: & Placa & \\
\hline
\end{tabular}

\begin{tabular}{|llll|}
\hline ITB : & TA BD : & TA Tibial D : & TA Pedia D : \\
& TA BI : & TA Tibial I : & TA Pedia I : \\
\hline
\end{tabular}

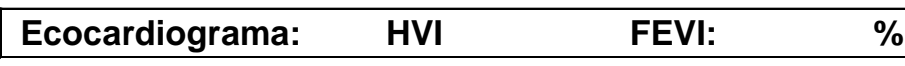



Anexo 2: Analítica tipo realizada a los paciente. 

Nombre:

Apellidos:

Fecha nacimiento:

№ Historia:

№ Seg. S.:

Tarj. sanitaria:
№ petición:

Cama:

\section{Comentarios:}

\section{LABORATORIO DE HEMATOLOGÍA}

\section{HEMATIMETRÍA}

\section{SERIE BLANCA}

Leucocitos

Neutrófilos \%

Linfocitos \%

Monocitos \%

Eosinófilos \%

Basófilos \%

Neutrófilos

Linfocitos

Monocitos

Eosinófilos

Basófilos

\section{SERIE ROJA}

Hematíes

Hemoglobina

Hematocrito

V.C.M

H.C.M

C.H.C.M

R.D.W

\section{SERIE PLAQUETAR}

Plaquetas

Reticulocitos

Reticulocitos \%

VSG 1a hora
Facultativo Responsable:

Resultado

Unidades

4.4

66.3

20.3

10.3

2.3

0.8

2.9

0.9

0.5

0.1

0

$\times 1.000 / \mu \mathrm{L}$

Finalización:

№

Recepción:

Diagnóstico:

Prueba

Valores de referencia

$$
\begin{array}{rll}
4 & - & 10.5 \\
41 & - & 72 \\
20 & - & 48 \\
3.3 & -10.8 \\
0 & - & 6.2 \\
0 & - & 1.8 \\
1.5 & - & 7.5 \\
0.8 & -5 \\
0.2 & -1.1 \\
0.1 & -0.65 \\
0 & - & 0.2
\end{array}
$$

3.95

11.9

35.2

89.1

30.1

33.8

14.6

212

0.0785

2

14 $x \mathrm{mill} / \mu \mathrm{L}$

$\mathrm{g} / \mathrm{dL}$

$\%$

$\mathrm{fL}$

pg

$\mathrm{g} / \mathrm{dL}$

$\%$

$\times 1.000 / \mu \mathrm{L}$

$x \mathrm{mill} / \mu \mathrm{L}$

$\%$

$\mathrm{mm}$
$3.8-5.1$

$11.4-15.1$

$34-45$

$80-98$

$27-34$

$32-35$

$12-15$

$150-350$

$0.4-2.5$

$1-20$ 
INFORME DE LABORATORIOS

\begin{tabular}{lll}
\hline Paciente: & Número petición: & $\mathbf{1 5 6 3 3 1 6 2}$ \\
№ Historia: & Destino: & NEFROLOGIA \\
F. extracción: & Servicio: & NEFROLOGIA
\end{tabular}

\section{LABORATORIO DE BIOQUÍMICA}

\section{BIOQUÍMICA EN SUERO}

Prueba
Sodio
Potasio
Cloruro
Glucosa
Urea
Creatinina
Uratos
Proteínas totales
Aspartato aminotransferasa (AST
Alanina aminotransferasa (ALT
Gammaglutamil transferasa (G
Bilirrubina Total
Fosfatasa alcalina
Lactato deshidrogenasa (LDH)
Hierro
Calcio
Fosfato
Magnesio
Creatina Kinasa
Proteína C reactiva

\section{Perfil lipídico}

Colesterol total

Triglicéridos

Colesterol HDL

Colesterol LDL

Indice de riesgo

\section{Diálisis Peritoneal}

Glucosa

Urea

Creatinina

Sodio

Cloro

Potasio

Proteínas totales
Facultativo Responsable: Dra. Calvo Antón

\begin{tabular}{|c|c|c|c|}
\hline Resultado & Unidades & Valores d & de ref. \\
\hline 131 & $\mathrm{mmol} / \mathrm{L}$ & 136 & 146 \\
\hline 3.8 & $\mathrm{mmol} / \mathrm{L}$ & 3.5 & -5.1 \\
\hline 95 & $\mathrm{mmol} / \mathrm{L}$ & 101 & -109 \\
\hline 78 & $\mathrm{mg} / \mathrm{dL}$ & 74 & 10 \\
\hline 161.6 & $\mathrm{mg} / \mathrm{dL}$ & 12.8 & -42 \\
\hline 7.41 & $\mathrm{mg} / \mathrm{dL}$ & 0.6 & -1. \\
\hline Método Jaffé co & trazabilidad IDMS. & & \\
\hline 5.38 & $\mathrm{mg} / \mathrm{dL}$ & 2.6 & -6 \\
\hline 6.47 & $\mathrm{~g} / \mathrm{dL}$ & 6.6 & -8.3 \\
\hline 17.1 & $\mathrm{U} / \mathrm{L}$ & 0 & -35 \\
\hline 19.1 & $U / L$ & 1 & -35 \\
\hline 23 & $U / L$ & 0 & -38 \\
\hline 0.4 & $\mathrm{mg} / \mathrm{dL}$ & $0.3-$ & - 1.2 \\
\hline 176 & $\mathrm{U} / \mathrm{L}$ & 30 & -12 \\
\hline 198 & $\mathrm{U} / \mathrm{L}$ & 100 & -15 \\
\hline 64 & $\mu \mathrm{g} / \mathrm{dL}$ & 50 & -1 \\
\hline 9.38 & $\mathrm{mg} / \mathrm{dL}$ & 8.6 & -10 \\
\hline 3.12 & $\mathrm{mg} / \mathrm{dL}$ & 2.4 & -4 \\
\hline 1.74 & $\mathrm{mg} / \mathrm{dL}$ & 1.5 & -2 \\
\hline 79 & $\mathrm{U} / \mathrm{L}$ & 0 & -14 \\
\hline$<1$ & $\mathrm{mg} / \mathrm{L}$ & 0 & -10 \\
\hline 180 & $\mathrm{mg}$ & & \\
\hline
\end{tabular}

Niños $<170$ mg/dL (Recomendaciones NCEP) Adultos $<200 \mathrm{mg} / \mathrm{dL}$ (Recomendaciones ATP III)

$82 \mathrm{mg} / \mathrm{dL}$

$<150 \mathrm{mg} / \mathrm{dL}$ (Recomendaciones ATP III)

$50 \quad \mathrm{mg} / \mathrm{dL}$

40 - 60 mg/dL (Recomendación ATP III)

$114 \mathrm{mg} / \mathrm{dL}$

Niños $<110 \mathrm{mg} / \mathrm{dL}$ (Recomendaciones NCEP) Adultos $<100 \mathrm{mg} / \mathrm{dL}$ (Recomendaciones ATP III)

$3.6 \quad 3.5-5$

$198 \quad \mathrm{mg} / \mathrm{dL}$

$159 \quad \mathrm{mg} / \mathrm{dL}$

$6.1 \quad \mathrm{mg} / \mathrm{dL}$

$130 \mathrm{mmol} / \mathrm{L}$

$104 \mathrm{mmol} / \mathrm{L}$

$3.4 \quad \mathrm{mmol} / \mathrm{L}$

$0.08 \quad \mathrm{~g} / \mathrm{dL}$

\section{GASOMETRÍA}

\section{Gasometría Venosa}

Presión barométrica

$\mathrm{pH}$

$\mathrm{pCO} 2$

7.37

46

19
$\mathrm{mmHg}$

$\mathrm{mmHg}$

$\mathrm{mmHg}$

$$
\begin{aligned}
7.32 & -7.42 \\
41 & -51 \\
24 & -40
\end{aligned}
$$

* Fuera del intervalo de referencia. Puede no tener importancia clínica. 
INFORME DE LABORATORIOS

\begin{tabular}{lll}
\hline Paciente: & Número petición: & $\mathbf{1 5 6 3 3 1 6 2}$ \\
№ Historia: & Destino: & NEFROLOGIA \\
F. extracción: & Servicio: & NEFROLOGIA
\end{tabular}

Bicarbonato Estandar (SBC)

$\begin{array}{ll}* & 23.7 \\ & 0.8 \\ & 1.3 \\ * & 4.83 \\ & 0.6\end{array}$

$\mathrm{mmol} / \mathrm{L}$

$26-32$

Exceso de Bases (EB)

$\mathrm{mmol} / \mathrm{L}$

$-2-3$

E. de bases en fluido extracelular (BEecf)

$1.3 \mathrm{mmol} / \mathrm{L}$

$-3-3$

Calcio iónico

$\mathrm{mg} / \mathrm{dL}$

$4.5-5.2$

Lactato

$\mathrm{mmol} / \mathrm{L}$

$0.7-2.1$

\section{E. ANEMIAS}

Ferritina

* $\quad 126.9$

$\mathrm{ng} / \mathrm{mL}$

$10-120$

ORINA

Prueba

\section{BIOQUÍMICA EN ORINA}

Diuresis 24 horas (mL): 1100

Prueba

Proteínas

Indice Proteinas/creatinina

Proteinuria de $24 \mathrm{~h}$

Creatinina

Urea

Sodio

Sodio en orina $24 \mathrm{~h}$

Indice Sodio / Creatinina

Potasio

Potasio en orina $24 \mathrm{~h}$

Indice Potasio / Creatinina

Cloruro

Cloruro en orina $24 \mathrm{~h}$

Indice Cloruro / Creatinina

\section{HORMONAS}

Prueba

PTHi

\section{PROTEÍNAS}

Prueba

Albumina

Transferrina

İndice de saturación de Transferrina
Facultativo Responsable:

Resultado
Valores de referencia
Resultado Unidades Valores de referencia

$0.31 \quad g / L$

* $\quad 1.09 \mathrm{mg} / \mathrm{mg}$ creatinina $\quad 0 \quad-0.2$ Proteinuria en rango nefrótico: Ratio $>3.5 \mathrm{mg} / \mathrm{mg}$ creatinina

$0.34 \quad g / 24 h$

$29 \mathrm{mg} / \mathrm{dL} \quad 15-278$

$\begin{array}{llll}3.61 & \mathrm{~g} / \mathrm{L} & 2.82 & -35\end{array}$

$\begin{array}{llll}68 & \mathrm{mmol} / \mathrm{L} & 15 & -237\end{array}$

$75 \mathrm{mmol} / 24 \mathrm{~h} \quad 27-287$

$236.1 \mathrm{mmol} / \mathrm{g}$ creatinina $26-297$

* $12.8 \mathrm{mmol} / \mathrm{L} \quad 22-164$

* $\quad \mathbf{1 4 . 1} \mathrm{mmol} / 24 \mathrm{~h} \quad 25-125$

$44.4 \mathrm{mmol} / \mathrm{g}$ creatinina $8-129$

$60 \mathrm{mmol} / \mathrm{L} \quad 24-255$

* $66 \mathrm{mmol} / 24 \mathrm{~h} \quad 110-250$

$208.3 \mathrm{mmol} / \mathrm{g}$ creatinina $\quad 39-348$

Revisado y validado por:

Resultado Unidades Valores de referencia

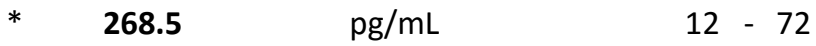

Revisado y validado por:

Resultado Unidades Valores de referencia

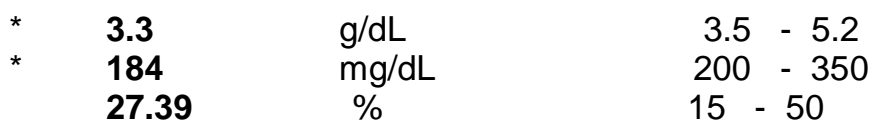

\footnotetext{
* Fuera del intervalo de referencia. Puede no tener importancia clínica.

** Fuera del intervalo de referencia. Probablemente con importancia clínica.
}

№ Petición: 15633162 
INFORME DE LABORATORIOS

\section{VITAMINAS}

Prueba

25-OH-Vitamina D3

Insuficiente

15 - 30 mcg/L Deficiencia severa < 15 mcg/L

11

$\mu g / L$
Revisado y validado por:

Dra.

Resultado Unidades Valores de referencia

$30-80$ 
Anexo 3 .Documento de consentimiento informado 



\title{
SERVICIO / UNIDAD: NEFROLOGÍA Y CIRUGIA VASCULAR
}

\author{
INVESTIGADOR RESPONSABLE: ÁLVARO REVILLA CALAVIA
}

TELÉFONO DE CONTACTO: 983420000 Ext 86269 EMAIL:alvarorevilla@yahoo.es

NOMBRE DE LA LÍNEA DE TRABAJO: CALCIFICACIONES EN PACIENTES CON ENFERMEDAD RENAL AVANZADA

\section{I) Finalidad de la línea de trabajo propuesta:}

Valorar la calcificación vascular y observar las posibles consecuencias que ello conlleva.

Los resultados de estos estudios ayudarán probablemente a diagnosticar y/o tratar de manera más precisa a los enfermos con una enfermedad como la suya.

\section{II) Algunas consideraciones sobre su participación:}

Es importante que Vd., como potencial donante de muestras, conozca varios aspectos importantes:

A) La donación de muestras es totalmente voluntaria.

B) Puede plantear todas las dudas que considere sobre su participación en este estudio.

C) Se solicita su autorización para la toma y uso en investigación biomédica de muestras de sangre. En dichas muestras se obtendrán y/o analizarán parámetros como el Calcio, Vit D, Colesterol, parathormona utilizando los métodos que el investigador principal considere necesarios para avanzar en la línea de trabajo arriba expuesta.

D) Se le tomará un volumen relativamente pequeño de sangre venosa mediante una punción en el brazo. La donación de sangre apenas tiene efectos secundarios; lo más frecuente es la aparición de pequeños hematomas en la zona de punción que desaparecen transcurridos 1 o 2 días.

E) No percibirá ninguna compensación económica o de otro tipo por las muestras donadas y éstas no tendrán valor comercial. No obstante, la información generada a partir de los estudios realizados sobre su muestra podría ser fuente de beneficios comerciales. En tal caso, están previstos mecanismos para que estos beneficios reviertan en la salud de la población, aunque no de forma individual en el donante.

F) Las muestras y los productos obtenidos de las mismas serán almacenados y custodiados en Laboratorio de Análisis Clínicos del Hospital Universitario Rio Hortega, lugar designado para este fin por el Investigador Principal del Estudio. La muestra quedará allí depositada de forma indefinida (siempre que no se haya consumido en su totalidad en el curso de los trabajos asociados a la misma). Si en dicho momento se propusiera el paso de las muestras a un Biobanco oficialmente reconocido, se le volverá a solicitar su consentimiento para ello. 
G) Los datos personales asociados a las muestras serán tratados según lo dispuesto en la legislación vigente sobre protección de datos de carácter personal (Ley Orgánica 15/1999), de 13 de diciembre) y cualquier otra que resultara aplicable.

H) La información obtenida se almacenará en una base de datos, en soporte informático, registrada en la Agencia Española de Protección de Datos, según la legislación vigente (Ley Orgánica 15/1999). Los datos registrados serán tratados estadísticamente de forma codificada. En todo momento el donante tendrá derecho de acceso, rectificación o cancelación de los datos depositados en la base de datos siempre que expresamente lo solicite. Para ello deberá ponerse en contacto con el investigador principal. Los datos quedarán custodiados bajo la responsabilidad del Investigador Principal del Estudio, Alvaro Revilla Calavia.

I) Las muestras y/o la información clínica asociada a las mismas podrán ser utilizadas por el grupo del investigador principal en estudios futuros de investigación relacionados con la línea de trabajo arriba expuesta. Dichas muestras y/o la información clínica asociada a las mismas podrán ser cedidas a otros investigadores designados por el Investigador Principal para trabajos relacionados con esta línea, siempre al servicio de proyectos que tengan alta calidad científica y respeto por los principios éticos. En estos dos últimos casos, se solicitará antes autorización al CEIC (Comité Ético de Investigación Clínica) del Área de Salud Valladolid Este.

J) La falta de consentimiento o la revocación de este consentimiento previamente otorgado no supondrá perjuicio alguno en la asistencia sanitaria que Vd. recibe/recibirá.

K) Es posible que los estudios realizados sobre sus muestras aporten información relevante para su salud o la de sus familiares. Vd. tiene derecho a conocerla y trasmitirla a sus familiares si así lo desea.

L) Sólo si Vd. lo desea, existe la posibilidad de que pueda ser contactado en el futuro para completar o actualizar la información asociada al estudio. 
CONSENTIMIENTO INFORMADO DEL PACIENTE POR ESCRITO.

Estudio CALCIFICACIONES VASCULARES EN PACIENTES CON ENFERMEDAD RENAL AVANZADA

Yo, paciente ó representante legal) (nombre y apellidos del

He leído la información que me ha sido entregada.

He recibido la hoja de información que me ha sido entregada.

He podido hacer preguntas sobre el estudio.

He recibido suficiente información sobre el estudio.

He hablado del estudio con (nombre y apellidos del investigador)

Comprendo que mi participación es voluntaria.

Comprendo que puedo retirarme del estudio:

1.- Cuando quiera.

2.- Sin tener que dar explicaciones.

3.- Sin que esto repercuta en mis cuidados médicos.

Por la presente, otorgo mi consentimiento informado y libre para:

- El fin para el que se utilizarán mis muestras y datos personales según lo recogido en la hoja de información al paciente que me ha sido entregada.

- Accedo a que los médicos del HOSPITAL UNIVERSITARIO RIO HORTEGA DE VALLADOLID contacten conmigo en el futuro en caso de que se necesite obtener nuevos datos. ...SI..... NO (marcar con una X lo que proceda)

- Accedo a que los médicos del HOSPITAL CLÍNICO UNIVERSITARIO DE RIO HORTEGA DE VALLADOLID contacten conmigo en caso de que los estudios realizados sobre mis muestras / datos aporten información relevante para mi salud o la de mis familiares ...SI..... NO (marcar con una X lo que proceda)

Una vez firmada, me será entregada una copia del documento de consentimiento.

FIRMA DEL PACIENTE / REPRESENTANTE LEGAL

NOMBRE Y APELLIDOS

FECHA

EN CALIDAD DE (Parentesco, tutor legar, etc.) 
CONSENTIMIENTO INFORMADO PARA INVESTIGACIÓN CLINICA

HOSPITALUNIVERSITARIO RIO HORTEGA DE VALLADOLID

Yo he explicado por completo los detalles relevantes de este estudio al paciente nombrado anteriormente y/o la persona autorizada a dar el consentimiento en nombre del paciente.

FECHA

CONSENTIMIENTO INFORMADO DEL PACIENTE POR ESCRITO.

\section{APARTADO PARA LA REVOCACIÓN DEL CONSENTIMIENTO (CONTACTAR CON EL INVESTIGADOR PRINCIPAL)}

Yo

revoco el consentimiento de participación en

el estudio, arriba firmado con fecha

Firma: 